Mesa redonda

\title{
ÉTICA E INFORMACIÓN
}

\author{
COORDINADORES
}

Estela Morales Campos Jaime Ríos Ortega 


\section{La presente obra está bajo una licencia de:}

$\underline{\mathrm{http}: / / \text { creativecommons.orq/licenses/by-nc-sa/3.0/deed.es MX }}$

\section{(c) creative}

\section{Atribución-No Comercial-Licenciamiento Reciproco 3.0 Unported}

Eres libre de:

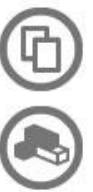

copiar, distribuir y comunicar públicamente la obra

hacer obras derivadas

Bajo las condiciones siguientes:

Atribución - Debes reconocer la autoría de la obra en los términos

especificados por el propio autor o licenciante.

No comercial - No puedes utilizar esta obra para fines comerciales.

Licenciamiento Recíproco - Si alteras, transformas o creas una obra a

partir de esta obra, solo podrás distribuir la obra resultante bajo una licencia

igual a ésta.

\section{Esto es un resumen fácilmente legible del:} texto legal (de la licencia completa)

En los casos que sea usada la presente obra, deben respetarse los términos especificados en esta licencia.
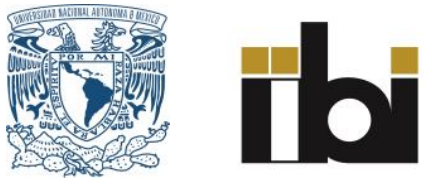


\section{Mesa redonda.}

Ética e infomación 


\section{COLECCIÓN}

SEMINARIOS DE INVESTIGACIÓN

Seminario bibliotecología, información y sociedad 2

Centro Universitario de Investigaciones Bibliotecológicas 


\title{
Mesa redonda. Ética e infomación
}

\author{
Memoria \\ 24, 25 de septiembre del 2003 \\ Coordinadores \\ Estela Morales Campos \\ Jaime Ríos Ortega \\ Participantes \\ Beatriz Casa \\ Hugo Figueroa \\ José de Jesús Hernández \\ Celia Mireles \\ Eduardo Salas \\ Relator: \\ Homero Quezada
}

Universidad Nacional Autónoma de México 2005 
P75M4 Mesa redonda. Ética e Infomación (2003 : México, D. F.)

2003

Mesa Redonda. Ética e Infomación : memoria, 24, 25 de septiembredel del 2003 / coordinadores Estela Morales Campos, Jaime Ríos Ortega. -- México : UNAM, Centro Universitario de Investigaciones Bibliotecológicas, 2005.

viii, 167 p. -- (Seminarios de Investigación. Seminario Bibliotecología, Información y Sociedad ; 2)

ISBN: 970-32-3152-7

1. Ética Profesional 2. Ética Bibliotecaria 3. Ética e Información 4. Conferencias I. Morales Campos, Estela, coord. II. Ríos Ortega, Jaime, coord. III. t IV. ser.

Diseño de portada: Ignacio Rodríguez Sánchez

Primera Edición 2005

DR (C) UNIVERSIDAD NACIONAL AUTÓNOMA DE MÉXICO

Ciudad Universitaria, 04510, México D.F.

Impreso y hecho en México

ISBN: 970-32-3152-7

El Seminario de Bibliotecología Información y Sociedad se creó en el marco del Xx Coloquio de Investigación Bibliotecológica y de la Información "Investigación Bibliotecológica: presente y futuro", y da origen a la serie que denominaremos Seminarios de investigación.

Los textos que a continuación se presentan han sido transcritos tal y como fueron entregados por los autores participantes, quienes se hacen responsables tanto de los contenidos como del estilo de sus respectivos documentos. 


\section{Contenido}

PRESENTACIÓN . . . . . . . . . . . . . . vii Estela Morales Campos

INFORMACIÓN, TECNOLOGÍA E INDUSTRIA

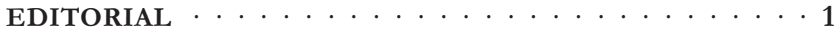

Beatriz Casa Tirao

ÉTICA DE LA INFORMACIÓN: PERSPECTIVAS

BIBLIOTECOLÓGICAS . . . . . . . . . . . . . . 11

Hugo Figueroa Alcántara

ASPECTOS ÉTICOS EN LA FORMACIÓN PROFESIONAL

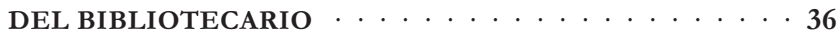

José de Jesús Hernández Flores

ÉTICA E INFORMACIÓN EN LA SOCIEDAD

POSMODERNA . . . . . . . . . . . . . . 45

Celia Mireles Cárdenas

LA BIBLIOTECA, LA ÉTICA Y LA

INFORMACIÓN $\ldots \ldots \ldots \ldots \ldots$

Estela Morales Campos

LA BIBLIOTECA PÚBLICA Y LOS VALORES

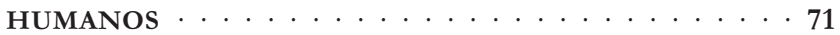

Jaime Ríos Ortega

ÉTICA E INFORMACIÓN . . . . . . . . . . . . . . . . . 81

Eduardo Salas Estrada

RELATORÍA DE LA MESA REDONDA

“ÉTICA E INFORMACIÓN" . . . . . . . . . . . . . . . . . . . 99

Homero Quezada Pacheco

BIBLIOGRAFÍA: ÉTICA Y BIBLIOTECOLOGÍA $\cdots \cdots \cdots$ 



\title{
Presentación
}

\author{
Estela Morales CAMPoS
}

Centro Universitario de Investigaciones

Bibliotecológicas/UNAM

1 I seminario permanente "Bibliotecología, Inforpaciones y sucesos que confluyen en el uso de la información, se reúne con el fin de discutir temas al respecto. En este cuaderno presentamos algunas reflexiones sobre la ética y la información, asunto que nos convocó el 24 y 25 de septiembre de 2003. Los miembros del seminario comunicamos nuestras ideas a todos aquellos que trabajan con la información y hacen posible su uso; allí, conviven las expresiones de profesores con mucha experiencia y las de jóvenes académicos que ofrecen su perspectiva, en esa ocasión poniendo en el centro la ética, los valores y la información. El resultado: "Información, tecnología e industria cultural: una reflexión desde la ética", por Beatriz Casa Tirao; "Ética de la información: perspectivas bibliotecológicas", por Hugo Figueroa Alcántara; "Aspectos éticos en la formación profesional del bibliotecario", por José de Jesús Hernández Flores; "Ética e información en la sociedad postmoderna", por Celia Mireles Cárdenas; "La Biblioteca, la ética y la información", 
por Estela Morales Campos; "La biblioteca pública y los valores humanos", por Jaime Ríos Ortega, y "Ética e información", por Eduardo Salas Estrada.

Como apoyo a este tema, al final se ofrece una bibliografía de artículos en español y portugués localizada en la base de datos INFOBILA, así como otros en inglés localizados en LISA y LIBRARY LITERATURE, preparada por José Juan Betán.

La logística del seminario y la relatoría del evento, han estado a cargo de Homero Quezada, a quien le expresamos todo nuestro reconocimiento. 


\title{
Información, tecnología e industria cultural: una reflexión desde la ética
}

\author{
Betriz Casa Tirao \\ Facultad de Filosofía y Letras/UNAM
}

\begin{abstract}
$\mathbf{E}$ ntre los muchos temas que hoy se plantean aquellos a quienes preocupa el devenir de la humanidad, hay uno que asume importancia por lo que significa en relación con el desarrollo general de los seres humanos y en particular con el aspecto intelectual del mismo. El tema es el que pone sobre la mesa la pregunta acerca de la capacidad para pensar de los hombres y mujeres que integran la sociedad actual. La pregunta que de esto deriva nos lleva a la consideración de un problema que afecta hoy a muchos grupos sociales, tanto en sociedades desarrolladas como en aquellas que se encuentran en niveles bajos y medios de desarrollo.

Vale la pena hacer algo de historia. El paso de la sociedad artesanal a la sociedad industrial trajo como consecuencia un cambio en los valores tradicionales. El individuo, que en la sociedad feudal se encontraba protegido dentro del gremio y aceptaba como un hecho
\end{abstract}


natural la autoridad del señor, perdió con la aparición de la máquina aquella seguridad que le era propia y que le permitía estabilidad en el rincón de vida que le había correspondido; ahora experimentaba una sensación de inseguridad y de encontrarse suspendido en el aire sin asidero alguno. Además, se produjo un aumento del ritmo de producción y con ello la aparición de la economía de mercado, con el régimen de la oferta y la demanda... y nuevamente el círculo se cierra.

No dudamos que la aparición de la máquina marca el inicio de uno de los períodos más importantes de la historia humana y que a partir de ella comienzan a generarse cambios fundamentales en la historia de la civilización. Es necesario reconocer el valor que ella tiene como elemento de progreso en la cultura, con un agregado que la revalora: la existencia de la máquina es producto de la acción y la creación humanas.

El maquinismo determinó la aparición de una estructura social distinta, capaz de contenerlo y en el comienzo de esta nueva cultura y en su desarrollo posterior, las posibilidades de la máquina parecieron infinitas y toda las acciones de los individuos, de una u otra manera, giraban alrededor de este concepto. Era necesario, pues, crear un ambiente, un modo de vida, acordes con este punto de vista y en esta red de actos que erigían a la máquina como dueña y señora de la sociedad, se fue enredando el individuo mismo. A aquella primera sensación de sentirse suspendido en el aire, 
Información, tecnología e industria cultural: una reflexión...

sin saber qué hacer con su libertad, el individuo reaccionó buscando desesperadamente convertirse en un engranaje más, en pasar desapercibido, en vivir una vida de rebaño que lo compensara de aquella otra perdida. Surge entonces el "hombre masa", concepto tan admirablemente tratado por pensadores de la talla de Elémire Zolla y Ortega y Gasset. Este hombre vive de manera inauténtica, conformista, se rige por estereotipos, falsea lo que hace, aun los sentimientos, aun el amor. El hombre masa es, además, un ser triste, solitario, incomunicado, que no piensa sino que asume el pensamiento de otros, no decide, no cuestiona: acepta sin discusión ni análisis todo aquello que de manera más o menos sutil se le impone.

La descripción anterior resume el impacto que la aparición de la máquina produjo en la humanidad. Esta ha recibido después otros productos que tienen que ver con el desarrollo cada vez más acelerado de la tecnología y que no han sido acompañados por procesos de reflexión que permitan ver en su verdadera dimensión estos productos. Estoy hablando, naturalmente, de la tecnología aplicada a múltiples actividades y, desde luego, también al campo de la información. Esta última aparece en diversos tipos de soportes, algunos de los cuales, a la fecha, corresponden a la tecnología de punta, la cual permite una mayor y mejor difusión de los contenidos de la información. 
Paralelamente a la situación anteriormente mencionada, se ha desarrollado toda una literatura escrita y oral encaminada a persuadir a las personas de determinadas cosas, a informar de acuerdo con objetivos previamente establecidos y que responden a tendencias de diversa índole. A esto se agrega el enorme desarrollo que la propaganda ha tenido en los últimos años y todo esto contribuye a estandarizar los gustos, a crear estereotipos, a elevar productos de la cultura al pináculo para después derrumbarlos aprovechando la fragilidad que la propia propaganda le ha conferido. Y de todo esto las víctimas son aquellas personas que consumen, a veces sin solución de continuidad, todo aquello que el aparato publicitario les ofrece. Y cuando hablo de esto no me estoy limitando algunos campos del quehacer humano sino que me refiero a todos ellos, ya que éstos que bien podemos llamar productos culturales, se dan también en el terreno de la ciencia, del arte y en otros donde el pensamiento humano debería expresarse de la manera más estricta, legítima y libre.

El instrumento más importante para que esta industria de la cultura extienda su poder es sin duda la información, la cual tiene la posibilidad de hacer que todos los elementos de la cultura pasen a formar parte de la experiencia humana. Como antes se mencionó, la información cuenta actualmente con el valioso apoyo de la tecnología y es acá donde me parece que vale la pena hacer un alto para la reflexión. 
Información, tecnología e industria cultural: una reflexión...

El campo de la información es vasto, rico y poco evaluado, lo cual supone que en él es posible encontrar diversos tipos de elementos, desde aquellos que representan una aportación valiosa para el campo del conocimiento hasta los que son producto de la moda o del momento de auge de un tema, muchas veces insuficientemente estudiado. La tecnología, cuyo valor es innegable, aporta agrandes posibilidades al procesamiento y conocimiento de la información desde hace ya tiempo y su aporte se hace cada día más importante dado el perfeccionamiento y desarrollo que día con día alcanza. De pronto ella también, la tecnología, parece convertirse en un producto que se integra a la industria cultural que he tratado de describir y esto sucede justamente cuando en ella pareciera depositarse toda la confianza y toda la responsabilidad en relación con la información para olvidar, quizá, que lo importante de esta última es su contenido y su apertura sobre un campo del conocimiento, cualquiera sea la índole de éste.

Debe reconocerse que ante el desarrollo de la tecnología ha habido en general una actitud pasiva, de la misma manera que la ha habido ante el desarrollo de la ciencia. Al respecto, Bunge menciona que "Los científicos se interesaron por los problemas de la conducta moral desde que advirtieron con qué facilidad pueden prostituirse la ciencia y sus cultores: el nazismo, la ciencia de partido, la bomba atómica y los juramentos 
de lealtad los despertaron de su siesta moral." ${ }^{\text {1 }}$ Así fue como después de la última carnicería mundial, señala el mismo autor, surgieron publicaciones que se ocupaban no sólo de ciencia, tecnología y política sino también de los graves problemas morales que plantea, por ejemplo, el colaborar con los organismos de la energía atómica. Aunque lentamente, este análisis del valor y de la posición de la ciencia en el mundo moderno, ha ido avanzando. Pero esto no parece suficiente; en algún punto de su obra, Bunge afirma que:

Participen o no en la generación de calamidades, la mayoría de los científicos, tecnólogos y administradores se lavan las manos y cierran los ojos al sufrimiento y la miseria. Lo que es peor, su posición en la sociedad es tal que deben hacerse los ciegos morales si pretenden funcionar con eficacia. En efecto, un profesional no puede trabajar eficientemente si permite que lo distraigan los clamores de desesperación: debe recluirse en su oficina o en su laboratorio si ha de proseguir su trabajo, sea éste investigar, diseñar u organizar.(A menos que su trabajo consista, precisamente, en aliviar calamidades o al menos prevenirlas). ${ }^{2}$

Así como la ciencia es revisada desde el punto de vista de la ética, ha llegado el momento de poner en

1 Mario Bunge, Ética, ciencia y tecnología, Buenos Aires, Edit. Sudamericana, 1996, p. 13.

2 Ibidem, p. 105. 
Información, tecnología e industria cultural: una reflexión...

tela de juicio el rol de la tecnología, no su valor y su importancia Como señala Ramírez Briceño, existe pasividad frente a la tecnología. ${ }^{3}$ Una forma de la pasividad está representada por la falta de control en el desarrollo de la tecnología, de manera que se trata de que todo siga de forma espontánea sin el interés por dar a la tecnología una dirección racional.

Otra forma de esa pasividad se manifiesta en atribuir a la tecnología vida propia y leyes propias, lo cual implica que ante su crecimiento no hay nada que hacer, sin recordar que la tecnología es, por fin, una creación del ser humano y debe estar a su servicio y no convertirlo en su servidor o su esclavo. Esto debe entenderse: nuevamente afirmo que no se trata de negar el valor de la tecnología sino, por el contrario, de evitar posiciones extremas frente al tema. No se trata de renunciar a la tecnología ni tampoco de renunciar a las capacidades humanas de decisión y reflexión sino, en cambio, se trata alcanzar una justa posición entre esos dos extremos. En este sentido es conveniente reflexionar acerca de que la tecnología no es desligable del contexto social, económico y político y a partir de esto se entiende que ella es un instrumento puesto al servicio de este contexto.

3 Edgar Roy Ramírez Briceño, La responsabilidad ética en ciencia y tecnología, Cartago, Editorial Tecnológica de Costa Rica, 1991, 102 p. 
Debe tenerse en cuenta que así como la ciencia no es neutral, la tecnología tampoco lo es ya que un objeto tecnológico es creado con fines predeterminados.

"La tecnología es neutral" es en el mejor de los casos, una expresión muy confusa. Si por ella se quiere decir que hay una colección de posibilidades disponibles a las individuales, posibilidades que en sí mismas no son buenas ni malas, entonces la frase es simplemente falsa en la mayor parte de los casos por el hecho de que no existe algo llamado tecnología de lo que podamos disponer libremente. Las patentes, les franquicias, así como las reglas del mercado, se encargan de excluir tal posibilidad. Si un país desea aprovecharse de la riqueza tecnológica tiene que pagar caro, o bien en términos de fuertes boicots, demandas legales e incluso bloqueos económicos y comerciales si no se ajusta a las reglas del juego. ${ }^{4}$

Con lo visto anteriormente es posible llegar a la conclusión de que, como antes se dijo, la tecnología también se ha convertido en mercancía, es decir en un elemento más de la industria cultural. La seducción que la tecnología ejerce va más allá de la utilidad que ella puede prestar y se enlaza con las extensiones de la sociedad de consumo.

4 Luis Camacho, "Influencias de la tecnología en los valores: consideraciones filosóficas", en Ciencia, responsabilidad y valores, Cartago, Editorial Tecnológica de Costa Rica, 1985. 
Información, tecnología e industria cultural: una reflexión...

En este punto es conveniente egresar a los primeros planteamientos, al tema que nos interesa específicamente, o sea a la actuación que asume la información en este plante escenario que describimos. Sabemos que en el mundo de la información existe actualmente lo que es posible denominar como una "explosión tecnológica" y en muchos sectores no se concibe la posibilidad de un adecuado manejo de la información sin este recurso. De alguna manera esta posición determina la actitud de darle autonomía a la tecnología, una autonomía que la transforma de un instrumento de ayuda en una razón de ser: la tecnología por la tecnología misma.

Es indudable que el carácter de la tecnología depende del empleo que de ella se haga y por ello es necesario someterla a los controles morales y sociales. Podemos decir que una tecnología es perversa cuando los fines para la que se la emplea lo son. Si estos fines se eliminan desaparece ese carácter perverso. Lo mismo sucede con el mal empleo de la buena tecnología. En el campo de la información la tecnología deja de ser buena cuando se le adjudica todo el valor y todo el sentido del trabajo en esta área y se olvida que la esencia del mismo se encuentra en el contenido de la información que se maneja, en su apertura sobre diversos campos del conocimiento y en su capacidad motivadora para inducir a la reflexión y a la búsqueda. 
Tanto el que crea como el que emplea tecnología de la información tiene una responsabilidad ética ante la sociedad. Creo que su labor debe ser tan inteligente y sutil que no permita que se establezcan confusiones en cuanto al valor de la tecnología frente al valor de la información misma. Me parece que ya es momento de que, quienes trabajamos en la organización y difusión de la información, así como quienes tenemos la obligación de formar el personal profesional capaz de realizar éstas, nos replanteemos el rol que compete a la tecnología en la cultura actual, su real dimensión en nuestro campo de trabajo y las disyuntivas éticas que nos propone. 


\title{
Ética de la información: perspectivas bibliotecológicas
}

\author{
Hugo Alberto Figueroa AlCÁntara \\ Facultad de Filosofía y Letras/UNAM
}

\begin{abstract}
T a ética de la información es un campo de estudio, Ureflexión e investigación cada vez más relevante en diversas áreas relacionadas con la información, ${ }^{1}$ entre ellas la bibliotecología. Por las repercusiones de la bibliotecología en la esfera social, vale la pena realizar acciones, programas, conferencias e investigaciones encaminadas a promover su análisis crítico, discusión académica y desarrollo de elementos teóricos, que permitan explicar ciertos fenómenos de la realidad social.

Esta colaboración, enmarcada en tal idea, consta de dos partes. En la primera se explican las características principales de la ética de la información, así como sus
\end{abstract}

1 Un excelente panorama al respecto lo ofrece Richard Severson en su The principles of information ethics. Armonk, NY: M.E. Sharpe, 1997. 172 p. 
temas fundamentales, ${ }^{2}$ mientras que en la segunda se enfatiza la relación entre ética de la información y el espacio de relaciones sociales, culturales, educativas, comerciales, políticas, entre otras, desarrollado a través de Internet, ${ }^{3}$ día a día más omnipresente y con mayores

2 Uno de los principales investigadores en el área de la ética de la información es el filósofo uruguayo Rafael Capurro. Actualmente investiga y enseña ética de la información en el Instituto de Filosofía de la Universidad de Stuttgart y en la Universidad de Ciencias Aplicadas de Stuttgart. Su sitio Web es http://www.capurro.de/. Dirige el International Center for Information Ethics (ICIE): http://icie. zkm.de/. El sitio Web del ICIE es muy interesante y completo, con excelentes recursos de información relativos a ética de la información: noticias, el campo de estudios de la ética de la información, instituciones, profesores e investigadores de diversas entidades a nivel mundial relacionados con el tema, publicaciones, etc. Esta última sección incluye un apartado (Biblioteca virtual) de documentos disponibles en línea, en texto completo, de especialistas de diversas partes del mundo. Para los interesados en profundizar en el tema, el Sitio Web del ICIE representa una magnífica fuente de información. Algunas de las ideas desarrolladas en el presente documento han tenido su origen en comunicación personal mantenida con Rafael Capurro, así como en documentos disponibles a través del sitio Web del ICIE.

3 Otro filósofo uruguayo, Bernhard Debatin, quien actualmente investiga y enseña en la Universidad de Leipzig, destaca en el estudio de la relación entre ética de la información e Internet. Uno de sus trabajos más relevantes en este tópico es: Principios de la ética en Internet: áreas de conflicto y perspectivas de solución. Disponible en: http:/ / www.uni-leipzig.de/ debatin/uruguay/etica.html. Para la segunda parte de este documento, algunas ideas se basan en conceptos desarrollados por Debatin. 
repercusiones en todos los ámbitos de las interacciones humanas.

\section{LA ÉTICA DE LA INFORMACIÓN, UN CAMPO ESPECIAL DE LA ÉTICA APLICADA}

La ética de la información, como campo de estudio, es un área especial de la ética, en particular de la ética aplicada.

El campo de la ética de la información es amplio y engloba o se relaciona con dilemas o problemas éticos emanados de:

- Los medios masivos de comunicación, que deviene en una ética de los medios. ${ }^{4}$

- Los usos de diversas tecnologías de la información, englobados bajo los conceptos de ética de la tecnología de la información o ética y tecnología de la información. ${ }^{5}$

- El entorno computacional, redes de cómputo, bases de datos, etcétera, esto es una ética computacional o ética

4 Rivers, William L. La ética en los medios de comunicación. México: Editorial del Valle de México, 1993. 436 p.

5 Compárense los trabajos de James Anderson y W. Kenneth (Ethics and information technology. New York: Springer Verlag, 2002. 280 p.), Case studies in information technology ethics (edited by Richard A. Spinello. 2nd ed. Englewood Cliffs, N. J.: Prentice Hall, 2002. 252 p.), Ethics and information technology (edited by Goran Collste. New Delhi, India: New Academic Press, 1998. 178 p.) y Ethics, information, and technolgy: readings (edited by Richard N. Stichler and Robert Hauptman. Jefferson, North Carolina: McFarland, 1997. 323 p.) 
relacionada con las computadoras, conceptos utilizados en la literatura especializada en español, equivalentes a los conceptos computer ethics, ethics and computing, morality and machines, usados en la literatura en inglés. ${ }^{6}$

- Las ciencias biológicas y de la salud, que deriva en la bioética. $^{7}$

- La bibliotecología, es decir ética bibliotecológica. ${ }^{8}$

- La actividad financiera y empresarial, que nos lleva a una ética de la información de los negocios y las finanzas.

6 Entre otras, destacan las obras de Kevin Bowyer (Ethics and computing: living responsibly in a computerized world. Los Alamitos, California: IEEE Computer Society, 1996. 449 p.), G. Deborah (Computer ethics. Englewood Cliffs: Prentice Hall, 1994. 181 p.), Stacey Edgar (Morality and machines: perspectives on computer ethics. 2nd ed. Sudbury, Massachusetts: Jones and Bartlett, c2003. 522 p.) y Tom Forester y Perry Morrison (Computer ethics: cautionary tales and ethical dilemmas in computing. Cambridge, Massachusetts: MIT, 1994. 347 p.)

7 Revísense por ejemplo los libros Health care and information ethics: protecting fundamental human rights (edited by Audrey R. Chapman. Kansas City, MO: Sheed \& Ward, 1997. 482 p.) y Human genetic information: science, law and ethics (Chichester: J. Wiley, 1990. 211 p.)

8 Véanse como ejemplos Mark Alfino y Linda Pierce (Information ethics for librarians. North Carolina: McFarland, 1997. 168 p.) y Allerton Park Institute ((31 : 1989 : Monticello, Illinois). Ethics and librarian / edited by F. W. Lancaster. Urbana-Champaign, Illinois: University of Illinois, Graduate School of Library of Information Science, c1991. 126 p.)

9 Dos trabajos valiosos sobre el tema son los de Richard De George (The ethics of information technology and business: fundamentals of business ethics. Oxford: Blackwell, 2003. 256 p.) y Richard Mason, Florence 
- Las interacciones humanas en el ciberespacio o ciberética. $^{10}$

Por lo tanto, la ética de la información puede definirse como el campo disciplinario especial de la ética aplicada que abarca preguntas concernientes a problemas éticos en los campos de los medios de comunicación e información, de las tecnologías de la información, de la bibliotecología, de las computadoras y las bases de datos, de la bioética, de los circuitos de información financieros y empresariales y del ciberespacio, ese entorno virtual generado a través de las redes de telecomunicación y de computadoras, de Internet y de la Web.

Las tareas más importantes de la ética de la información son, entre otras, la observación, análisis, estudio e investigación, así como la reflexión y críticas fundamentadas, de la conducta individual y social en el campo de la información; el análisis de las estructuras de poder determinantes de las relaciones informativas; crítica de los mitos informativos, observación de los planteamientos éticos en el campo de la información y propuestas al respecto.

Mason y Mary J. Culpan (Ethics of information management. Thousand Oaks, California: Sage, 1995. 327 p.)

10 Sobre este tema emergente existe una creciente y abundante bibliografía, que se ilustrará en la segunda parte de este trabajo. 


\section{ELEMENTOS TEÓRICOS ESENCIALES DE LA ÉTICA DE LA INFORMACIÓN}

Teóricamente la ética de la información es:

- Una teoría que explora la manera en que las estructuras de poder y de dominación, en diferentes niveles, influyen en las actitudes y tradiciones relativas al ciclo social de la información en diversos entornos culturales.

- Una teoría enfocada a la libertad, que desarrolla un reflexión crítica de las actitudes y tradiciones éticas y morales en el campo de la información, tanto en un nivel individual como colectivo.

A partir de estas dos vertientes teóricas, la ética de la información indaga y valora:

- El desarrollo de los valores éticos y morales en el campo de la información.

- La creación y disolución de estructuras de poder y dominio en el contexto de los flujos nacionales e internacionales de información, en las diferentes actividades humanas.

- Los mitos alrededor de la información.

- Complejidades, contradicciones, paradojas, intencionalidades y ambigüedades desarrolladas en el marco social de la información.

- El surgimiento de conflictos éticos en el entorno de la información. 


\section{ÉTICA PARA ESPECIALISTAS DE LA INFOR- MACIÓN}

En el corpus teórico de la Bibliotecología y Estudios de la Información, desde un punto de vista docente y de investigación, es indispensable incluir tópicos curriculares y líneas de investigación vinculados con la ética de la información, porque esto permitiría desarrollar en los ámbitos de enseñanza, investigación y profesional:

- Un Juicio crítico y habilidad para reconocer y articular conflictos éticos en el campo de la información.

- El sentido de la responsabilidad respecto a las consecuencias de las interacciones individuales o colectivas en el campo de la información.

- El diálogo intercultural sobre la base del reconocimiento de diferentes tipos de culturas y valores sociales.

- El conocimiento básico acerca de las teoría y conceptos éticos y acerca de su relevancia en el trabajo cotidiano de los especialistas en información.

\section{ASPECTOS HISTÓRICOS DE LA ÉTICA DE LA INFORMACIÓN}

Si bien la ética de la información como concepto y teoría articulada es relativamente nueva, sus raíces y tradiciones históricas y culturales se remontan al mismo nacimiento de las grandes civilizaciones. El estudio de 
la ética de la información dentro de diferentes tradiciones culturales es una tarea abierta. Respecto a la tradición occidental, destacan los siguientes aspectos.

\section{La tradición occidental}

En la tradición occidental, la ética de la información tiene sus raíces en la cultura oral de la antigua Grecia. El Ágora (lugar de reunión y de comercio) y la libertad de expresión fueron fundamentales en la democracia ateniense. Los cínicos cultivaron la libertad de expresión como una forma especial de libertad. Sócrates practicó su pensamiento en lugares públicos y nunca escribió sus argumentos. Platón discutió en sus diálogos la transición de una cultura oral a una cultura escrita. ${ }^{11}$ Bajo la influencia del cristianismo, se desarrolló una cultura del libro, que se centró principalmente en el libro de libros, la Biblia.

La invención de la Imprenta por Gutenberg ${ }^{12}$ así como la Reforma ${ }^{13}$ fueron factores fundamentales que influyeron, en el periodo moderno, en la idea de la

11 Una obra que espléndidamente explica la milenaria relación dialéctica entre cultura oral y cultura escrita es la de James O'Donnell. Avatares de la palabra: del papiro al ciberespacio. Barcelona: Paidós, 2000. 199 p.

12 Man, John. Gutenberg : how one man remade the world with words. New York: J. Wiley, c2002. 312 p.

13 The reformation and the book / edited by Jean-Francois Gilmont. Aldershot: Ashgate, 1998. 498 p. 
libertad de comunicación, que implicó la libertad de comunicar ideas a otros no tan sólo por escrito sino también en forma impresa.

La Revolución francesa, entre otros aspectos, al expropiar bienes de la nobleza y de la Iglesia, promovió la idea de la creación de espacios públicos y de bibliotecas, libros, etc., también de uso común. Proyectos como el de la Enciclopedia francesa y el acceso público a las bibliotecas, crearon un nuevo tipo de libertad de información, que culminó en el principio de libertad de Prensa como uno de los pilares de las democracias modernas. ${ }^{14}$

La tradición occidental de la ética de la información desde la antigua Grecia hasta inicios del siglo XX, se caracteriza por dos ideas fundamentales:

- Libertad intelectual y de expresión

- Libertad de publicación de obras impresas y, particularmente, libertad de prensa.

Pero un tercer elemento se integra posteriormente, el cual cobra cada vez mayor importancia, por ejemplo en un entorno digital cada vez más interconectado: Libertad de acceso a la información.

A la vez, se ha fortalecido una perspectiva valiosa que vincula la ética de la información con los derechos humanos fundamentales. Surge así todo un marco social,

14 Keane, John. The media and democracy. Cambridge : Polity, 1991. $202 \mathrm{p}$. 
cultural, jurídico y democrático bajo el concepto de derecho a la información. ${ }^{15}$

\section{ÉTICA DE LA INFORMACIÓN Y DERECHOS HUMANOS}

Desde la perspectiva de la ética de la información, en la Declaración Universal de los Derechos Humanos existen diversos elementos que fundamentan una reflexión ética sobre la responsabilidad de los especialistas de información. Los siguientes tópicos de la Declaración Universal de los Derechos Humanos son de gran importancia en el entorno y competencia de la ética de la información:

- Respeto a la dignidad de todo ser humano.

- Confidencialidad.

- Igualdad de oportunidades.

- Derecho a la esfera privada.

- Derecho a la libertad de intelectual y de expresión.

- Derecho a participar en la vida cultural de la comunidad.

- Derecho a la protección de los intereses morales y materiales relativos a cualquier producción científica, literaria o artística. ${ }^{16}$

15 Bonet, Jordi. El derecho a la información en el Convenio Europeo de los Derechos Humanos. Barcelona : PPU, 1994

16 Declaración Universal de los Derechos Humanos (1948). Disponible en: http://www.un.org/spanish/aboutun/hrights.htm 
Por otra parte, resulta claro que si la información continuamente se produce, recicla, selecciona, organiza y distribuye, surgen en estos procesos otros tópicos de interés para la ética de la información.

\section{TÓPICOS ÉTICOS DE LA PRODUCCIÓN DE INFORMACIÓN}

Los dilemas relacionados con la protección de la propiedad intelectual son algunos de los más importantes y difíciles problemas éticos, morales y legales en el campo de la producción de la información. Distintas tradiciones relacionadas con los procesos propios del ciclo social de la información, las tecnologías de información empleadas y la naturaleza dual de cualquier material bibliográfico (en el sentido de expresar una obra, esencialmente fruto intelectual intangible, materializada en el objeto que permite su difusión) han derivado en diferentes tipos de normas y leyes en diversas regiones del mundo:

- La tradición europea enfatiza los derechos morales de los autores (derecho de autor). Protege sobre todo la integridad y el reconocimiento de la autoría de la obra de un autor, así como su reputación. 
- La tradición angloamericana enfatiza la propiedad de los derechos económicos (copyright). Estos derechos pueden ser transferidos.

Se han realizado esfuerzo notables para armonizar estas dos visiones, por ejemplo:

La Convención de Berna (1886 y revisiones posteriores) ${ }^{18}$ Protege: libros, esculturas, arquitectura, etc. Vigencia del derecho a recibir regalías: la vida del autor más 50 años. Esto hace una diferencia entre los derechos económicos y los morales. En caso de que un autor negocie o transfiera los derechos patrimoniales de sus obras, esto no incluye los derechos morales, que son inalienables e imprescriptibles.

Convención Universal sobre Derecho de Autor (Ginebra, 1952 y París, 1971). Protege obras literarias, científicas y artísticas, con especial énfasis en los derechos de reproducción. Duración de la protección: No menos de la vida del autor más 25 años después de su muerte. ${ }^{19}$

Pero ahora se presentan nuevos problemas en un entorno digital cambiante. La digitalización permite que

17 Pedley, Paul. Copyright for library and information service professionals. London : ASLIB, 1998. 64 p.

18 Homenaje al año mundial del derecho de autor: centenario de la Convención de Berna. Buenos Aires: Bias, 1986. 429 p.

19 Convención Universal sobre Derecho de Autor (Ginebra, 1952 y Paris, 1971). Disponible en: http://portal.unesco.org/culture /es/ev.php@URL_ID=1814\&URL_DO=DO_TOPIC\&URL_SECTI $\mathrm{ON}=201 . h \mathrm{tml}$ 
múltiples copias y variantes de una obra sean muy fáciles de hacer, prácticamente de manera instantánea. La globalización e internacionalización que permite Internet cambia la dimensión y perspectivas de la legislación y control nacionales. Esta nueva configuración hace surgir preguntas tales como: ¿Debería la información ser considerada siempre como una propiedad? ¿Debería la noción de conocimiento compartido convertirse en más importante que la noción de derechos de propiedad intelectual? ¿Cómo se puede garantizar el acceso a la información digital? ${ }^{20}$

\section{TÓPICOS ÉTICOS DE LA SELECCIÓN, ADQUI- SICIÓN Y ORGANIZACIÓN DE LA INFORMACIÓN}

Los dilemas éticos relativos a la selección, adquisición y organización de la información se relacionan con la censura y el control. Las respuestas a estos problemas varían históricamente de acuerdo con los intereses del poder político, económico, religioso y militar vigente en cierto momento histórico. Ciertas tradiciones culturales y morales juegan también un papel muy importante en aspectos tales como qué es considerado

20 Lessig, Lawrence. El código y otras leyes del ciberespacio. Madrid : Taurus, c1999. 540 p. 
ofensivo. La principal pregunta ética en este campo es: ¿Cuáles son los límites de la libertad intelectual? ? $^{21}$

Los sistemas de clasificación, los tesauros, los motores de búsqueda no son neutrales. En muchas ocasiones no se reconocen estos problemas. En Internet, debido a la gran cantidad de información que se maneja, estos problemas adquieren mayor relevancia.

\section{TÓPICOS ÉTICOS DE LA DISEMINACIÓN DE LA INFORMACIÓN}

Los dilemas éticos concernientes a la diseminación de la información se relacionan con problemas de acceso público a la información, tanto a un nivel individual como colectivo y social.

Las personas están interesadas en un acceso a la información libre e igualitario. Al mismo tiempo se tiene que reconocer que la información es producto del esfuerzo intelectual, es decir implica trabajo y tiene por lo tanto un valor económico que debe ser protegido. El dilema principal es, entonces, ¿Qué tipo de información y para quiénes debe ser libre?

La problemática del acceso público a la información como un tópico social tiene que ver con el problema relevante de la creación de iguales oportunidades de

21 Jones, Barbara M. Libraries, access, and intellectual freedom. Chicago : American Library Association, 1999. 266 p. 
acceso, tanto para sociedades y naciones ricas como pobres.

De ahí que temas de gran importancia son:

- Infodivisión (brecha digital) y capitalismo informacional.

- Propiedad intelectual y economía de acceso.

- Libertad de expresión y tradiciones morales.

- Acceso universal y gobierno de la red.

- Confidencialidad de la información y de los usuarios. $^{22}$

\section{PERspectivas}

Todos estos dilemas éticos se vuelven más críticos como un resultado de la globalización de la información a través de Internet. Surgen preguntas sin fácil solución como ¿Quién debe controlar la información que proviene de otra cultura o país? $\mathrm{O} \dot{E}$ En realidad no debe hacerse ningún esfuerzo al respecto? ¿Cómo pueden las leyes, geográficamente limitadas, regular la dimensión polifacética y sin fronteras físicas del ciberespacio?

Posibles soluciones se tratan de encontrar en diferentes niveles:

22 Vital links for a knowledge culture: public access to new information and communication technologies / edited by Liss Jeffrey. Strasbourg: Council of Europe, 2001. 193 p. 
- Auto-regulación. Esta es la solución ética propagada por la Comunidad Internet, particularmente a través de software que permite la filtración de información. Otra estrategia es la Netetiqueta. Otros tipos de autoregulación son los que se llevan a cabo en algunos Grupos de Discusión a través del moderador.

- Campañas. Por ejemplo las campañas de incluir en los sitios Web listones azules, rojos, negros, etc. como símbolos universales en las comunidades virtuales contra la censura, la discriminación, la pandemia del sida, el terrorismo, etc.

- Códigos de ética. De diferentes instituciones, sociedades, comunidades, asociaciones de profesionistas, etc.

- Regulaciones legales. A nivel nacional, multinacional e internacional.

- Regulaciones técnicas. Murallas de seguridad, Software de filtrado, etc.

La Internet brinda un cambio drástico en la concepción global de la libertad de información, autorregulación, acuerdos multinacionales, flujos de información en naciones ricas y pobres, entre otros aspectos. Por tal motivo, en la segunda parte de esta contribución se detallan varios temas de interés derivados de la relación entre Internet y ética de la información. 


\section{INTERNET Y ÉTICA DE LA INFORMACIÓN ${ }^{23}$}

Cuando desde el campo de competencia de la ética de la información se estudian ciertos fenómenos que ocurren en Internet, pueden identificarse ciertas categorías críticas y dilemáticas. Un ejemplo claro de la actualidad y relevancia de este tipo de temáticas y enfoques

23 Como se indicó en la primera parte, hay una bibliografía abundante y en continuo crecimiento relacionada con este tema emergente. Para un panorama al respecto pueden consultarse las siguientes obras: Cyberethics: social \& moral issues in the Computer Age (edited by Robert M. Baird, Reagan Mays Ramsower, Stuart E. Rosenbaum. New York: Prometheus Books, 2000. 356 p.), Ethics and electronic information: a Festschrift for Stephen Almagno (edited by Barbara Rockenbach and Tom Mendina. Jefferson, North Carolina: McFarland, c2003. 213 p.), Ethics and electronic information in the twenty-first century (edited by Lester J. Pourciau. West Lafayette, Indiana: Purdue University, 1999. 334 p.), Cees Hamelink (The ethics of cyberspace. Thousand Oaks, California: Sage Publications, 2001. 224 p.), Micah Hester y Paul J. Ford (Computers and ethics in the cyberage. Englewood Cliffs, N.J Prentice Hall, 2000. 498 p.), Gerald Koocher (Ethics in cyberspace. Mahwah, NJ: Lawrence Erlbaum Assoc, 1996), Readings in cyberethics (edited by Richard A. Spinello y Herman T. Tavani. Sudbury, Massachussets: Jones \& Bartlett, 2001. 618 p.), Richard Spinello (Cyberethics: morality and law in cyberspace. 2nd edition. Sudbury, Massachusetts: Jones \& Bartlett Pub, 2002. 238 p.), Virtual morality: morals, ethics and new media (edited by Mark J. P. Wolf. New York: Peter Lang Publishing, 2003.), Hugo Figueroa Alcántara ("Ciberespacio y ética hacker". En Topodrilo. No. 48 (septiembre-noviembre de 1997). p. 22-25.) y Hugo Figueroa Alcántara ("Juegos de identidades en el ciberespacio". En Revista digital universitaria. Vol. 2, no. 4 (31 de diciembre de 2002). Publicación en línea. Artículo disponible en: http://www.revista.unam.mx/vol.2/num4/art3/index.html. 
está representado por el contenido del International ICIE Symposium 2004: Localizing the Internet: Ethical Issues in Intercultural Perspective (Karlsruhe, Alemania, 4-6 de 2004), que reunirá a más de 40 profesores e investigadores de todas partes del mundo, cuyos ejes de enseñanza e investigación giran alrededor de tópicos tales como: Internet y desarrollo social, político, cultural, económico; desarrollo de comunidades, reestructuración de los medios y sus normativas, mejoramientos de los niveles de bienestar social, cultural y de acceso a Internet para la población de todas partes del mundo, etc.; todo lo anterior bajo una perspectiva ética y multicultural. ${ }^{24}$

Si se revisa la literatura concerniente a esta vertiente de la ética de la información, pueden detectarse dos categorías que destacan: Brecha digital y Contenido digital.

Por Brecha digital se entiende el conjunto de problemas implicados en el acceso desigual a la información que se da en Internet, a nivel global y local. Contenido digital se relaciona con la creación, selección, organización, adaptación y difusión de la información digital.

24 International ICIE Symposium 2004: Localizing the Internet: Ethical Issues in Intercultural Perspective (Karlsruhe, Alemania, 4-6 de 2004). Disponible en: http://icie.zkm.de/congress2004. 
En cada una de estas dos categorías pueden identificarse tópicos candentes, que a continuación se analizan.

\section{BRECHA DIGITAL}

Un tema por demás recurrente es el de las barreras de acceso a Internet, por motivos económicos, técnicos, socioculturales e interculturales. ${ }^{25}$ Debido a estas restricciones, muchas veces solamente una pequeña capa privilegiada de la población tiene acceso a Internet. Esta situación se da tanto a nivel interno de un país, como a nivel regional e internacional, por lo que en la literatura sobre el tema se estudia el fenómeno de división digital, brecha digital, información para los pobres e información para los ricos, etc., derivándose de esto diversos dilemas éticos.

Otro problema que ha acompañado el desarrollo de Internet es el de la creciente comercialización y la apropiación de bienes y espacios públicos por parte de grandes corporaciones. Si bien se crean nuevos mercados, también florecen nuevos problemas e injusticias. Por ejemplo, los llamados servicios extra y de suscripción pueden tener una influencia decisiva sobre la generación

25 Para profundizar en estos temas se recomienda ampliamente $L a$ galaxia Internet de Manuel Castells (Barcelona: Arete, 2001. 316 p.), así como su monumental trilogía La era de la información (México: Siglo XXI, 1999. Contenido: v. 1, La sociedad red; v. 2, El poder de la identidad; v. 3, Fin de milenio) 
de contenidos y los procesos de selección. El aspecto ético más relevante se relaciona con el riesgo de que Internet se transforme, de un medio público de acceso público, gratuito y descentralizado, independiente y multifacético para la creación y distribución de información, a un medio por pago de acceso a contenidos, orientado hacia el consumo, dominado por las grandes corporaciones y que por ende suministre entretenimientos prefabricados e información convencional a los usuarios.

Y como todo exceso es malo, otro problema de gran envergadura es el del exceso de información. Por lo general, la enorme cantidad de información disponible en Internet está mal estructurada y se presenta al usuario como una masa de datos inabarcable, anónima e irreal, cuya calidad y credibilidad resultan difícil de evaluar. La complejidad, cantidad y arbitrariedad de la información repercute en un sentimiento de desorientación y agobio por parte de los usuarios. Asuntos éticos de gran importancia se vinculan con la confiabilidad y autenticidad de la información, así como en el peligro de que se genere en los usuarios de Internet una visión acrítica y desvalorizada de la información que circula en Internet o bien una adicción patológica, más orientada a los medios y no al contenido. Éticamente emergen también problemas relacionados con la identidad en el ciberespacio: multifacética o anónima en algunos casos, abusiva o delictiva en otros. Según los niveles de 
formación, competencia mediática y tiempo disponible, una vez más puede abrirse una brecha enorme entre los conocimientos de quienes están en condiciones de servirse de Internet como fuente de conocimientos con competencia y precisión, y quienes quienes lo ven, sobre todo, como algo desordenado, arbitrario y difícil de entender. Por consiguiente, con Internet el problema de la selección de informaciones útiles y su transformación en conocimientos útiles y contextuales se convertirá probablemente en el desafío más importante, tanto para los expertos como para los usuarios comunes.

\section{CONTENIDO DIGITAL}

Otro de los principales puntos críticos tiene que ver con la veracidad y confiabilidad de los recursos de información provenientes de Internet. No obstante los avances, hasta la fecha todavía no se ha alcanzado un grado de exactitud y confiabilidad de los recursos de información disponibles a través de Internet, equivalente a los aplicados en los medios no digitales. Por ejemplo, una de las principales cualidades de la Web, la propiedad hipertextual de que todo se puede vincular con todo, genera, paradójicamente, la ilusión de información verídica y de calidad, cuando en muchas ocasiones más bien ocurren fenómenos opuestos. Como signos indudables de nuestro tiempo, se genera una tendencia hacia la mezcla, el pastiche, la apropiación, 
descontextualización o deformación de información de todo tipo, un verdadero juego de espejos, laberintos y falsificaciones, dificultándose la identificación plena de las fuentes originales y de contenido veraz.

Otro gran problema está representado por contenidos éticamente cuestionables. En términos generales, hay que aprender a diferenciar entre los contenidos éticamente cuestionables pero legales, y aquellos éticamente inaceptables e ilegales a la vez. Si bien estos rubros resultan muy complejos, polémicos y subjetivos, es posible reconocer tres áreas de intensa reflexión y análisis ético: en primer lugar, los contenidos moralmente problemáticos, cuyo objetivo es atacar las normas y los valores de otros (incitar al odio, denigrar minorías y personas procedentes de otras culturas); en segundo término, contenidos propagandísticos extremos, que apuntan a la difusión agresiva e intolerante de ideologías radicales (extremismo político, fundamentalismo religioso); en tercer lugar, contenidos violentos que desprecian la dignidad y la vida humana (imágenes deformantes, pornografía infantil); todos estos contenidos son considerados inmorales en la mayoría de las sociedades y quedan prohibidos. Por supuesto, estas formas se mezclan con otras de manera compleja y con fronteras digitales difusas, por lo que en muchos casos su ubicación y clasificación resulta difícil. En esta zona de problemas se suele plantear un conflicto en última instancia, entre la libertad de expresión y la 
censura, que llevará casi siempre a la búsqueda de soluciones graduales, acordes con la situación. En tal sentido, también resulta crucial desarrollar una ética del ciberespacio, acorde con la naturaleza inmaterial y de reproducción instantánea de los medios digitales y de Internet, por ejemplo una ética del ciberespacio basada y vinculada con los derechos humanos. ${ }^{26}$ Los problemas de la seguridad y el abuso de los datos están relacionados con la zona problemática de los contenidos éticamente cuestionables. Por un lado, Internet permite, sin restricciones, copiar y adaptar datos, juntar informaciones de todo tipo sobre los usuarios y vincularlas, por ejemplo para elaborar un perfil de usuario. La digitalización y el desarrollo impresionante de gigantescas bases de datos, además interconectadas, facilita el acceso no autorizado y la manipulación encubierta de datos a gran escala. Estos elementos inciden en la necesidad de una protección eficaz del copyright y de la esfera privada, por ejemplo a través de restricciones de ingreso, marcas de agua digitales, criptografía, etc. Por otra parte, la digitalización de la información facilita también el abuso sistemático a través de la difusión y manipulación no controlada de los datos; la falta casi total de obstáculos para la publicación y la transferencia digital de datos agilizan la difusión y

26 Hamelink, Cees J. The Ethics of Cyberspace. Thousand Oaks, California: Sage, 2001. 224 p. 
almacenamiento rápido y anónimo de textos, imágenes y sonidos inofensivos, pero también provenientes del extremismo político, y la pornografía violenta o infantil. En este contexto se plantea un conflicto ético fundamental entre la necesidad indiscutible de disponer de tecnologías de codificación contra el acceso no autorizado a determinados datos y la utilización de estas tecnologías con la finalidad de encubrir actividades éticamente cuestionables o delictivas.

Todo este panorama nos proporciona ante todo un punto de partida de tópicos a considerar cuando incursionamos en el tema de la ética de la información desde una perspectiva bibliotecológica.

\section{CONCLUSIONES}

La principal conclusión es que en el contexto del enfoque social vinculado con la enseñanza e investigación de la bibliotecología y estudios de la información, un tema vital es el de la ética de la información.

Enseñar e investigar ética de la información desde una perspectiva bibliotecológica, favorecerá sin duda a la disciplina, a la profesión y a nuestros interlocutores fundamentales: los autores, productores, intermediarios y usuarios de información. Nos sensibilizará a todos los actores que participamos en el ciclo social de la información (autores, editores, productores, libreros, proveedores, bibliotecólogos, usuarios de información, etc.), acerca del carácter crítico y 
Ética de la información: perspectivas bibliotecológicas

complejo de los diferentes asuntos relacionados con la ética de la información.

Queda así, en el marco de la ética de la información, todo un programa abierto de temas para enseñar, analizar, discutir, reflexionar e investigar en nuestro medio, para poder contribuir con obras mexicanas, al esfuerzo internacional que se está haciendo al respecto y poder favorecer un diálogo ético e intercultural, serio, abierto y de magnífico nivel, tan necesario en nuestros días, que nos ayude, entre todos, a construir el mejor de los mundos posibles, menos desigual, más tolerante y más fraternal. 


\title{
Aspectos éticos en la formación profesional del bibliotecario
}

\author{
JOSÉ DE JESÚS HERNÁNDEZ FLORES \\ Eescuela Nacional de Biblioteconomía y Archivonomía/sEP \\ Instituto de Investigaciones Estéticas/UNAM
}

\begin{abstract}
Dara entender la ética profesional, hay que tener claridad en los términos involucrados y comprender la importancia de la ética que algunos autores han considerado como "El conjunto de principios, actitudes, normas específicas y maneras de juzgar las conductas, que caracterizan a un determinado grupo de profesionales".

Edward Gross define al profesional como la persona que posee un amplio conocimiento teórico aplicable a la solución de problemas vitales recurrentes, pero no estandarizables y que se sienten en la obligación de realizar su trabajo al máximo de sus competencias, al mismo tiempo que se identifican con colegas.

Una profesión aparece ligada a la vocación; lo que se espera del profesional es que se consolide en su disciplina y en su vida totalmente. Implícitamente se tiene la necesidad permanente de una educación continua
\end{abstract}


así como de alta especialización, factores que le ayudaran a prepararse y mantenerse actualizado profesionalmente para ofrecer sus servicios de calidad a la sociedad, realizando satisfactoriamente sus actividades.

En resumen, podemos decir que la ética es la esencia de los principios morales que rigen a la conducta humana, como el deber, la justicia, el derecho, la responsabilidad, la conciencia, entre varios más. La conjugación de la vocación y la ética profesional permiten actuar con autonomía en la toma de decisiones, con solidaridad y respeto al grupo al que se pertenece.

$\mathrm{El}$ ejercicio de la profesión tiene una labor fundamentalmente social; la misión de bibliotecario profesional nos obliga y exige una actuación ética en un marco de valores, comprometiéndonos a ser portadores y promotores de una moral y ética en el ejercicio de la disciplina, en lo individual así como en lo gremial dentro de la sociedad.

Los valores y ética constituyen las piedras angulares en el desarrollo profesional para el reconocimiento, logrando la confianza de la sociedad, instituciones y usuarios, al ser considerados como el factor primordial y detonante en el desarrollo en sectores prioritarios para la nación, por ejemplo, educación, ciencia y tecnología.

Una gran mayoría de personas habla indistintamente de ética y moral para hacer referencia a los actos humanos y calificarlos como buenos o malos; resulta difícil 
hacer la diferencia en un contexto ordinario, para muchos lo anterior carece de importancia.

Campo Vidal nos dice que en este último cuarto de siglo el mundo ha cambiado no sólo de centuria, ha cambiado de era. Hemos pasado de la sociedad industrial a la sociedad del conocimiento. Nada es igual en el trabajo, en la educación, en la administración, en la información. La información sufre nuevas amenazas entremezcladas con nuevas oportunidades y desafíos. Sin embargo sería bueno hacer una reflexión sobre moral, principios, ética y valores, así como las posibles repercusiones en nuestra práctica profesional, veamos algunas definiciones:

- Moral: Juicios de valor que son parte de la cultura de una sociedad, mediante los cuales se califican los actos como buenos o malos.

- Principios: Normas de conducta de una persona mediante los cuales rige sus actos.

- Valor: En un sentido moral, es una cualidad del o de los actos.

- Ética: Considerada como una reflexión filosófica, objetiva y racional sobre la moral.

Para entender al escala en la sintonía de la ética, si las personas en general siguieran un esquema relativamente simple dentro de la sociedad, podemos decir que fomentando y cultivando valores, serían un factor primordial que permitiría sustentar una alta moral. Así tenemos que conjugados los valores con la moral se 
Aspectos éticos en la formación profesional del bibliotecario

convierten en puntos fundamentales que ofrecen claridad y permiten actuar con ética profesional. Empero al ser humano le resulta difícil seguir normas, además que en la actualidad para muchos no hay claridad en los beneficios de actuar con ética.

Mario Benedetti, en uno de sus poemas, hace reflexionar acerca de los valores:

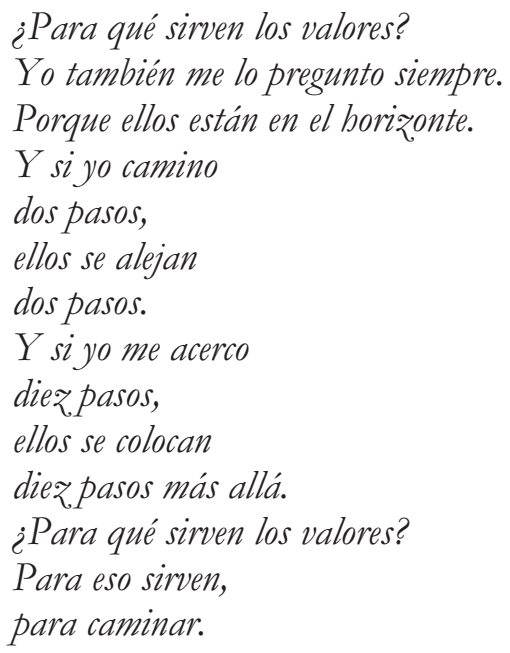

Posiblemente para el ser humano le sea difícil actuar y tener claridad sobre los valores como algo concreto y absoluto, pero sin embargo se convierten en la brújula de sus acciones y en el sustento de una consolidación ética y profesional, reportando, tanto a la sociedad 
como a la profesión, grandes resultados y enormes satisfacciones, avanzando en el reconocimiento social de la profesión.

Los eslabones fundamentales para consolidar valores son la familia y la educación a través de las instituciones que tienen el deber de formar y consolidar hombres con valores basados en la dignidad, honestidad, responsabilidad y solidaridad, con una ética clara y sólida en su ejercicio profesional.

Cabe mencionar algunas recomendaciones que ha hecho Carlos Kazuga en conferencias a universitarios y que se basa en cuatro pasos:

1. El bien ser educado y formado en los valores,

2. El bien hacer tener el mayor cuidado en lo encomendado y hacerlo con calidad,

3. El bien estar la satisfacción de haber hecho bien las cosas encomendadas y

4. El bien tener la consecuencia de todo lo anterior estará en el reconocimiento laboral, moral, ético y hasta en lo económico.

Carlos Kazuga Osaka, en una visita a la UNAM, afirmó que la base del éxito es una educación de valores conjugado con una ética laboral, además plantea la necesidad de cumplir con las obligaciones y dar más de lo debido. En Japón, subrayó, no se acumulan conocimientos, la educación es formativa, de valores; por lo 
tanto, un país que carece de buena educación está destinado al fracaso.

Si la sociedad cuenta con profesionales, egresados de licenciaturas (Bibliotecología, Historia, Pedagogía, etcétera), con una alta conciencia y claridad de la importancia de una ética profesional, podemos enfrentarnos con alternativas y objetividad a los retos. En lo que nos corresponde, se pueden diseñar, consolidar e implementar sistemas de información eficientes y de calidad, aplicando políticas de información que se requieren con urgencia, para sustentar el servicio bibliotecario que tanto demanda la sociedad, con valores agregados; con veracidad en las fuentes, oportunidad de la información, rapidez en los servicios solicitados, además de contar con altos niveles de calidad en la información solicitada.

La conjugación de valores, ética y trabajo profesional fortalecen y dan vigor a una dignidad profesional, factores fundamentales para orientar el trabajo especializado e incidir en el diseño de políticas y estrategias de servicio para los usuarios.

Por otro lado, la misma tecnología nos obliga a un trabajo profesional y ético, con los beneficios que reporta como velocidad, precisión, flexibilidad, reducción de tiempo y de costos, atributos necesarios e indispensables en la actualidad para la sociedad inmersa en economías globalizadas, con mercados libres y altamente competitivos. 
El desarrollo de las aplicaciones de la informática es un factor de transformación de la organización económica y social, conviene pues a nuestra sociedad contar con profesionistas para estar en condiciones de proveerla y a la vez dominarla, con el fin de ponerla al servicio de la democracia y el desarrollo humano.

\section{CONCLUSIÓN}

Cuando aplicamos ciertas reglas o normas para nuestra conducta, lo podemos considerar como tener principios que inciden en nuestros valores, haciéndose más fácil actuar con ética en nuestras vidas profesionales. La ética es la propuesta y aceptación de valores universalmente válidos. No podemos dejar de subrayar que los valores morales se conjugan con nuestra racionalidad, en otras palabras son lo más humano de nuestra humanidad, tal vez por eso son tan frágiles.

Finalmente nos enfrentamos al reto de hacer una gestión con ética y efectividad en los resultados que coadyuven a la integración y articulación de los valores individuales, permitiendo la integración hacia los objetivos planteados.

Cortina resume muy bien la importancia de los compromisos éticos, cuando dice que en ellos se envuelven los tres dominios que operamos los seres humanos y estos son el pensar, el sentir y el actuar. 
Aspectos éticos en la formación profesional del bibliotecario

Será importante diseñar una estrategia educativa, que conjugue en sus aspectos pedagógicos y profesionales, la difusión y asimilación de la importancia de una ética profesional, considerando las nuevas exigencias que se generan en la sociedad con el uso de nuevas tecnologías.

\section{BIBLIOGRAFÍA}

Campo Vidal, Manuel. "Información Poder y ética en el siglo XXI”, en El País, 19-05-2004.

Derecho y ética de la información, el largo sendero hacia la democracia en México. Ernesto Villanueva, coordinador ; Javier Alatorre [et al.]. México: Media Comunicación, 1995.283 p.

Ethics and information technology / ed. by Goran Collste. Delhi, India: New Academic, 1998. 178 p.

Kazuga Osaka, Carlos, en Boletín del Liceo Mexicano Japonés, $1999.8 \mathrm{p}$.

Prado Galán, Javier. Ética, profesión y medios : la apuesta por la libertad en el éxtasis de la comunicación. México: Universidad Iberoamericana, 1999. 73p.

"Presencia del director de Yakult México, en el plantel 4", en Suplemento ENP, de la Gaceta UNAM, núm. 3,607, del 6 de febrero de 2003. p. iii. 
Mesa redonda. Ética e infomación

Trueba Olivares, Eugenio. Ética profesional para el ejercicio del derecho. México: Universidad de Guanajuato, 1993. $238 \mathrm{p}$.

Vogel Zolondz, Alfredo. Nuevas tecnologías de la información: su impacto en la sociedad del siglo XXI. México: EDAMEX, 2001. 208p.

Zamorano García, Enrique. Ética profesional: el tercer cantero. México: IMCP, 2003. 229p. 


\title{
Ética e información en la sociedad postmoderna
}

\author{
Celia Mireles CáRdenas \\ Escuela de Bibliotecolgía e Información \\ de la UASLP
}

$\mathrm{n}$ el código de ética de la ALA se menciona que
los dilemas éticos ocurren cuando existe un conflicto de valores dentro de las sociedades, situación que parece predominar a inicios del siglo XXI en las llamadas sociedades modernas y postmodernas, en las cuales se cuestionan todas las actividades científicas, tecnológicas, económicas y sociales del ser humano, pero sobre todo, las consecuencias de las mismas para las generaciones futuras.

El presente trabajo se refiere brevemente a los principales postulados de lo que algunos llaman paradigma de la post-modernidad en relación con la ética y los valores sociales, así como su incidencia en las tareas bibliotecarias e informativas actuales.

\section{ÉTICA Y VALORES SOCIALES}

El objetivo de la ética es la búsqueda de lo que es aceptable o no en determinadas situaciones, así como 
de los principios, normas o reglas que deben guiar la conducta de un individuo como miembro de una sociedad. La suma de estos principios que brindan coherencia a las acciones de los individuos es lo que comúnmente llamamos valores.

Los valores pueden definirse como las cualidades que atribuimos a determinadas situaciones y que influyen en la opinión y conducta de los individuos. Así, los seres humanos eligen una serie de principios bajo los cuales orientan sus actividades y por consiguiente las funciones de sus gobiernos e instituciones sociales. Cuando estos valores son aceptados y compartidos por una comunidad se les llaman valores éticos, cuya característica principal es la fuerza impositiva que obliga a reconocerlos más allá de intereses personales.

Idealmente los valores éticos al estar por encima de las creencias individuales deben ser lo más objetivos posibles, pero al ser creaciones humanas se construyen, cambian y evolucionan de acuerdo con las relaciones familiares, religiosas, culturales, económicas políticas y tecnológicas por las que atraviesen los individuos y las sociedades. ${ }^{1}$

Por tanto, las discusiones sobre los valores que deben guiar la actuación de las personas, instituciones o

1 Comparación de los valores predominantes en distintas etapas de la historia, esquema basado en los argumentos de Joseph M. Valles, en Ciencia Politica: una introducción. 
disciplinas no es un tema acabado, máxime en etapas de transición como la vigente en la que los cambios sociales y culturales son acelerados por el fenómeno de la globalización que pone a la vista de las mayorías esquemas valorativos de las diferentes comunidades del mundo.

\section{VALORES EN LAS SOCIEDADES MODERNAS Y POSTMODERNAS}

La libertad, la igualdad y la fraternidad, ideales postulados a partir del inicio de la Revolución Francesa de 1789 , se convirtieron en el marco valorativo a partir de los cuales se definen las actuaciones de los gobiernos y de las instituciones públicas modernas, inmersas dentro de una corriente liberal en donde el intercambio libre y abierto de mercancías e ideas entre los individuos se convierte en la mejor estrategia para conservar la libertad de cada ciudadano y el bien público de la mayoría.

Esta tendencia supone el principio de la eficiencia y de la óptima relación medios-fines propia de la racionalización instrumental como elementos responsables del desarrollo de la civilización: la revolución industrial, el capitalismo, el progreso científico y sus aplicaciones tecnológicas.

El llamado paradigma de la post-modernidad tiene sus inicios hacia 1968 y se desenvuelve dentro de una economía neoliberal en la que el libre mercado, la mundialización de los intercambios y el gran poder 
socializador de los medios comunicación de masas son elementos claves para comprender el estado y desarrollo de las sociedades actuales, ya que este término presupone la existencia de sociedades que transitan por una etapa pre- moderna (democracias fracasadas) y otras que se sitúan en la modernidad (democracias en construcción). ${ }^{2}$

Ángel Pérez define la post-modernidad como

[...]una condición propia de la vida contemporánea, con unas características económicas, sociales y culturales bien determinadas por la globalización de la economía de libre mercado, la extensión de las democracias formales como sistemas de gobierno y el dominio de la comunicación telemática que favorece la hegemonía de los medios de comunicación de masas y el transporte de instantáneo de la información a todos los rincones de la tierra. ${ }^{3}$

Estos cambios engloban los siguientes aspectos:

- Desvanecimiento de la racionalidad moderna

- Relativismo cultural

- Los cuestionamientos al progreso científico-tecnológico

Así, la post-modernidad se caracteriza por la pérdida de los fundamentos tradicionales sin que hayan aparecido otras alternativas con la suficiente estabilidad y

2 Tony Blair, citado por Héctor Abad, en "Neocolonialismo postmoderno".

3 Ángel Pérez Gómez, en La cultura escolar en la sociedad neoliberal. 
aceptación para que se consideren orientadoras de las prácticas sociales, en donde se presenta el dilema igualdad-libertad, que conjunta situaciones contradictorias como:

$\begin{array}{ll}\text { Solidaridad-Competitividad } & \begin{array}{l}\text { Identidad cultural - Diversidad } \\ \text { cultural }\end{array} \\ \text { Socialismo-Liberalismo } & \text { Instituciones-Mercado } \\ \text { Interés público-Interés privado } & \end{array}$

En este contexto, la ética entendida como el intento racional de vivir mejor ${ }^{4}$ se enfrenta a tres desafíos principales: medio-ambientalismo, feminismo y multiculturalismo, ${ }^{5}$ es decir, en las sociedades contemporáneas se pueden observar fenómenos relativos a la otredad, la pluralidad, mezclas entre la tolerancia e indiferencia, ambigüedad y relativismo, así como la incertidumbre cultural, filosófica, científica y artística.

Estas ambigüedades ocasionan que la ética en la actualidad se considere como individualista, con un enfoque pragmático en el que no se meditan las acciones y las consecuencias más allá de la satisfacción personal en el presente; la ética de todo se vale para lograr los fines propuestos en beneficio propio y en la cual las apariencias, las formas y la imagen prevalecen en la cultura

4 Fernando Savater, Ética para Amador.

5 James P. Streba, citado por Francisco Fernández, en Reivindicación de la política como ética de lo colectivo. 
actual, es decir, existe una supremacía de la estética sobre la ética. ${ }^{6}$

Dentro de este ambiente, se ha generado un ciudadano emergente con hábitos, valores, intereses, formas de pensar, de sentir y de actuar diferentes a las tradicionales, ante el cual las instituciones sociales como la biblioteca tienen que lidiar y satisfacer en sus nuevos requerimientos.

En cuanto a la ética, cabe recordar que al igual que el ser humano, evoluciona en sí misma como un proceso social, ${ }^{7}$ cambia y se desarrolla de acuerdo con las influencias recibidas del medio ambiente en que se genera. Por esto cabe la pregunta ¿qué es ética en la época de globalización postmoderna? Como posible respuesta a lo anterior, existen tres propuestas:

- Ética de la Responsabilidad: Weber propone la formulación de derechos humanos definidos de forma genérica sin referencia a ninguna moralidad específica de organización económica o política. Está ética no juzga los actos ni por sus fines ni por sus resultados, sino por los medios utilizados, es decir, los procedimientos son lo único que puede justificar una acción.

6 Angel Pérez Gómez, idem

7 Edgar Morin, Introducción al pensamiento complejo.

8 Fernando Fernández., Idem. 
- Habermas, propone el respeto y la facilitación de la comunicación ilimitada, es decir, garantizar las posibilidades de igualdad de acceso e intervención de todos los interlocutores en el proceso de comunicación.

- Gadamer propone el dialogo permanente como la única estrategia inagotable de redefinición constante de las condiciones, procesos y resultados de la comunicación e interacción humana. "El dialogo es la contrapartida inevitable de la debilidad.",

\section{LA BIBLIOTECA EN LA SOCIEDAD POSTMODERNA}

Las instituciones, reflejan y hasta cierto punto mediatizan los valores y las relaciones sociales de una sociedad determinada

Berger y Luckman

La biblioteca pública es una institución social nacida bajo los preceptos de la modernidad, por lo que convierte los valores democráticos en el fundamento de su actuación dentro de las sociedades. De esta manera, ha desarrollado y producido una cultura específica de tradiciones, costumbres, rutinas y en ocasiones, rituales, con los que tiene que enfrentar las nuevas circunstancias económicas, políticas y sociales marcadas

9 Ángel Pérez Gómez. Ibidem, p50. 
por la post-modernidad, dentro de una economía de mercado en donde igual se venden productos materiales, que ideas, valores, experiencias o emociones.

Considerada como garante de la libertad de expresión, de la libertad de acceso a la información de los ciudadanos, mediadora cultural, defensora de diversidad y pluralidad de ideas, tiene entre sus funciones la selección, organización, difusión, preservación y en ocasiones, control sobre ciertas informaciones consideradas no aptas para ciertos públicos, por lo que su actuación requiere del establecimiento de códigos de ética que guíen y regulen sus actividades, pero que a la vez respondan a las circunstancias actuales. Sin embargo, dentro de la cultura postmoderna, la biblioteca se enfrenta a nuevas situaciones e interpretaciones de los fundamentos clásicos como:

"Desfondamiento de la racionalidad moderna "toda verdad y todo valor dependen de cada persona o criterio." Al ser la verdad una construcción social, y al haber múltiples comunidades sociales, entonces se puede afirmar que no existe una sola verdad y que todas son igualmente válidas para quien las postula, lo que elimina la posibilidad de discernir racionalmente sobre ellas. ${ }^{10}$ Lo anterior también se puede aplicar a los valores, costumbres y creencias, por lo tanto sólo se

10 Fernando Savater. Op. Cit. 
puede esperar a que cada individuo actué en relación con su propia conciencia.

a) Relativismo: multiculturalismo y aldea global

La aceptación de las diferencias, la igualdad y el pluralismo de ideas, valores, costumbres y creencias proporciona una amplia visión de la riqueza cultural humana (mestizaje cultural), sin embargo, al tener acceso directo e inmediato a ideas y costumbres provenientes de todo el mundo, se corre el riesgo de uniformar culturas, por lo que se plantea el dilema de proteger la diversidad, pero también la identidad de los pueblos; es decir, reconsiderar el universalismo en contra de los efectos de la globalización.

b) Influencia de los medios de comunicación

Amplios sectores de la población tienen una fuerte dependencia informativa de los medios de comunicación masiva (TV, radio, periódicos, Internet, etc.), lo que permite una influencia directa sobre las costumbres y valores locales, además de contribuir a la insensibilidad, alineación e indiferencia de los públicos hacia ciertos hechos y temas, además de convertir a la opinión pública en un factor primario de poder en la toma de decisiones públicas.

c) Subinformación y sobre información

La información, aunque ahora es mucho más accesible para las mayorías que hace décadas, debido principalmente a la difusión de los medios masivos de comunicación, provoca situaciones de sobrein- 
formación y subinformación, ya que no toda la población puede acceder a ella en calidad y cantidades iguales, ni mucho menos con la misma capacidad intelectual para asimilar, discernir y elegir la que mejor responda a sus intereses y expectativas, por lo que se convierte en un factor de progreso, pero también de discriminación.

De acuerdo con lo antes expuesto, la biblioteca tiene la necesidad de ampliar su compromiso social en este nuevo contexto cultural y de fomentar el respeto a las diferentes manifestaciones culturales, pero también debe proteger la identidad de las culturas locales sin promover el aislamiento. Debe jerarquizar entre valores, ideas y creencias con el riesgo de caer en la intolerancia, como por ejemplo ¿cuál es la prioridad en la selección de materiales y en la oferta de servicios para atender a una población igualmente válida, plural y diversa? En este punto, la biblioteca deberá establecer las condiciones para que el ciudadano elija aquella información que le permita formarse una opinión personal, para lo cual la selección de los contenidos de las colecciones se convierte en la actividad primaria de las labores bibliotecarias profesionales.

A su vez, al transitar por en una economía neoliberal, la biblioteca debe buscar el equilibrio entre las demandas del mercado y sus funciones sociales, ya que como menciona Giddens "Un ciudadano no es lo mismo que un consumidor, ni es lo mismo la libertad de 
comprar y vender en el mercado, ya que los mercados no crean ni sostienen valores éticos que se han de legitimar a través del diálogo democrático y sostenidos a través de la acción pública."

De esta manera, la biblioteca también adquiere la responsabilidad de buscar fuentes alternativas de financiamiento para la prestación y difusión de sus servicios, así como fomentar el dialogo entre los diferentes sectores de la población.

Para cumplir con estor retos, Ángel Molina engloba en seis apartados las responsabilidades éticas de las instituciones y profesionales de la información postmodernos:

- Formación de una opinión crítica madura

- Pasar de una actitud de poder a una actitud de servicio

- Tener en cuenta los valores de veracidad, imparcialidad, completitud y justicia

- Respeto a los preceptos de igualdad, libertad y solidaridad.

- Fomentar el valor del diálogo (respeto y participación).

- Ayudar a racionalizar la información recibida a través de los medios de comunicación, a valorarla y criticarla. $^{11}$

11 Ángel Cuenca Molina, "Ética de la comunicación", en Anales de Documentación. 


\section{A MANERA DE CONCLUSIÓN}

1. La modernidad sigue siendo punto importante de partida para la conformación de democracias; sin embargo, el postmodernismo, como un nuevo paradigma a partir del cual se intenta explicar el comportamiento del ser humano en las sociedades actuales, cuestiona los fundamentos filosóficos de las ciencias dando nuevas interpretaciones a los conceptos clásicos de igualdad, libertad y fraternidad que han devenido en el fin de la racionalidad, el relativismo cultural y los cuestionamientos éticos sobre el desarrollo y uso de las tecnologías.

2. Cada etapa histórica posee o construye sus propios valores, por lo que las preocupaciones éticas son siempre importantes para cualquier sociedad principalmente cuando hay conflicto entre sus miembros. Sin embargo, debemos recordar que los valores al ser un producto humano cambian y se desarrollan conforme a las circunstancias de los individuos que los producen, por lo tanto no son un producto acabado y el reto será el encontrar (si es que existen) aquéllos valores o principios fundamentales, independientes de las consecuencias y de los contextos aplicables a todas las sociedades en pos de una convivencia mundial comprometida con el futuro de la humanidad. 
3. Para informarse las sociedades actuales han creado una fuerte dependencia de los medios de comunicación de masas los cuales reproducen esquemas de comportamiento ajenos a las comunidades locales. Esto tiene como una de sus consecuencias la generación de conflictos valorativos entre los públicos espectadores, lo que lleva en determinados casos a jerarquizar los valores individuales o colectivos y establecer prioridades entre ellos.

4. Como sostiene Hans Kung, la humanidad se enfrenta al reto de construir una ética mundial en donde existan ideas, valores, ideales y fines obligatorios a todos los seres humanos que se encuentren por encima de las diversas morales y hábitos culturales, ya que de ello depende no solo la convivencia social, sino la pertinencia de diversas instituciones que, como la biblioteca, buscan el bien común de la sociedad.

5. El papel de la biblioteca debe fortalecerse y convertirse en garante del respeto y promoción del multiculturalismo y de la identidad de las comunidades, mediante el contenido de las colecciones y el fomento a la libertad informativa que permita el diálogo y el debate racional y permanente sobre los acontecimientos y temas fundamentales para los ciudadanos. 
Mesa redonda. Ética e infomación

Cuadro comparativo de valores predominantes en distintas etapas de la historia del hombre:

\begin{tabular}{|c|c|c|}
\hline $\begin{array}{c}\text { SOCIEDADES AGRARIAS, } \\
\text { PRE - INDUSTRIALES O } \\
\text { PRE-MODERNAS }\end{array}$ & $\begin{array}{l}\text { SOCIEDADES } \\
\text { INDUSTRIALES } 0 \\
\text { MODERNAS }\end{array}$ & $\begin{array}{c}\text { SOCIEDADES } \\
\text { POST-INDUSTRIALES, } \\
\text { DE LA INFORMACIÓN O } \\
\text { POST - MODERNAS }\end{array}$ \\
\hline Respeto a las tradiciones & $\begin{array}{l}\text { Solidaridad de clase } \\
\text { social }\end{array}$ & $\begin{array}{l}\text { Autorealización personal, } \\
\text { Diferenciación individual } \\
\text { frente a grupo }\end{array}$ \\
\hline $\begin{array}{l}\text { Jerarquía, Diferencia entre } \\
\text { autoridades }\end{array}$ & $\begin{array}{l}\text { Libertad política, } \\
\text { Competitividad socio- } \\
\text { económica, productivismo }\end{array}$ & Autonomía en el trabajo \\
\hline Visión religiosa del mundo & Secularidad & $\begin{array}{l}\text { Libertad de las formas de } \\
\text { relación social, sexuales y } \\
\text { religiosas }\end{array}$ \\
\hline $\begin{array}{l}\text { Renuncia al bienestar } \\
\text { inmediato en búsqueda de la } \\
\text { recompensa en el más allá }\end{array}$ & $\begin{array}{l}\text { Afán de bienestar } \\
\text { inmediato }\end{array}$ & $\begin{array}{l}\text { Mayor preocupación por } \\
\text { la calidad de vida }\end{array}$ \\
\hline $\begin{array}{l}\text { Inseguridad de la humanidad } \\
\text { ante su desconocimiento } \\
\text { sobre el mundo y la } \\
\text { sociedad. }\end{array}$ & $\begin{array}{l}\text { Racionalidad: el hombre } \\
\text { se siente capaz de } \\
\text { construir el futuro de la } \\
\text { sociedad debido a la } \\
\text { aplicación de la ciencia y } \\
\text { tecnología }\end{array}$ & $\begin{array}{l}\text { Inseguridad por el futuro, } \\
\text { debido al uso y } \\
\text { consecuencias de la } \\
\text { utilización indiscriminada } \\
\text { de la ciencia y tecnología }\end{array}$ \\
\hline
\end{tabular}


Ética e información en la sociedad postmoderna

\section{REFERENCIAS}

ABAD, Héctor. "Neocolonialismo postmoderno", en http://jaibana.udea.edu.co/ Web-etica/Abad. html (consultado el 15 de septiembre de 2003).

Anteproyecto del código de ética del profesional bibliotecario. Asociación de Bibliotecarios de Córdoba (Argentina). Trabajo presentado en la XXVII reunión de Bibliotecarios realizada en Buenos Aires del 13 al 17 de abril de 1993.

Código de ética profesional. Colegio Nacional de Bibliotecarios. (México).

Código de ética de la Asociación de Bibliotecas de las Estados Unidos (American Library Association), 1995.

Cuenca Molina, Ángel. Ética de la comunicación, en Anales de documentación. (no. 2, 1999), pp. 9-19

De Fleur, Melvin y Sandra J. Ball-Rokeach. Teorías de la comunicación de masas. México: Edit. Paidós, 1991

El código de ética de la Asociación de Bibliotecas de los Estados Unidos. Adoptado por el Concilio de la Asociación de Biblioteca de los Estados Unidos (ALA) el 28 de junio de 1995 
Fernández Buey, Francisco. "Reivindicación de la ética de lo colectivo (IV)", en http://lainsignia.org /2002/noviembre/dial_001.htm (consultado el 20 de septiembre de 2003)

Gutiérrez Sáenz, Raúl. Introducción a la ética. México: Edit. Esfinge: 1990.

Morin, Edgar. Introducción al pensamiento complejo. Barcelona: Edit. Gedisa, 1990.

Pérez Gómez, Ángel I. La cultura escolar en la sociedad neoliberal, 3a. Ed. Madrid: Edit. Morata, 2000.

Pérez Pulido, Margarita. "Códigos de ética de los bibliotecarios y otros profesionales de la información: comentario y análisis comparativo", en http:/ / 66.70.224.146/documentos/documentos /eticabibliotecarios.doc. (Consultado el 12 de septiembre de 2003)

Valle, Josep M. Ciencia politica: una introducción. Barcelona: Edit. Ariel, 2000. 


\title{
La biblioteca, la ética y la información
}

\author{
Estela Morales CAMpos \\ Centro Universitario de Investigaciones \\ Bibliotecológicas/UNAM
}

\begin{abstract}
T os bibliotecólogos, archivistas y otros profesionales afines que inciden en las diferentes fases del proceso del ciclo de la información, también comparten el compromiso de actuar sobre la base de valores de convivencia del grupo social al que pertenecen. Éste, en la actualidad y para el medio de la información y sus servicios y su comunidad, se conforma de lo más cercano, del espacio inmediato, y al mismo tiempo del espectro más amplio, la globalidad, que acoge y se nutre de cada una de nuestras localidades.

Para poder lograr esa convivencia con la comunidad a la que potencialmente sirve una Biblioteca, cada uno de sus componentes (los usuarios, los productores de información y los bibliotecólogos) tiene que recurrir a la ética, entendida como el área del conocimiento que estudia cómo debemos vivir - ya sea como individuos o en función de los demás-, cómo debemos
\end{abstract}


comportarnos, y qué reglas y códigos orientan nuestra conducta para lograr esa convivencia en sociedad.

Una vida en sociedad necesariamente tendrá restricciones para convivir con los demás componentes del grupo y respetar al otro.

La aceptación de estas normas y códigos será exitosa en la medida en que haya un convencimiento personal, que estimule y sensibilice a la sociedad, al gobierno, a las instituciones.

Un ambiente que favorece esta sensibilización es el que se apoya en una rica oferta de oportunidades educativas, a fin de cultivar el razonamiento, el análisis, el conocimiento, que fortalezcan el ejercicio responsable de la libertad de elegir, de actuar respecto a todas las posibilidades que se ofrezcan. Cuando se tiene el derecho a elegir conscientemente, se asume el respeto a las múltiples asociaciones y a las diversas manifestaciones.

En una región como la latinoamericana, la clave del cambio social y de la convivencia respetuosa del uno y del otro es la educación, que además va a favorecer la asociatividad y la solidaridad.

Cuando las instancias del gobierno y la sociedad tienen un compromiso total con la educación, que contemple al individuo y a la sociedad en cada una de sus facetas y sus relaciones, entonces se asume, por lo tanto, que no son aceptables la intolerancia, el individualismo ni el desconocimiento de la pluralidad y la diversidad. Así, la Biblioteca estará comprometida a constituir el 
espacio donde se ejerza la democracia y una amplia convivencia social.

Una sociedad de la información y el conocimiento afronta, paralelamente a su desarrollo y acceso a la tecnología, una crisis ética al encarar el surgimiento de nuevos valores como la efectividad, la competitividad, la productividad, la inmediatez, la rapidez, la brevedad, el costo-beneficio y el respeto al medio ambiente y a los recursos naturales; a veces, tendrá que enfrentar también la ausencia de valores ya tradicionales como la tolerancia, la honestidad, la amistad, la equidad, la solidaridad y compromiso con los desposeídos y marginados del desarrollo.

En nuestros días -tiempos complejos de multirrelaciones, mezclas y nuevas situaciones, nuevos fenómenos y, por lo tanto, múltiples causas y productos-, la escuela, la universidad y la Biblioteca tienen un compromiso con su esencia y sus causas para promover temas de ética y valores que propicien una sociedad más justa y participativa, que favorezca la inclusión social y el desarrollo generalizado. Para tener una exitosa participación en nuestra sociedad, todo ser humano debe contar con un fácil acceso a la información, un ejercicio consciente de la lectura y una apropiación plena del conocimiento; la sociedad posee una institución que propicia el uso democrático y equitativo de la información: la biblioteca. 
La Biblioteca - de cualquier tipo: pública, escolar o académica-, como meollo de su existencia, debe propiciar el uso efectivo de la información y responder a valores que demanda una sociedad global y local, multicultural y plural.

Los sistemas complejos en que se realiza la vida de las localidades, de los países, las regiones y la globalidad, ponen en primer plano los derechos humanos, la libertad intelectual, la libertad de prensa, el derecho a la información, el libre acceso a la información, en contrapartida con los derechos a la privacidad, la confidencialidad y a la seguridad nacional, que demandan de los profesionales de la información y de la biblioteca una actitud de respeto a su usuario, a la comunidad, al individuo, al otro, por lo que su desempeño debe apegarse a la objetividad, a la imparcialidad y a la equidad.

La sociedad evoluciona, cambia, se construye día a día; esto impacta en los valores reconocidos y aceptados por la sociedad y puede generar conflictos, por lo que los códigos reguladores del comportamiento de los hombres deben ser aceptados por todos, porque los valores también se construyen día a día.

La Biblioteca tiene como insumo esencial a la información, que es una representación del conocimiento y un producto cultural de primer orden que representa ideologías, posiciones políticas, sentimientos religiosos y múltiples formas de una rica diversidad y pluralidad; por ello, el bibliotecólogo tiene que tener como 
principio rector la búsqueda de la equidad y decir no a la intolerancia, al fundamentalismo y a la censura; al mismo tiempo, debe cuidar y velar por la privacidad de los usuarios y la confidencialidad de los datos personales y de sus hábitos de lectura.

Muchos códigos de ética del gremio bibliotecario hacen énfasis en el respeto a la privacidad y confidencialidad respecto a los datos del usuario, así como a la pluralidad y diversidad de su comunidad, como es el caso del Código de Ética del Colegio Nacional de Bibliotecarios de México.

En el campo de la información, todos los actores participantes deben estar comprometidos con principios y valores pertinentes a cada aspecto del ciclo de generación -uso de la información-, ya que en todos ellos se interactúa con la sociedad porque así como el hombre crea y genera información, también él es el destinatario para su uso, su lectura, su aplicación; actualmente, todos -creadores, productores, usuarios- tienen que asumir que el ambiente natural de la información es la tecnología y la globalización, una impacta a otra, se potencian y enriquecen, como insumo y como fenómeno.

La tecnología y la globalización no se pueden entender sin la información que conducen, trasmiten, intercambian y utilizan; tampoco, sin acontecimientos que han crecido en cuanto a su complejidad: la migración, el terrorismo, el narcotráfico y la inseguridad; 
en consecuencia, el uso de la información se ve afectado por estos fenómenos.

Los valores también se modifican por las nuevas composiciones sociales que se generan por la migración, el multiculturalismo, la interdependencia, las exclusiones o inclusiones en los grupos humanos, lo que también produce conductas compatibles o incompatibles con usos establecidos o con nuevos usos y hábitos.

En un escenario social tan complejo, los ciudadanos también cambian; podemos ver que aparecen ciudadanos emergentes que tienen diferentes expectativas respecto a las instituciones culturales con presencia social más permanente como la Biblioteca.

Los medios con los que tiene un contacto cotidiano como la radio, la televisión y el Internet, algunas veces ofrecen a ese ciudadano opciones que le permiten seleccionar la información, manipularla, dirigirla a ciertos subconjuntos de público y también excluir a otros; como contrapartida, deberíamos considerar a la Biblioteca como una institución comprometida con sus usuarios, que se preocupa por su formación como seres humanos y ciudadanos libres, independientes, autosuficientes, que pueden ejercer sus derechos y responder a sus obligaciones; que a partir de la información que manejan adecuadamente, su libre selección, su opinión y su actitud incidan en su desarrollo.

Para apoyar de esta manera a sus usuarios, la Biblioteca tiene que estar comprometida con valores 
que defienda y acepte su localidad y el mundo, que respete ante todo los derechos humanos y un ambiente democrático de convivencia, donde los usuarios de información no sean clientes, sino fundamentalmente usuarios (tal como el médico comprometido con su sociedad lo hace con sus pacientes, más no con sus clientes); por lo tanto, no debe poner en el centro de sus decisiones y objetivos el comercio, el mercado, para vender información, sino ofrecerla y promover su uso de manera activa y consciente, a fin de formar lectores, seres sociales y ciudadanos.

La Biblioteca y todo su personal, profesional o no, bibliotecólogo o de otras especialidades, tiene que asumir compromisos sociales basados en principios éticos aceptados por la comunidad profesional: la de usuarios y la del entorno local y global.

Así, la Biblioteca, que desde siempre ha sido un gran espacio democrático donde ha estado representada la globalidad, buscará incluir a los excluidos sobre la base de la igualdad y la equidad, que ayude a lograr una justicia global, porque si ésta no es global no será duradera por la migración real y virtual de hombres, de ideas, de información.

Para que las Bibliotecas puedan garantizar el ejercicio de los derechos fundamentales de los hombres con relación al uso de información, como la libertad de elegir, la libertad intelectual y el derecho a la información y su acceso, tiene que evitar a toda costa la censura de 
la información que se produce a escala global y, por lo tanto, que no interfiera su adquisición, su clasificación, su oferta y su acceso.

Aunado a estas garantías debe estar presente el aseguramiento de la privacidad y confidencialidad de los datos personales de sus usuarios con relación a sus lecturas y el uso de los materiales y servicios utilizados en la Biblioteca.

Estos enunciados tan generales y fundamentales forman parte de la aceptación y respeto que se tenga de uno mismo, del yo y del otro, de los ciudadanos de un país y del mundo; de reconocer y respetar la diversidad y pluralidad de nuestras comunidades; y no provocar un choque de civilizaciones que presupone débiles y dominantes, fuertes y subordinados, lo cual estaría en contradicción con los principios antes citados de igualdad, equidad y respeto a la diversidad que actualmente se reconoce en la globalidad.

Toda profesión se forja en función de las necesidades, problemas y demandas de una comunidad, y la Bibliotecología está comprometida con la sociedad que la crea y para la cual existe. Los bibliotecarios, desde que estudian y en su práctica profesional, no deben olvidar su compromiso social en cualquiera de los aspectos, áreas o proyectos en que se desempeñen. Además de su compromiso social, de su comunión con sus principios éticos, tienen que asumir un papel como actores del desarrollo nacional y, ahora en la globalización, también 
del internacional; en su comunidad, tienen que participar en su entorno social, económico y político. Toda su actuación, su conducta y su desarrollo profesional debe guiarse por los principios de respeto, tolerancia y cualquier otro que privilegie su código de ética, en beneficio del mejor uso de la información, para satisfacer los intereses individuales y colectivos. Es necesario contribuir al desarrollo de los usuarios y de las comunidades sobre la base de los valores tradicionales y los que emergen con los cambios sociales y económicos como la efectividad, la competitividad, la inmediatez, el progreso tecnológico entre otros; todos éstos surgen de estructuras basadas en el conocimiento, donde la educación hace la diferencia y donde se involucra la Biblioteca, ya que es la que propicia de manera más amplia y democrática el acceso de todos los ciudadanos a la información para ser parte de la sociedad de la información, buscando favorecer las capacidades a partir del conocimiento para insertarse competitivamente en la economía global. 


\section{BIBLIOGRAFÍA}

Afino, Mark y Linda Pierce. Information Ethics for Libraries. North California, Jefferson, 1997. 168 p.

Bunge, C. A. "Ethics and the Reference Librarian", Reference Librarian, núm. 66, 1999, p. 25-43.

Colegio Nacional de Bibliotecarios, A. C. Código de ética profesional, en http://www.cnb.org.mx/cnbcodigo.htm

Fernández de Zamora, Rosa María. "Los códigos de ética en América Latina", Panorama: revista de la Universidad Autónoma de Baja California Sur, núm. 50, oct.-dic., 2004, p. 18-21.

Lopera Lopera, Luis Hernando. "Una ética bibliotecológica para afrontar los retos de nuestro tiempo", Revista Interamericana de Bibliotecología, vol. 25, núm. 1, ene.-jun., 2002, p. 65-88.

Pullinger, David. "Librarians: Experts in Internet Ethics", Christian Librarian, núm. 28, 2004, p. 26-39.

Servidio, Roberto. "Algunas reflexiones sobre ética profesional”, en Memorias del Primer Encuentro Centroamericano de Asociaciones de Bibliotecarios. San Salvador, 27-31 de abril de 2004. San Salvador, IFLALAC-ABES, 2004, p. 49-50.

Vaagan, Robert W. "The Ethics of Librarianship: an International Survey", Serial Librarian, vol. 47, núm. 1-2, 2004, p. 251-252. 


\title{
La biblioteca pública y los valores humanos $^{1}$
}

\author{
JAIME RÍOS ORTEGA \\ Centro Universitario de Investigaciones \\ Bibliotecológicas/UNAM
}

a biblioteca pública es una entidad cultural en la
que convergen diferentes perspectivas de proyectos cognoscitivos individuales, así como de realización social. La biblioteca pública está abierta a la preparación del ciudadano y a la cohesión e identificación de comunidades particulares, cada vez más conscientes del entorno mundial y globalizado. Aunque se han delimitado los fines de la biblioteca pública, se hace necesaria una reflexión más amplia sobre la riqueza del carácter social de esta entidad cultural, pero en particular sobre los valores desde los cuales orienta su interacción con

1 La versión amplia de este documento fue publicada como: "La biblioteca pública: un lugar de valores" en Memoria del Segundo Encuentro Internacional sobre Bibliotecas Públicas: Modelos de Biblioteca Pública en Iberoamérica, Puerto Vallarta, Jalisco, México, del 21 al 23 de agosto de 2003. México: CONACULTA, Gobierno de Jalisco, 2003. p. 311-322. 
la sociedad y los individuos. Por lo anterior, cabe preguntarse: ¿cuál es el núcleo de valores que imprimen sentido y orientación al quehacer de la biblioteca pública? ¿Cómo se recrean y fortalecen en la biblioteca pública estos valores sin perder el equilibrio entre la formación del ciudadano y el desarrollo de la comunidad? Estas preguntas se responden sintéticamente más adelante y conviene adelantar que la reflexión sobre esta entidad social nos permite observar una perspectiva sobre el modo de hacernos más humanos y de considerar que la biblioteca pública, con base en los valores que la sustenta, es un instrumento de civilización y entendimiento.

\section{LOS VALORES}

En general podemos afirmar sobre las bibliotecas que presentan, desde hace algunos siglos, dos características distintivas: 1) son metamórficas y 2) son espacios organizados que contienen la memoria social. ${ }^{2}$ La biblioteca pública es quizá el mejor ejemplo de ello, ya que ha incorporado la transformación incesante de la experiencia humana en el espacio y temporalidad en que está inserta y, asimismo, se ha constituido en la solución afortunada contra la memoria limitada y perentoria del hombre, por

2 Incluso si pensamos en nuestras bibliotecas personales, observaremos que estas han cambiado y que están inundadas de memoria social, es decir de autores y de saberes. 
ello, pues, se ha convertido en la memoria colectiva de carácter infinito.

Pero ahí no terminan las cosas. Si se observa con un poco de cuidado, cobrará mayor nitidez un acto que de modo permanentemente sucede en la biblioteca pública, pero que por ser cotidiano no llama la atención. Me refiero al momento en que un individuo ha decidido encontrarse con alguna de las manifestaciones de la memoria colectiva. Casi sin percatarnos, frente a nosotros, está sucediendo uno de los actos de comunicación más importantes en términos universales, esto es, el individuo inicia la lectura y, a partir de ese momento, da lugar a la vinculación intersubjetiva con otros seres humanos. En esta vinculación intersubjetiva, que la biblioteca pública propone y concreta, se genera la interacción social, eso que, simplemente dicho, nos hace más humanos.

Como bien se habrán percatado, ya estamos en el tema de los valores. Por ello conviene precisar lo que entenderemos por este concepto. Una concepción estándar del valor nos indica que es un rasgo de las cosas o las personas o estados de cosas en virtud del cual se justifica una actitud positiva hacia ellas. En ocasiones se piensa que los valores son cuestión de gusto o inclinación personal. La diferencia fundamental consiste en que estos gustos o preferencias no son razonadas. La naturaleza de los valores es más compleja porque se vincula con lo que preferimos y 
con lo que consideramos preferible, esto es, más digno y, en consecuencia, con mérito. Así, lo que tiene mérito y lo que carece de él, es algo que, como afirmación, puede apoyarse con razones. Cuando se carece de razones para apoyar una valor, sólo se está mostrando una preferencia, un gusto.

Postulo entonces que la biblioteca pública es un lugar de valores en el cual existen personas, objetos y proceso valiosos. Las razones que le dan valía a esta institución social son de orden moral, ético, político y social. Por lo tanto, no es sólo por gusto que hablamos de la biblioteca pública, sino también porque hay argumentos y creencias válidas sobre los valores que recrea e integra.

\section{LOS VALORES EN LA BIBLIOTECA PÚBLICA}

Comienzo por señalar que para mí la biblioteca pública no puede reducirse a las tecnologías, artefactos y soportes de información que en ella existen, junto con los saberes técnicos que ahí se aplican. Por el contrario, su realidad es compleja en razón de su naturaleza ética y social. De modo que parto de considerar a la biblioteca pública como un sistema de acciones intencionales. Esto significa que incluye a los agentes que deliberadamente busca determinados fines, de acuerdo con ciertos intereses y para ello practican ciertas creencias, conocimientos, valores y normas. Este conjunto de fines, normas y valores es creado por seres humanos a partir 
de su experiencia social y con base en el razonamiento colectivo, es decir, el diálogo. Ello hace posible que se pueda discutir, sobre la base de razones válidas, la naturaleza legitima de los valores que las bibliotecas públicas promueven y recrean. Uno de los ejemplos más importantes sobre lo que debe considerarse como valores legítimos que dan vida a las entidades sociales a las que nos ocupamos son, sin duda, el Manifiesto de la IFLA/UNESCO sobre la biblioteca pública.

Un punto fundamental de la valoración de estos sistemas de acciones intencionales es el tratamiento que se da a los individuos y a la sociedad como agentes morales. Este tratamiento está claramente indicado en el Manifiesto antes citado y son, por supuesto, la persona y la libertad, así como la sociedad y su desarrollo.

En el trasfondo de estos valores están los imperativos o principios kantianos, siguientes:

1. Tratar a la persona como un fin y jamás como un medio

2. Respetar a las personas como agentes autónomos. Lo que significa comprender que los sujetos tienen capacidad de realizar acciones con base en las decisiones que tomen ellos mismos, sin engaño ni coacción.

Asimismo, está presente otro principio que señala la posibilidad de elegir libremente el mejor modo de convivencia social. 
Es sobre la base de estos principios que califico a la biblioteca pública como una institución representativa de la modernidad y sus valores fundamentales, a saber: la razón, la libertad y la forma de gobierno elegida libremente. De acuerdo con estos valores, lejos estamos de pensar que la biblioteca pública sea una entidad éticamente neutral.

Son también los agentes que en la biblioteca pública interactúan quienes hacen de esta entidad social un espacio de recreación de valores. Bibliotecarios y usuarios dan vida a un organismo dinámico compuesto por prácticas, acciones y estructuras, orientadas al logro de fines generales y personales.

Al plantearse fines, los agentes intencionales lo hacen con base en sus creencias y valores, y por tanto, actúan en función de lo que considera valioso. En esta entidad social, fines generales y personales coexisten por obra de unos y otros.

Bienes valiosos como son el conocimiento, la educación, la cultura, la democracia, se constituyen en valores que orientan los fines del trabajo que se realizan dentro de las bibliotecas públicas. Esto es importante tomarlo en cuenta ya que las actividades técnicas y de servicio que se realizan dentro de ellas no son, a secas, acciones mecánicas y sin sentido ancladas a racionalidades administrativas. 
Se constata, pues, que un valor fundamental para la biblioteca pública es el principio ontológico de la realización. Asimismo se hace evidente, de acuerdo con lo indicado en el Manifiesto IFLA/UNESCO, el principio de elección política y social, así como el principio de educación.

Estos valores se articulan en el marco de los derechos humanos universales y bien vale la pena una mínima reflexión sobre ellos. Se trata de derechos que las sociedades modernas reconocen en todas las personas, ya que forman parte de la especie humana y, en consecuencia, todos los seres humanos deben disfrutar de ellos. Sin embargo, su reconocimiento depende de otros seres humanos. Por tanto, su formulación se ha hecho sobre la base de razones válidas a través de la discusión y el diálogo. Por analogía, se desprende que no es diferente la creación de los valores de la biblioteca pública. Esto nos da la pauta para considerar que los valores de la biblioteca pública son legítimamente objeto de escrutinio y que debiéramos profundizar en la racionalidad de los fines que en dichos valores subyacen.

Dos ideales regulativos se desprenden de los valores proclamados para la biblioteca pública:

1. El libre acceso a la información y al conocimiento, como condición necesaria de la democracia.

2. La educación permanente o "educación para toda la vida" como condición necesaria para el desarrollo de los individuos y del país. 
Son estos dos principios en los que se articulan los objetivos de la biblioteca pública. Dada su importancia en el contexto de este documento, me permito enumerarlos como medios fundamentales para lograr los fines anteriores, por tanto les asigno un carácter instrumental y son los siguientes:

1. Hábitos de lectura.

2. Apoyos a la educación.

3. Desarrollo personal.

4. Creatividad.

5. Cultura y patrimonio. ${ }^{3}$

6. Comunicación y diversidad cultural.

7. Culturas orales.

8. Acceso a la información.

9. Servicios a entidades públicas y privadas.

10. Cultura y alfabetización informática.

Dada la naturaleza y las necesidades sociales de los seres humanos, no es casual el interés esencial en la democracia, la educación y el desarrollo. Son estos valores a los que se articula la biblioteca pública y al promoverlos los hace más valiosos. Recíprocamente, son también ellos quienes le dan valía a la biblioteca pública. Al punto que en el presente es impensable un país democrático con alto nivel educativo y desarrollo social, sin bibliotecas públicas. Por las mismas razones,

3 No dejemos de lado el hecho de que las ciencias son parte de la cultura del hombre. 
es posible especular que las bibliotecas públicas en proceso de consolidación, tienen viabilidad en tanto los sistemas políticos de los países en los que están insertos logren su madurez democrática y avancen en su desarrollo social.

\section{CONSIDERACIONES FINALES}

Pueden sintetizarse los ideales reguladores de esta entidad social en cinco valores: autorrealización, democracia, libertad, educación y progreso. Sin embargo, las condiciones del mundo en que nos toca vivir hacen necesario estar abiertos para incorporar otros valores centrados en la capacidad de aprender vivir el cambio y la comunicación intercultural. No se trata de renunciar a los valores clásicos, sino de interrogarse sobre los nuevos medios con que nos vincularemos a los usuarios que llegan a la biblioteca pública en medio de un mundo desencantado. Sería contrario a toda lógica que la biblioteca pública perdiera su capacidad de comunicación respecto a los propios agentes que le dan vida. La biblioteca pública es ya una institución de centurias, por ello confío en que dentro de ella se dialogará cuanto sea necesario y se actuará de modo que la intención continúe por la ruta de hacernos más racionales, más dignos, más libres y dotados de mejores sistemas de convivencia social. En síntesis, que la biblioteca pública nos lleve a ser más humanos. 
Mesa redonda. Ética e infomación

\section{BIBLIOGRAFÍA}

Gill, Philip. Directrices IFL A / UNESCO para el servicio de bibliotecas públicas. México, IFLA, UNESCO, CONACULTA, 2002.

Sartori, Giovanni. ¿Qué es la democracia? México, Nueva Imagen, Tribunal Federal Electoral, 1993.

Shera, Jesse. Los fundamentos de la educación bibliotecológica. México, UNAM, CUIB, 1990.

Touraine, Alain. ¿Podremos vivir juntos? Iguales y diferentes. México, FCE, 1996

Villoro, Luis. El poder y el valor: fundamentos de una ética política. México, FCE, 1997. 


\title{
Ética e información
}

\author{
EDUARDO SALAS ESTRADA \\ Eescuela Nacional de Biblioteconomía y \\ Archivonomía/SEP
}

\begin{abstract}
D
e entrada pareciera que todos tenemos claro que la ética es una forma de comportamiento que cada individuo adopta para contribuir al desarrollo de la sociedad de la que forma parte.

Una vez que el individuo alcanza una preparación profesional su ética individual necesariamente se verá modificada para que, sin contravenirla, acoja los lineamientos éticos de la profesión que practica, y es aquí donde podrían surgir algunos conflictos, ya que involucramos no solo al yo, sino al nosotros, como grupo profesional al servicio de la sociedad, pero todavía más complejo resulta hablar de la sociedad, especialmente en la era de la globalización y de las telecomunicaciones y los desafíos éticos que representa la prestación de nuestros servicios.

Sin embargo, vale la pena acudir a una definición de diccionario para tomar el concepto de ética como punto de partida.
\end{abstract}


Ética (del Griego), tiene que ver con la conducta, de ethos costumbre y costumbre moral es en última instancia la teoría de qué es bueno o digno de consideración, de buena conducta y carácter, de los derechos y obligaciones morales. ${ }^{1}$

Ética en filosofía, es el estudio y la evaluación de la conducta humana a la luz de los principios morales. "Ciencia Moral" y "Filosofía Moral" generalmente son usadas como sinónimos de ética.

La ética trata de cómo nosotros debemos vivir y en particular sobre cómo nosotros debemos vivir en relación con los demás. A veces cuando hablamos de ética estamos hablando de un conjunto de reglas, códigos que orientan o guían nuestra conducta. Otras veces hablamos del estudio o la investigación acerca de cómo debemos vivir y comportarnos. ${ }^{2}$

Los objetivistas creen que existen verdades morales que no pueden ser no morales, independientemente de lo que nos gusta o disgusta. Es cierto, es cierto tanto si nos gusta como si no, que el sol es más grande que la luna y que los humanos necesitan el oxígeno para vivir, así que es cierto que determinados actos son correctos y otros son incorrectos.

1 Encyclopedia of Library and Information Science. Ed. by Kent y Lancour. V. 5, p. 244-251.

2 John Wecket, p. 23. 
Centrémonos ahora en el relativismo y preguntémonos qué dice y cómo lo afronta. Deben distinguirse dos tipos principales. Uno de ellos, el relativismo cultural, sostiene que los valores morales son relativos a la cultura o sociedad particular que los acepta: no solo difieren de una cultura o sociedad a la otra, sino que cada valor no es tanto una cuestión de superioridad o inferioridad sino de cultura o sociedad y así ser aceptado o prohibido. Una práctica puede ser moralmente aceptada en una cultura y prohibida en otra, pero no podemos decir que ninguna de las dos está en lo cierto, porque no hay ninguna verdad que sostener. Sus valores son simplemente diferentes y eso es todo. ${ }^{3}$

Si todas las personas obedecieran sólo aquellos principios de comportamiento que son forzados por la ley, el mundo estaría en un estado de caos. Reinhold Nieburh dice que el orden y la justicia no pueden mantenerse sin ella; que el egoísmo de los individuos y de las naciones debe ser aprovechado, que toda la justicia política y el orden es alcanzado por hombres y naciones que tienen un margen de bondad y virtud más allá de su propio interés.

Clyde P. King ha señalado que el problema con cada una de las profesiones es que creen que deberían heredar la tierra. Ingenieros, ministros, doctores, abogados

3 Wecker, p. 29. 
- cada grupo siente una superioridad profesional que indica un orgullo de grupo, como también un egoísmo grupal. Los credos éticos tienden a cambiar este egoísmo hacia los ideales del servicio público, Las relaciones entre los individuos como entre las diversas profesiones han llegado a ser cada vez más importantes.

Algunas personas no piensan en restricciones a ninguna persona o grupo; este concepto puede conducir a la anarquía. Lo que parece correcto a una persona puede parecer absurdo a otra, pero ningún hombre de negocios o profesional puede solo vivir en sí mismo, y por años los grupos organizados han establecido una serie de principios para guiar a sus miembros. Una profesión surge cuando la sociedad reconoce el valor intrínseco de los servicios que ofrecen los miembros del grupo, en forma individual o colectivamente. El desarrollo de un patrón de conducta ética profesional no es un asunto individual. Una organización progresiva debe agrupar su visión y su sabiduría. Los códigos de ética escritos han encontrado ser uno de los medios de poner en claro, objetivamente, las normas de una asociación para regir el comportamiento y las actitudes de sus miembros. Los ideales de los hombres, los proyectan mejor a sí mismos dentro de la realidad cuando cristalizan en documentos.

Obviamente la autoridad ante quien somos responsables no se restringe a lo que la ley nos ordena hacer o a abstenernos de hacerlo. Las bases fundamentales de 
la felicidad y la seguridad es la obediencia a un código de ética, una autoridad más allá de los requerimientos del gobierno porque su cumplimiento comienza y termina en uno mismo. Es una tarea auto-impuesta, auto-obligatoria. Obediencia a lo que no puede hacerse cumplir no puede ser obligatorio excepto por el individuo; sólo él debe imponérselo a sí mismo.

\section{PRINCIPIOS DE ÉTICA}

A través de la historia, la humanidad ha intentado desarrollar valores y creencias para guiar exitosamente la moralidad de nuestra conducta. Hemos hecho preguntas tales como, Que es el bien y el mal, lo bueno o lo malo, lo justo o lo injusto, lo aceptable o lo inaceptable. Los productos de esos esfuerzos son teorías y principios que pueden aplicarse a una diversidad de situaciones que enfrentamos. ${ }^{4}$

El pensamiento ético es definido como el examen sistemático de los asuntos éticos en un momento de verdad para determinar si una conducta actual o contemplada de un agente, es ética o no ética o si, alternativamente, no hay consideraciones éticas involucradas.

4 Mason, p. 83. 
El pensamiento ético es necesario cuando el comportamiento de un agente puede afectar materialmente la habilidad de un participante para lograr sus metas. - ¿Cuáles son los hechos?

- ¿ Qué principios éticos, normas o reglamentos deberían aplicarse?

- ¿ Quién debería decidir?

- ¿ Quién debería beneficiarse con esa decisión?

- ¿Cómo debería tomarse la decisión?

- ¿ Qué pasos deberían tomarse para prevenir que este asunto ocurra otra vez?

\section{¿POR QUÉ INFORMACIÓN Y ÉTICA?}

Se ha dicho que en cada nueva era hay un nuevo conjunto de desafíos y problemas éticos para que los resuelva la gente. Esos desafíos pueden surgir en cualquier momento y cuando se toma una decisión o se emprende una acción. Esos puntos cruciales en el tiempo son importantes "momentos de verdad" que delinean el futuro. La nueva era en la que nos encontramos inmersos ahora puede con justicia llamarse era de la información. Hacia los años cincuenta, cerca del $50 \%$ de los trabajos tenían que ver con la generación, el proceso, la recuperación o la distribución de información. Hacia los ochenta, había alcanzado el 77 \%. En el año 2000 se espera que la cifra haya alcanzado el $95 \%$. La mayoría de este manejo de información involucrará computadoras 
y avanzados mecanismos de comunicaciones. Mucho de este trabajo se hará en casa así como en la oficina, o dondequiera que la persona viaje. ${ }^{5}$

Una combinación de servicios de Información y Entretenimiento "Infotainment" como teléfonos, televisión, publicaciones, películas, radio, espectadores deportivos y similares, sobrepasaron el trillón de dólares anuales en ventas, mientras que los usuarios clamaban por más noticias, entretenimiento y servicios de información por medio de la red de computadoras llamada "Internet" y estas cifras están creciendo exponencialmente.

El ascenso en la información abre posibilidades dramáticas de cambio en nuestra sociedad. Surgen innovaciones que hacen que la información esté más disponible para más gente de manera más barata, rápida, precisa, y cautivante, y ello induce el cambio social en el curso de su uso.

Todo esto pone al uso de la información justo en el campo de la ética. Dondequiera que las acciones de los seres humanos afecten la estabilidad de otros seres humanos para lograr sus propias metas, las evaluaciones éticas son necesarias, aceptan la mayoría de los filósofos.

5 Mason, Richard O, Ethics of Information Management, p. 1. 
Para Alfino y Pierce ${ }^{6}$ es necesario, en primer lugar, señalar que, para tener una idea más clara de lo que es el bibliotecario y lo que debería ser y cómo éste tendría que trabajar a través de los desafíos éticos, hay que comprender el contexto histórico y social de nuestra profesión.

Los bibliotecarios criados en la era de la libertad intelectual, también están cuestionando las suposiciones acerca del "valor de neutralidad" en el trabajo de servicio de consulta. La palabra normalizada sobre el tema del "valor de la doctrina de neutralidad" es de D. J. Foskett, quien en 1962 publicó el libro The Creed of a Librarian - No Politics, No Religion, No Morals. Él dice, por ejemplo, que "Durante el servicio de consulta, el bibliotecario debe virtualmente desaparecer como persona individual, excepto hasta donde su personalidad aclare el trabajo de la biblioteca". Algo menos dramático, aunque es una expresión más oficial del valor de la neutralidad, puede encontrarse en el Código de Ética de la American Library Association, que empieza con un llamado a "responder todas las solicitudes con precisión, imparcialidad y cortesía".

El concepto tradicional de las "ideas" desde la tradición filosófica aplicada a los grandes objetos (nobles y buenos) objetos de reflexión (justicia, las virtudes, las

6 Alfino, p. 9.

7 ALA, The 1995 Code of Ethics. 
formas de las cosas). La codificación de las expresiones en el lenguaje de tales ideas fueron típicamente tratadas por los filósofos como algo entre una molestia menor y una tragedia.

La información, parece ser una clase de "idea codificada" en un sistema de expresiones. A partir de esto estamos en posición de trazar algunas conclusiones acerca de cómo debería ser utilizada la palabra información, y cómo la comprensión contemporánea del término permanece en relación con la terminología más tradicional. Datos, información, conocimiento, trabajos culturales y sabiduría pueden ser referentes a distintos objetos de pensamiento que varían por su nivel de organización. Los llamados datos "brutos", como las mediciones de un termómetro, tienen un relativo valor bajo de organización. Juicios en los que predicamos una cosa sobre otra, tiene una organización mayor. Los juicios simples acerca del mundo o eventos son la clase de comunicaciones a los que generalmente les aplicamos el término "información". Conocimiento es más que una colección de tales juicios, es un sistema de información altamente organizado y validado. Conocimiento y productos culturales, especialmente aquellas formas de conocimiento que están absolutamente interrelacionados y aquellos artefactos culturales que son altamente simbólicos, están entre las estructuras de información más organizadas en el pensamiento humano. Sabiduría y conocimiento profundo 
Mesa redonda. Ética e infomación

pueden pensarse como las organizaciones más altamente destiladas del pensamiento en la experiencia humana. Podemos representar esas relaciones de la manera siguiente:

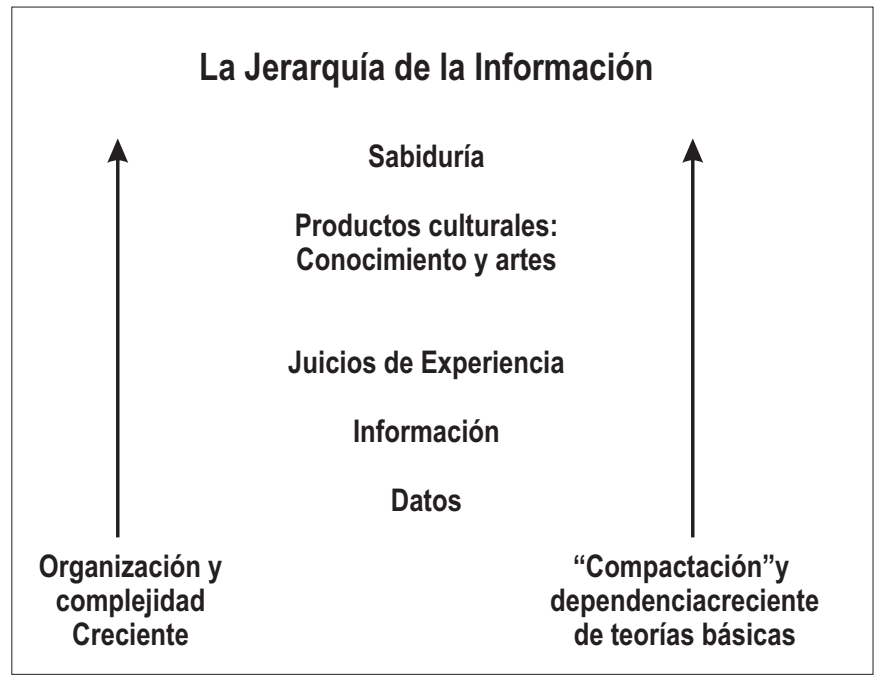

Puesto que las diferentes teorías éticas enfatizan diferentes aspectos de la acción humana, podemos organizar útilmente las teorías éticas distinguiendo tres principales características de las acciones humanas: las motivaciones o razones de una acción, el actor o agente de la acción, y los productos o consecuencias de la acción. El primero se enfoca en las motivaciones, es un 
poco más oscuro que los otros. Se refiere a las intenciones conscientes del agente y cómo lo que queremos hacer afecta el avalúo y justificación, pero también a las "bases racionales" de una acción. Cuando enfatizamos las bases racionales de una acción, a veces estamos preguntando ¿qué comprensión de la naturaleza del ser humano se presume en la acción previa a la actuación?

Mientras necesitamos decir más acerca de los más importantes ejemplos de cada clase de teoría, podemos resumir nuestra organización de teorías éticas de la siguiente manera:

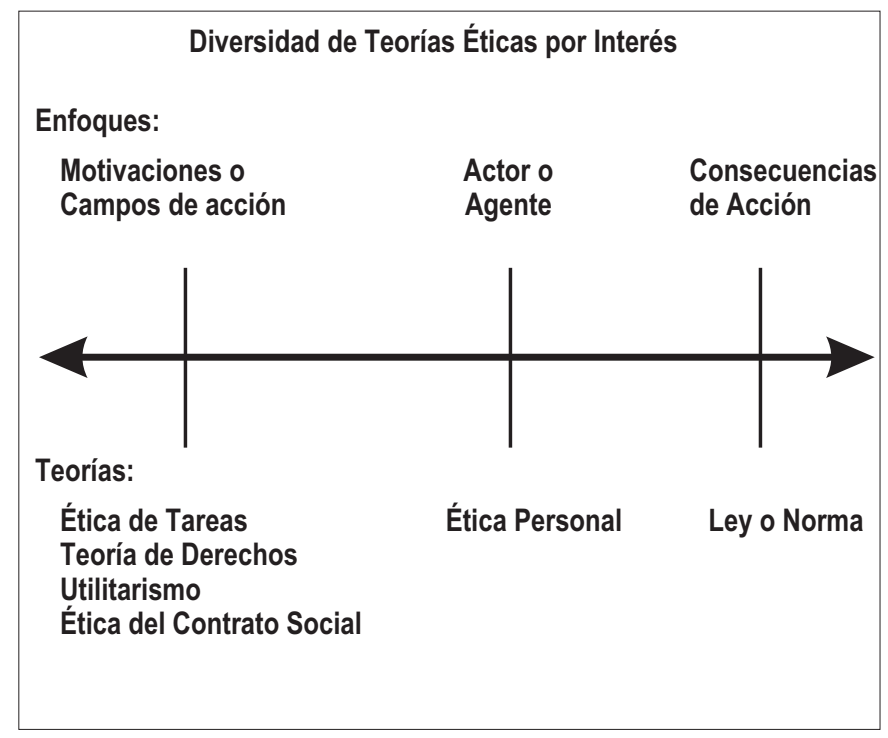


La discusión ha llegado a las conclusiones siguientes:

1. El tamaño y la complejidad de las colecciones de hoy significa que los intentos de grupos de la comunidad, por imponer un grupo de valores morales sobre la biblioteca, no son factibles;

2. La comunidad debe cambiar su punto de vista de la biblioteca como un guardián moral y

3. Ese papel será reemplazado por la biblioteca como una fuerza educativa de la comunidad;

4. La biblioteca tiene una responsabilidad profesional para planear como cubrir las necesidades de información de toda la comunidad; $y$

5. Moverse hacia la educación cambiará la forma en que la biblioteca actúa con los usuarios. Más tiempo y compromiso serán necesarios para cubrir las necesidades de información de la persona

Para Mason y colaboradores ${ }^{8}$ es necesario considerar nuestras habilidades para:

a) Identificar y enmarcar asuntos éticos que rodean a la información y su uso,

b) Examinar aquellos asuntos que utilizan, teorías y principios éticos, y

c) Aplicar las teorías y principios a situaciones que desarrollen en los niveles individual, organizacional y social - todas esas habilidades siendo sello (o signo) de un profesional.

8 Mason, Op. Cit. 
Una sencilla lógica subraya este trabajo:

- En cada nueva era, una sociedad debe desarrollar de nuevo su propio conjunto de valores morales y éticos y renegociar su contrato social.

- La sociedad moderna ahora está profundamente inmersa en una era de información y está en el proceso de crear una sociedad de información. Se estima, sólo como un indicador, que hacia el año 2000 más de $95 \%$ de todos los trabajos requerirán que al menos alguna parte del tiempo se dedique a la generación, procesamiento, recuperación, o a la distribución de información. Todos los trabajos necesitarán utilizarla.

- Por lo tanto, la sociedad moderna debe desarrollar un nuevo contrato social y una apropiada postura moral y ética para la era de la información.

\section{NECESIDAD DE UN NUEVO CONTRATO SOCIAL}

Los desafíos que presenta la sociedad de información reclama un nuevo contrato social. Un contrato social es el acuerdo implícito que los miembros de una sociedad hacen entre ellos para traer una nueva sociedad que sea quien regule las relaciones entre ellos mismos, incluyendo sus planes para gobernarse. Ese contrato debe reflejar las actividades primarias sociales y económicas de la sociedad. Como la información y la tecnología de la información mueven el corazón de 
nuestro sistema social, nuestro contrato mutuo debe incorporar provisiones para manejar los efectos sobre las personas, organizaciones y el funcionamiento de la sociedad como un todo.

Un contrato social para la era de información debe tratar diversas tensiones sociales clave que son peculiares al uso de la información.

Una de esas tensiones se enfoca en el tema de quien posee y controla la información producida por los miembros de la sociedad. Esta tensión se revuelve alrededor de los derechos de propiedad intelectual y profundiza demandas de la gente que comparte conocimientos, ideas e información contra los reclamos de quienes la producen para obtener los beneficios para ellos mismos.

Una segunda tensión se enfoca en la recolección y compartir la información acerca de la gente. Por un lado está el compartir ampliamente la información a todos los miembros de la sociedad que puede construir relaciones más confiables y tomar decisiones más seguras. El otro lado honra la dignidad y la autonomía de las personas para compartir sólo aquélla información acerca de ellos mismos, que ellos eligen (su propia elección). Privacidad es el nombre dado a este asunto.

Preocupaciones por la calidad de la información producida subrayan la tercera tensión. Un punto de vista reclama que toda la información producida y proporcionada debería ser tan precisa, válida, confiable y 
clara como sea posible concebirla, mientras que el punto de vista contrario sostiene que los recursos y competencias necesarias para evitar errores son muy escasos y deben ser conservados. Imprecisiones, y sus efectos, deben tolerarse. Nosotros llamamos a este asunto precisión.

Sin embargo otra tensión fundamental se centra en asegurar justicia e imparcialidad entre los que producen información y quienes quieren usarla. Una aspecto de este asunto involucra el acceso de los miembros al cuerpo de información de la sociedad. Algunos argumentan que, en efecto, todos los miembros de la sociedad deberían tener acceso universal a toda esta información. La posición contraria argumenta que el acceso debería dictarse exclusivamente por la posibilidad económica de uno para pagar por ella o por la necesidad legítima de saber.

Gatekeeping es el tema de la quinta tensión. Una posición sostiene que la información debería permitirse que fluya libre y expeditamente a través de la sociedad; "dejar que busque su propio nivel" ninguna información debería ser ocultada o bloqueada. Esto puede ser pensado como la posición de "Primera Enmienda". El punto de vista antitético resalta la necesidad de censura, secreto, confidencialidad, y otros mecanismos de control para prohibir el flujo de información que se percibe como peligrosos o de mal gusto. 
Finalmente una tensión central se revuelve alrededor de la introducción de tecnología en el sistema social mismo. Es la tensión creada por la Instrumentación tecnológica. Una lado de esta tensión cree que las nuevas tecnologías son parte de una marcha inevitable del progreso. La nueva tecnología debe emplearse sin importar cómo afecta los trabajos de la gente o sus vidas. En contra de este punto de vista protecnologista está el punto de vista que busca evitar la molestia, desplazamiento y miseria humana que acompaña a la innovación tecnológica. La calidad de vida debe dominar el progreso tecnológico que este tiene.

El nuevo contrato social para la era de la información debe contener provisiones para resolver estas seis tensiones básicas: derechos de propiedad intelectual, privacidad, la calidad y precisión en la información, justicia de la información, gatekeeping, y la instrumentación tecnológica.

- ¿Quién posee y controla la información producida por los miembros de la sociedad?

- ¿Quién reúne y comparte información acerca de la gente?

- Precisión. Aspectos sobre la calidad de la información que se produce y la que se proporciona.

- Justicia Informativa. Asegurar justicia y uso justo entre quienes producen la información y quienes pretenden utilizarla. 
- Controlador. Una posición está a favor del libre flujo de la información hacia la sociedad mientras que otro aboga por la censura, el secreto y la confidencialidad y otros mecanismos de control para prohibir el flujo de la información.

Vivimos hoy en una sociedad de información, en la que la mayoría de la gente vive y trabaja en el contexto de la información y de la tecnología de la información y comunicación. Esta es la culminación de la evolución de la humanidad que comienza en la antigüedad y ha continuado hasta nuestros días. El desarrollo del conocimiento y la información ha sido un factor crítico en el crecimiento y el desarrollo de una sociedad basada en la información a través del tiempo y ha creado una "era de la información". Por esto es que esta evolución puede describirse como el crecimiento de la información. ${ }^{?}$

Los motivos por los que la humanidad se embarcó en el crecimiento de la información son cuatro:

- Buscar el bienestar y evitar la miseria,

- Trabajar por la seguridad y evitar el miedo de la incertidumbre,

- Buscar la recreación y el entretenimiento y evitar el fastidio, la molestia y la depresión,

9 Mason, p. 31 
- Trabajar a favor del control y el orden y evitar el caos. $^{10}$

La calidad del servicio bibliotecario depende en gran medida de la efectividad del bibliotecario ejerciendo en forma individual. Los miembros individuales, por la forma de su práctica, reflejan al total de la profesión. La profesión bibliotecaria a través de su organización colegiada deberá tener un mayor interés en revisar y desarrollar su código de ética, así como ejercer con la mayor responsabilidad el trato con las personas o grupos cuyas prácticas o acciones se reflejen desfavorablemente sobre la profesión como un todo.

\section{BIBLIOGRAFÍA}

Alfino, Mark. Information Ethics for Librarians / Mark Alfino and Linda Pierce. Jefferson North Carolina, Jefferson, 1997. 168 p.

Encyclopedia of Library and Information Science, Ed. by Allen Kent y Harold Lancour. New York, Marcel Dekker, 1971 - . 47 vols.

Mason, Richard O., Ethics of Information Management / Richard O. Mason, Florence M. Mason, Mary J. Culnan. Thousand Oaks, Sage, 1995. 327 p.

Weckert, John. Ética informática y de las ciencias de la información. Madrid, Fragua, 2000. 287 p.

10 Ibidem, p. 32 


\title{
Relatoría de la mesa redonda "Ética e información"
}

\author{
Homero Quezada Pacheco \\ Centro Universitario de Investigaciones \\ Bibliotecológicas/UNAM
}

\begin{abstract}
T a mesa redonda "Ética e información", del semiInario permanente "Bibliotecología, Información y sociedad" se realizó en dos sesiones. La primera tuvo lugar el 24 de septiembre de 2003 y fue moderada por el maestro Jaime Ríos Ortega (del CUIB). Se contó con la participación de la maestra Beatriz Casa Tirao, del licenciado Hugo Figueroa Alcántara (ambos, del Colegio de Bibliotecología de la Facultad de Filosofía y Letras de la UNAM), del licenciado José de Jesús Hernández Flores, del licenciado Eduardo Salas Estrada (representantes de la Escuela Nacional de Biblioteconomía y Archivonomía), de la licenciada Celia Mireles (de la Escuela de Bibliotecología e Información de la Universidad Autónoma de San Luis Potosî), de la maestra Lina Escalona Ríos y del doctor Roberto Garduño Vera (del CUIB).

El maestro Jaime Ríos comenzó explicando que la dinámica de trabajo consistiría, durante la primera
\end{abstract}


sesión, en exponer los documentos elaborados por algunos miembros del seminario. Tras las reflexiones suscitadas, durante la segunda reunión se verterían los puntos de vista de cada uno de los participantes, tratando de vincular tanto las ideas de los textos leídos, como la discusión y las conclusiones correspondientes, con los programas y planes de estudio en la licenciatura y en el posgrado.

El licenciado Hugo Figueroa leyó el documento "Ética de la información: perspectivas bibliotecológicas". Ahí, señaló que la ética de la información representa un campo de estudio cada vez más relevante en diversas áreas, entre las cuales se encuentra la bibliotecología. La exposición se dividió en dos apartados. En el primero se elucidaron las características principales de la ética de la información: ésta, además de constituir una rama de la ética aplicada, se relaciona con problemas ligados a los medios de comunicación, a las tecnologías, a la computación, a la bibliotecología, a los circuitos financieros, y a las interacciones humanas en Internet. Asimismo, se presentan algunos elementos teóricos esenciales de la ética de la información, como la exploración de las estructuras de poder en diversos niveles y las libertades concernientes a las tradiciones éticas y morales, así como a aspectos normativos. Desde el punto de vista educativo, se sugiere incluir tópicos relacionados con la ética de la información. También traza un panorama general de algunos aspectos 
históricos de la ética de la información, sobre todo en la tradición occidental. Toma en cuenta, por otra parte, la ética de información y los derechos humanos, pues existen elementos que fundamentan una reflexión sobre la responsabilidad que al respecto tienen los especialistas en información. Aborda la preocupación en torno a los dilemas relacionados con la protección de la propiedad individual, pues éstos constituyen uno de los aspectos morales, éticos y legales. Se describen algunos dilemas éticos relativos a la selección, adquisición y organización de la información, así como a los concernientes a la diseminación de la información. En la segunda parte de la exposición, compartió algunas reflexiones en torno a determinados fenómenos y categorías en Internet, dos de las cuales, por lo demás fundamentales, son las englobadas bajo los conceptos de "brecha digital" (conjunto de problemas implicados en el acceso desigual a la información) y el de "contenido digital" (relacionado con la selección, difusión y adaptación de la información digitalizada).

La licenciada Celia Mireles presentó el documento "Ética e información en la sociedad posmoderna", donde planteó que el concepto de modernidad, pese a que sigue siendo un paradigma histórico de primer orden, ha sido desplazado por el de posmodernidad, una etapa a partir de la cual se tratan de explicar las actuaciones del ser humano y de las sociedades actuales. La posmodernidad matiza algunos de los fundamentos filosóficos y 
científicos precedentes para brindar nuevas interpretaciones que, como resultado, han devenido en el relativismo cultural y en los cuestionamientos éticos sobre el desarrollo y uso de las tecnologías. Agregó que las preocupaciones éticas han sido siempre importantes en cualquier sociedad y recordó que éstas cambian y se desarrollan conforme las circunstancias de los individuos; como no constituyen un producto acabado, hay que saber encontrar los valores o principios fundamentales, independientemente de los múltiples contextos, para establecer una convivencia mundial comprometida con el futuro de la humanidad. Señaló, por otra parte, que las sociedades contemporáneas han creado fuertes dependencias hacia los medios de comunicación de masas, que, muchas veces, reproducen esquemas de comportamiento ajenos a comunidades determinadas, y, por ello, se crean conflictos de valores entre el público espectador. Subrayó el hecho de que la humanidad se enfrenta al reto de construir una ética mundial en donde existan valores obligatorios, que se posicionen por encima de las diversas morales y hábitos culturales, pues de ello depende, además de la convivencia social, la pertinencia de instituciones que buscan el bien común, como las bibliotecas. Concluyó con la idea de que, precisamente, las bibliotecas se fortalecerían al convertirse en garantes de promoción del multiculturalismo y de la defensa de comunidades locales, a 
través de las colecciones y el fomento a las libertades informativas.

La maestra Beatriz Casa expuso el documento "Información, tecnología e industria cultural: una reflexión desde la ética". Entre otros planteamientos, la autora sostuvo que, desde la aparición de las máquinas en la historia de la humanidad, irrumpió una estructura social distinta a la de la Edad Media; comenzó así una nueva cultura, pues las posibilidades de las máquinas parecían infinitas y la vida de los individuos, de un modo o de otro, giraban alrededor de ese concepto. La humanidad, al buscar convertirse en parte de esa nueva etapa, dio lugar al "hombre masa", un ser conformista e incomunicado, que asume el pensamiento de otros. Posteriormente, las sociedades han sufrido otros cambios derivados del acelerado desarrollo de la tecnología (incluido el de la información), que no siempre se han visto acompañados por procesos de reflexión necesarios. Al mismo tiempo, se ha producido una literatura encaminada a crear estereotipos y estandarizar gustos, de acuerdo con objetivos que responden a tendencias de diversa índole. El instrumento más importante para que la cultura extienda su poder, argumentó la maestra Casa, es la información, pues constituye un universo vasto, rico y poco evaluado; y la tecnología ha aportado grandes posibilidades al procesamiento y conocimiento de esa información. Es necesario reconocer, por ende, que, ante el desarrollo 
de la tecnología, ha habido en general una actitud pasiva. Así como la ciencia ha sido revisada desde el punto de vista de la ética, consideró la maestra Casa, ha llegado el momento de poner en tela de juicio el papel de la tecnología (no su valor ni su importancia), pues existe pasividad frente a ella. Una forma de tal actitud se hallaría representado por la falta de control en el desarrollo de la tecnología; otra, en atribuir a la tecnología vida y leyes propias: no se trata de renunciar a la tecnología ni tampoco a las capacidades humanas de reflexión, sino de alcanzar una justa posición entre esos dos extremos. Hay que tener en cuenta, por lo tanto, que así como la ciencia no es neutral, la tecnología tampoco lo es. Indudablemente, el carácter de la tecnología depende del empleo que de ella se haga y por ello es necesario someterla a los controles morales y sociales. Tanto el que crea como el que emplea tecnología de información, concluyó, tiene una responsabilidad ética frente a la sociedad.

Finalmente, el maestro Jaime Ríos leyó la ponencia intitulada "La biblioteca pública: un lugar de valores". El texto inicia explicando que las bibliotecas se han caracterizado, desde hace siglos, por que son metamórficas y porque son espacios organizados de la memoria colectiva (al respecto, las bibliotecas públicas serían el mejor ejemplo). Allí ocurre uno de los actos de comunicación más importantes en términos universales: la vinculación intersubjetiva con otros seres humanos a 
través de la lectura. Además, la biblioteca pública es un lugar de valores en el cual existen personas, objetos y procesos importantes; y las razones que dan valía a esa institución social son de orden moral, ético y político. Precisamente, al establecer algunos de los valores en esos recintos, Jaime Ríos subraya que éstos no pueden reducirse a las tecnologías ni a los saberes técnicos, sino que tienen que apoyarse en un sistema de acciones intencionales, donde se practiquen creencias, conocimientos, valores y normas. A ese respecto, uno de los ejemplos más notables sobre lo que debe considerarse como valores son los establecidos en el Manifiesto de IFLA / UNESCO sobre la biblioteca pública. Allí se clarifica el tratamiento que se da a los individuos como agentes morales. Además, se halla presente el principio que señala la posibilidad de elegir libremente el mejor modo de convivencia social. Sobre estos y otros principios, se califica a la biblioteca pública como una institución representativa de la modernidad y sus valores fundamentales. Por otra parte, un valor esencial para la biblioteca pública es el principio ontológico de la realización; además de éste, se desprenden dos ideales regulativos: el libre acceso a la información y al conocimiento, como condición de la democracia; y la educación permanente para el desarrollo de los individuos y los países. Sin embrago, las condiciones del mundo en que nos ha tocado vivir hacen necesario estar abiertos a otros valores centrados en la capacidad 
de aprender a vivir el cambio y la comunicación intercultural.

La segunda sesión del Seminario en torno al tema "Ética e información" se realizó el 25 de septiembre de 2003. El encuentro estuvo moderado por el doctor Roberto Garduño y contó con la participación de la maestra Beatriz Casa, del licenciado Hugo Figueroa, del licenciado José de Jesús Hernández, del licenciado Eduardo Salas, de la licenciada Celia Mireles, de la maestra Lina Escalona y del maestro Jaime Ríos.

José de Jesús Hernández explicó, a través de un documento elaborado para tal ocasión, que las instituciones tienen el deber de formar hombres con responsabilidad y calidad total. Para ello, es indispensable considerar cuatro pasos: el bien ser, el bien hacer, el bien estar y el bien tener. Por lo tanto, para que los sistemas de información sean eficientes y de calidad, se requiere de sistemas de información eficientes y de calidad, así como de políticas de información que sustenten, a su vez, una política de calidad. Ante la pregunta de ¿para qué sirve la ética?, José de Jesús Hernández recuerda que, en la actualidad, existen presiones morales, financieras, ideológicas y políticas en contubernio con el soborno; por ello, es preciso desarrollar una conciencia ética clara y vigorosa de la propia dignidad personal. Define la ética como un valor que defiende el ideal de verdad por encima del lucro, por lo cual se deben respetar los principios en el manejo de información 
por todos los actores involucrados al respecto: instituciones, bibliotecas, directivos y bibliotecarios profesionales. En consecuencia, el código de ética debe cumplirse a cabalidad, pues su violación puede acarrear sanciones que contemplen la expulsión de los transgresores.

Eduardo Salas leyó su documento, en el cual explicó la manera en cómo funciona la jerarquía de la información, así como un esquema derivado de la diversidad de teorías éticas por interés. De ello, se desprenden conclusiones como las siguientes: la comunidad debe cambiar su apreciación en cuanto considerar a la biblioteca como un guardián moral, pues ésta debe ser vista como una fuerza educativa; asimismo, la biblioteca esgrime una responsabilidad profesional para satisfacer las necesidades de la comunidad y debe orientarse hacia la educación para cambiar la forma en la que actúa con los usuarios. Basándose en la autoridad de autores como Richard Mason y Mary J. Culnan, Salas consideró que es necesario tomar en cuenta nuestras habilidades para: identificar asuntos éticos que rodean a la información y su uso; examinar todos aquellos aspectos que utilizan teorías y principios éticos, y aplicar éstos a situaciones que se desarrollen en niveles individuales, organizacionales y sociales. Por otra parte, Salas señaló que el desarrollo del conocimiento y de la información ha sido un factor crítico en un crecimiento que ha desembocado en la llamada "era de la información"; los motivos por 
los cuales se ha llegado a ese desarrollo comparten aspectos como: procurar el bienestar y evitar la miseria; trabajar por la seguridad y hacer a un lado el miedo a la incertidumbre; buscar la recreación y el entretenimiento y sortear el fastidio, y esforzarse a favor del control y el orden para no incurrir en el caos. Salas concluyó su documento asentando algunos principios genéricos sobre la ética.

Hugo Figueroa, tomando como referencia el documento de Eduardo Salas, señaló que existen algunos aspectos éticos relacionados, por un lado, a una ética de contacto social y, por otro, a una ética personal. Convendría, dijo, aclarar esa posición para evitar caer en malos entendidos. Ante ello, Beatriz Casa afirmó que identificar una ética personal y una ética social no necesariamente implicaba una circunstancia negativa, porque tal posibilidad enriquecía la discusión. José de Jesús Hernández consideró oportuno plantear el porqué y el para qué en torno al tema de ética e información, además de introducir las interrogantes acerca de cómo y de qué manera se podría integrar la discusión a los programas y planes de estudio. Beatriz Casa indicó que, antes de eso, habría que preguntarse cómo integrar el problema de la ética a nuestras propias vidas, porque, sostuvo, no hay que creer que la información supera ese conflicto. En el mismo sentido, Celia Mireles dijo que sería importante compaginar la ética profesional y la ética personal. 
Jaime Ríos propuso reflexionar sobre el valor de la información, tratando de identificar elementos particulares al respecto. Consideró relevante establecer los nexos entre ética y bibliotecología (y no sólo los de ética e información); de ahí podrían derivar otras relaciones como las de ética y bibliotecas, ética e Internet, ética y usuarios, etcétera. El problema, sostuvo, empieza por saber cuáles son las fuentes normativas desde las cuales se funda el núcleo básico de valores, pues, a partir de ahí, se pueden empezar a desarrollar las probables consecuencias en términos conductuales y en términos de repercusión social. Ponderó también que, en el campo de la ética, es sustantivo identificar el concepto de valor, pues éste puede connotar distintos sentidos y distintas perspectivas de análisis. Otro de los temas de su interés concierne a dos esquemas de comprensión: la ética de la responsabilidad y la ética de la convicción en la práctica bibliotecológica. Hugo Figueroa juzgó muy importantes los señalamientos de Jaime Ríos y agregó algunos de los valores que, desde su perspectiva, podrían ser objeto de análisis y discusión: acceso a la información, libertad intelectual, no censura, responsabilidades ética y morales, libertad de publicación y de expresión, no discriminación; Figueroa dudó, sin embargo, si tales postulados constituyen valores éticos o principios éticos. Beatriz Casa negó que, desde el punto de vista de la axiología, fueran valores; en cambio, constituyen situaciones, acciones, 
actitudes, circunstancias, en las cuales se pueden diferenciar valores. Añadió, complementando la intervención de Jaime Ríos, que convendría no incurrir en el error de creer que hay un valor de la información; existe en cambio una escala de valores aplicables en el ejercicio de la información, pero no propiamente un valor de la información.

Hugo Figueroa, abordando el aspecto de los códigos de ética, afirmó que el elaborado por el Colegio Nacional de Bibliotecarios es acertado, pues coincide en puntos esenciales con códigos de otros países; con ello, se comprueba que hay acuerdos sustanciales en ese terreno en ámbitos internacionales. Eduardo Salas consideró que los valores tomados en cuenta por los informadores tendrían que relacionarse con la honestidad, pues, al fallar en ésta, se estaría dejando de ser eficaces en el desempeño profesional. Por eso, abundó, hay que encontrar una definición clara acerca de cuáles son los valores de los bibliotecólogos. Lina Escalona opinó que, para ella, es fundamental reflexionar acerca de qué se entiende por valor dentro del campo ético, así como el relacionado con la sociedad de la información. Relató su experiencia en el Colegio de Bibliotecología, cuando se reformularon los planes de estudios correspondientes, y recordó que una de las preguntas que se hacía la comisión para esa tarea era saber cómo enseñar un valor que posiblemente, como profesores, no se sabía de qué manera transmitirlo o si era posible 
transmitirlo; enfatizó en el hecho de que hay que hacer conciencia acerca de cuál es la responsabilidad de los bibliotecólogos frente a la sociedad, ya sea como manejadores de información o como intermediarios de la misma.

El seminario acordó abordar el tema ética de la bibliotecología, más que el de ética de la información. En ese sentido, Celia Mireles dijo que es más importante enseñar lo que significa informar, así como propiciar el diálogo y brindar todas las opciones existentes alrededor de un tema, para que cada cual actúe de acuerdo con su conciencia. José de Jesús Hernández señaló que por eso es importante tratar de convencer a los alumnos en el sentido de que los valores éticos profesionales tienen una razón de ser. Beatriz Casa advirtió que se volvía a tocar el principio del problema ético: no el que atañe directamente a la bibliotecología, sino el que concierne a la ética social y personal. Jaime Ríos aseveró que a él le preocupaba fijar la delimitación de cuál es el concepto de valores que la disciplina discute para revisar las fuentes normativas de donde surgen esos valores. Por otra parte, propuso que convendría que Hugo Figueroa volviera a recordar los ideales regualtivos relacionados con la disciplina para contar con un inventario sobre el cual abundar. Beatriz Casa hizo hincapié en que, más bien, ese listado habría que vincularlo a hechos que enriquecieran propiamente los valores. Hugo Figueroa argumentó que 
sería importante añadir lo que Salas expuso acera de identificar y enmarcar asuntos éticos que rodean a la información en su uso. A ello, afirmó, habría que agregar la propuesta de Jaime Ríos en cuanto a no soslayar la ética de la convicción. El Seminario en su conjunto acordó definir el problema como "Temas éticos relacionados con la bibliotecología". Tras la lectura del Código de ética profesional, Jaime Ríos insistió en no olvidar las fuentes informativas, pues se trataba de elementos sustantivos en la conformación del núcleo ético de la información. Hugo Figueroa estuvo de acuerdo en identificar tales fuentes normativas, pero también en explorar la manera en cómo se llega a éstas. Eduardo Salas acotó que el Manifiesto de la UNESCO para las Bibliotecas Públicas retoma esas fuentes de la Declaración Universal de los Derechos del Hombre, pero vertidos en el contexto de la información. Hugo Figueroa hizo patente que, además de ese manifiesto relativo a bibliotecas públicas, también existía el correspondiente a bibliotecas escolares, así como el elaborado por la IFLA sobre libertad intelectual y sobre Internet. Jaime Ríos agregó que lo importante era que, una vez identificadas esas fuentes normativas, de qué manera éstas incidían en la práctica profesional bibliotecológica, para, precisamente, ubicar los valores más notables al respecto. 
Relatoría de la mesa redonda "Etica e información"

El Seminario estuvo de acuerdo en tratar de profundizar a futuro el concepto de valores para, de ahí, enriquecer el conjunto de los "Temas éticos relacionados con la bibliotecología". También acordó considerar como tarea pendiente ubicar la mayor cantidad posible de fuentes normativas (de carácter universal y de regulación social), inherentes a la práctica de la disciplina. 


\section{Bibliografía: Etica y bibliotecología}

\section{ARTÍCULOS EN ESPAÑOL Y PORTUGUÉS LOCALIZADOS, EN SU MAYORÍA, EN LA BASE DE DATOS: INFOBILA}

1. Titulo: Código de ética bibliotecaria: (Adoptado por el Consejo de la ALA en el invierno de 1939) Fuente: Notas Bibliotecológicas / comp. Garnetta Kramer

Edición: $2^{\mathrm{a}}$ ed.

Pie de Imprenta: México: Pax-México, Librería Carlos Césarman, 1972

Paginación: p. 179-183

Notas: Adoptado el 18 de junio de 1948. Enmendado el 2 de febrero de 1961 y el 27 de junio de 1967 por el Consejo de la ALA. julio de 1970 Resumen: Se cita el Código de Ética Bibliotecaria adoptado por el Consejo de la ALA (American Library Association) en el invierno de 1939, en donde se describen los diferentes papeles que juega: del bibliotecario ante la autoridad máxima; ante los usuarios de la biblioteca; en la biblioteca; dentro de 
su profesión, y su papel en la sociedad. Incluye la Declaración de Derechos Bibliotecarios, adoptada en junio de 1948 y enmendada en 1961 y 1967. Clasificación: Z665/N66/1972

2. Título: El código de ética de las Asociación de Bibliotecas de los Estados Unidos. [Adoptado por el Consejo de la Asociación de Biblioteca de los estados Unidos (ALA) el 28 de junio de 1995]

Fuente: http:/ /www.ala.org/ala/oif/statementspols/ codeofethics/coehistory/codigodeetica.pdf [Consultado el 15 de agosto de 2005] 3. Titulo: Ética profesional... o que mis pares me lo demanden

Revista: Revista CTPCBA

Fascículo: No. 13 (mar. 1998), p. 6-9

4. Título: Informe final

Fuente: Seminario de Evaluación del Ejercicio

Profesional de la Bibliotecología en el Uruguay

1943-1983 ( 1983 : Montevideo, Uruguay)

Pie de Imprenta: Uruguay: Asociación de Bibliotecólogos y Afines Del Uruguay, 1983 Paginación: 19 p.

Resumen: del seminario de evaluación del ejercicio profesional de la Bibliotecología, destacando los temas como: ética del bibliotecario, evaluación y perspectivas de la biblioteca pública y el mercado laboral 
Clasificación LAT/000514

5. Titulo: Propuesta de código de ética para la Comisión Integrada en Entidades Profesionales de Mercosur

Pie de Imprenta: Buenos Aires: ABGRA, 1999

6. Autor: Acosta Sánchez, Isabel

Titulo: Algunas consideraciones acerca de la ética del trabajador de la información

Revista: Actualidades de la información científica y técnica

Fascículo: Año 20, no. 1 (feb. 1989), p. 87-104

Resumen: Se aborda el papel de la ética en la elevación de la actuación del hombre en la sociedad, y en particular la ética del trabajador de la información y lo que incide en el mejoramiento de la calidad de los servicios.

Clasificación: REV

7. Autor: Albaric, Michel

Título: La investigación requiere de una ética

Pie de Imprenta: [s.1.]: [s.n.], [1981]

Paginación: $6 \mathrm{~h}$.

Resumen: Reflexiones sobre la ética profesional dado que la actualidad impone una nueva situación debido a que las técnicas de informática documental le dan un nuevo impulso a los debates clásicos sobre informática y libertad. Se debe garantizar la calidad los servicios basándose en la conciencia de los deberes respecto de los cuales existen cuatro puntos 
esenciales que aquí se abordan: a) la libre circulación del saber, la cuestión de la censura y del secreto, b) la responsabilidad del derecho al error y el sentido del servicio, c) las posturas éticas y humanas de las técnicas, y d) la formación humana de los futuros colegas./ CUIB

Clasificación: AV 580/IFLA/1981

8. Autor Cor. Asociación Panameña de Bibliotecarios Titulo: Código, discursos, reglamento Revista: Boletín de la Asociación Panameña de Bibliotecarios

Fascículo: Año 9 (dic. 1985), p. 32-52

Resumen: Presenta el código de ética profesional con funciones y obligaciones para bibliotecarios

Panameños.

Clasificación: REV

9. Autor: Betancourth L., Héctor Manuel

Título: El bibliotecólogo del eje cafetero y su diseño ético

Pie de Imprenta: Armenia, Colombia: (HMBL, MCT), 1994

Paginación: 145 h.-_Tesis (Profesional Ciencia de la Información y la Documentación) — Universidad del Quindío

Resumen: El trabajo está dividido en dos secciones: en la primera se hace una conceptualización sobre ética, se analiza el campo en el cual se desempeña, su carácter histórico y la forma como se enfoca en la 
actualidad. En la segunda, se analiza el compromiso ético del Bibliotecólogo, el papel que juega dentro de la sociedad, la importancia de que rija su profesión por unos principios éticos. Para el desarrollo del trabajo se tuvo en cuenta estrategias metodológicas muy concretas, basadas en el estudio, la observación y encuestas de lo que ha sido la labor bibliotecaria en el Eje Cafetero.

Clasificación: TESIS

10. Autor: Caballero Valdés, Adalys

Titulo: El bibliotecológo y el profesional de la información modernos. Ética, papeles y perfiles Revista: Ciencias de la información Fascículo: Vol. 29, no. 1 (marzo 1998), p. 3-13

Notas: Versión de la ponencia presentada al VIII Forum Científico. Facultad de Comunicaciones. Universidad de la Habana, obtuvo mención especial por parte del jurado

Resumen: Se abarcan algunos aspectos relativos a al formación y superación de los modernos bibliotecólogos y profesionales de la información, sus áreas de conocimeitnos y de aplicación, específicamente se puntualiza la necesidad de elementos concernientes a la ética profesional. Se analizan cuáles son los aactuales papeles que extienden las funciones del bibliotecólogo más allá de su institución, asi como los diferentes perfiles que lo conforman como profesional que trabaja con 
información. Se enfatiza la necesidad de sustituir la imagen distorsionada del profesional de la información relatada por algunos autores, por una nueva, acorde con el dasarrollo de los nuevos tiempos./ OCV, SPG

Clasificación: REV

11. Autor: Carsen, Tatiana M.

Titulo: Derecho a la información: una aproximación hacia una ética y conducta profesional

Fuente: Reunión Nacional de Bibliotecarios (29 : 1995

: Buenos Aires, Argentina) trabajos presentados

Fuente: La biblioteca y la información en la transformación social, económica y cultural Pie de Imprenta: Buenos Aires, Argentina: Asociación de Bibliotecarios Graduados de la República Argentina (ABGRA), 1995

Paginación: p. 37-40

Resumen: El derecho a la información es enmarcada dentro de los Derechos Humanos. Se le relaciona con las concepciones y trato entre el bibliotecario y el usuario y los factores sociales que inciden en el vínculo bibliotecario-sociedad. Recomienda que se explicite el compromiso de los bibliotecarios en la aceptación de los derechos y garantía de los individuos y grupos que están relacionados con la información.

Clasificación: Z765/A1R48/1995 
Mesa redonda. Ética e infomación

12. Autor Cor. Colegio de Bibliotecólogos y Archivólogos de Venezuela

Título: Código de ética del Colegio de Biblotecólogos y Archivólogos de Venezuela

Pie de Imprenta: Caracas:[El Colegio], 2001

Paginación: $4 \mathrm{~h}$.

Resumen: Versa sobre el código de ética presentado por el colegio para regir el ejercicio profesional de la Bibliotecología y la Archivología en Venezuela dentro de las múltiples relaciones de estos profesionales con otros colegas, usuarios, organizaciones públicas y privadas y en la sociedad en general./NM

Clasificación: LAT/9317

13. Autor Cor. Colegio Nacional de Bibliotecarios, A.C., México

Titulo: Código de ética

Pie de Imprenta: México: Centro Universitario de Investigaciones Bibliotecológicas, Universidad

Nacional Autónoma de México, 1991

Descripción física 1 tríptico ; $22 \mathrm{~cm}$.

*Clasificación: f/020.69 C689c [ ${ }^{*}$ El Colegio de México]

14. Autor: Costa Carballo, Carlos Manuel da Titulo: Tecnologías informáticas y datos personales : en busca de un compromiso ético para su protección Revista: Ciencias de la información

Fasciculo: Vol. 27, no. 2 (jun. 1996), p. 82-88 
Resumen: Se parte del supuesto de que existe una obligatoriedad, el respeto a la intimidad de las personas. Se plantean tres niveles de control respecto de esa intimidad: el primero hace referencia a los códigos de ética profesionales, a tradiciones escritas, a los juramentos y compromisos; el segundo, a la legislación positiva; y el tercero a las directivas, recomendaciones y reglamentos. Y se hace un análisis del primer nivel solamente (puesto que han sido analizados en otras ocasiones. Se propone un compromiso ético para el tratamiento de datos personales.

Clasificación: REV

15. Autor: Cuenca, Molina, Ángel

Título: Ética de la comunicación.

Revista: Anales de documentación (No. 2, 1999), p. 9-19

En línea: http://www.um.es/fccd/anales/ad02/ ad0200.html

16. Autor: Cuvertino de Yanzón, Patricia; Cecilia Fraguerio y Aída Paradello de Parodi, Título. Anteproyecto del código de ética del profesional bibliotecario

Fuente: Reunión Nacional de Bibliotecarios (27:1993:

Buenos Aires 6-9 noviembre)

Pie de Imprenta: Buenos Aires : ABGRA, 1993.

Paginación: p.1-24

Clasificación: Z765/A1R48/1993 
17. Autor: Escobar Carballal, Sarah T.

Titulo: Ética del bibliotecario

Fuente Congreso de la Asociación Cubana de

Bibliotecas (1 : 1996 : Cuba). Trabajos

Pie de Imprenta: Cuba: Biblioteca Nacional José Martí, ASCUBI, 1996

Paginación: p. 6-12

Resumen: El comportamiento de las personas, tanto en la rutina diaria como en momentos de conflicto, supone siempre una elección y ésta refleja los valores y principios del individuo que la realiza. La acción de decidir y diferenciar lo conveniente de lo perjudicial, implica elegir una opción a partir de un juicio moral o ético. Las decisiones del hombre son influidas por las del grupo social con el cual convive. Los estudios que se realizan sobre la organización de las bibliotecas y la eficiencia del personal, han permitido detectar factores que afectan el trabajo bibliotecario relacionado con la ética. Se detallan aquí estos estudios./ STEC

Clasificación: LAT/000370

18. Autor. Fernández de Zamora, Rosa María

Titulo: Los códigos de ética en América Latina

Revista: Panorama : revista de la Universidad

Autónoma de Baja California Sur

Fasciculo: No. 50, (oct./dic., 2004), p. 18-21

Resumen: Las asociaciones profesionales de bibliotecarios surgieron y se desarrollaron en 
América Latina durante el siglo XX, la mayoría de ellas ha adoptado principios éticos para la práctica de la profesión. Sin embargo en esta era de la información, globalización y de la influencia de Internet en los servicios bibliotecarios, las asociaciones deben enfrentar éstos con estrategias inteligentes y códigos efectivos con el fin de que el comportamiento corresponda a los tiempos que se están viviendo. Destaca también, que se necesitan normas éticas para todos los empleados de bibliotecas o centros de información sean o no profesionales porque su conducta afecta positiva o negativamente el prestigio o imagen de la profesión /CUIB

Clasificación: LAT/001706

19. Autor: Garcia, Joana Coeli Ribeiro

Título: Bibliotecário : informar tudo a todos?

Revista: Informacao and Sociedade : estudos

Tit.Par. Should librarians inform everyone about everything?

Pie de Imprenta: Brasil: [s/n],1992

Fascículo: Vol. 2, Núm. 1, p. 78-85

Resumen: Apresenta a maxima a biblioteconomia e o codigo de etica dos bibliotecarios como elementos que se contrapoem na questao do sigilo, uo da confidencia, no relacionamento do bibliotecario de referencia com os usuarios.

Clasificación REV 
20. Autor: García Pérez, Nora Victoria

Titulo: Ética profesional y discapacidad

Fuente: Jornadas Mexicanas de Biblioteconomía (33:

2002 : Monterrey, N.L.). Memoria

Pie de Imprenta: México: AMBAC, 2003

Paginación: p. 111-118

Resumen: Trato aquí de retomar algunos elementos que se desprenden de la ética de los bibliotecarios profesionales enfocando el servicio que ofrecen a personas que cuentan con algún tipo de discapacidad en general. Se define la ética profesional, se analizan algunos puntos del Código de Ética Profesional del Bibliotecario editado por el Colegio Nacional de Bibliotecarios tratando de demostrar la importancia que tiene la aplicación de la ética bibliotecaria para otorgarle servicios adecuados a las personas con discapacidad, y se resaltan algunos puntos de nuestro código ético. Se propone una posible solución al problema de las bibliotecas que no tienen presupuesto, instalaciones ni mobiliario adecuado para los diferentes usuarios con discapacidad /N.V.G.P.

Clasificación: Z673/J66/2003

21. Autor: Gordillo Gordillo, Roberto Antonio

Titulo: Mesa redonda sobre ética profesional: acotaciones en torno a unas normas que podríamos adoptar quienes laboramos en las bibliotecas mexicanas 
Fuente: Jornadas Mexicanas de Biblioteconomía (16 : 1985 : Pachuca, Hgo.). Memorias

Pie de Imprenta: México: AMBAC, 1986

Paginación: p. 267-278

Resumen: Propone que se estudie y avance en materia de ética profesional bibliotecaria. Hace un paralelismo entre la ética profesional para los abogados y los bibliotecarios. Da lineamientos que permitan a la comunidad bibliotecaria proponer normas que rijan la conducta profesional del personal que labora en bibliotecas mexicanas./ CUIB Clasificación: Z673/J66/1985

22. Autor: Gordillo Gordillo, Roberto Antonio

Título: Ser y proceder de un bibliotecario en México : Conferencia Magistral

Fuente: Reunión Estatal de Bibliotecarios de Sonora (1991 : Hermosillo, Sonora). Memoria

Pie de Imprenta: México: [s.n.], 1991

Paginación: p. 7-13

Resumen: El autor hace una disertación acerca del ser, la forma de ser y el cómo llegar a ser. Con estos antecedentes, define qué es "ser bibliotecario", para después hablar sobre el proceder de un bibliotecario en México. Al finalizar da una lista de sugerencias referentes al código de ética que debería regir las acciones de los bibliotecarios en México / CUIB Clasificación: LAT/001644 23. Autor: Gordillo Gordillo, Roberto Antonio 
Título: Sobre la pertinencia de adoptar un código de ética profesional para bibliotecarios mexicanos Fuente: Seminario Nacional de Bibliotecarios Titulados de México (1989 : México, D. F). Bibliotecología, Información y Sociedad en México : memorias

Pie de Imprenta: México: CONACYT, 1990

Paginación: h. 5-15.

Resumen: Descripción y análisis para adoptar un código de ética que sirva de instrumento para dignificar la profesión y lograr que su presencia sea tomada en cuenta y respetada tanto por la sociedad como por las instituciones

Clasificación: Z665.2/M45S45/1989

24. Autor: Lopera Lopera, Luis Hernando

Titulo: Una ética bibliotecológica para afrontar los retos de nuestro tiempo

Revista: Revista Interamericana de Bibliotecología Editorial Colombia, 2002

Fascículo: Vol. 25, Núm. 1 (ene./jun.), p. 65-88 Resumen: La bibliotecología y el ejercicio de la profesión, como toda actividad humana, requieren de un contenido ético acorde con la época y con el tipo de sociedad que enmarca sus acciones. Se propone un fundamento de ética bibliotecológica a partir del pensamiento de José Ortega y Gasset, de José Luis Aranguren y de la ética discursiva de Adela Cortina. La tesis que se desarrolla es que la biblioteca 
como institución social y el bibliotecólogo que actúa de acuerdo a su misión personal y profesional, tienen una responsabilidad social para con la comunidad a la cual prestan sus servicios /L.H.L.L.

\section{Clasificación: REV}

25. Autor: Muller, Ory Terezinha Lisboa

Titulo: Por uma classe mais digna

Revista: Boletím ACB

Fascículo: Vol. 2, no. 2 (julho-dez. 1982), p. 3-7

Resumen: Hace una llamada a sus colegas

bibliotecarios para ser mas responsables en el trabajo encomendado como profesionistas

Clasificación: LAT/000719

26. Autor: Pérez Pulido, Margarita

Titulo: Códigos de ética de los bibliotecarios y otros profesionales de la información: comentarios y análisis comparativo.

Fuente: www.anabad.org/archivo/docdow.php?id

$=15$ [Consultado el 12 de septiembre de 2003]

27. Autor: Popper, Karl

Titulo: Tolerancia y responsabilidad intelectual

Fuente: http://www.solotxt.com/valverde/kpopper. htm [Consultado 15 de agosto de 2005] 28. Autor: Ribas Pinke, María Antonia Título: Ética profesional del bibliotecario Revista: Bibliotecología y documentación Fascículo: Año 2, no. 3-4 (enero-jun./jul.-dic. 1980), p. $55-91$ 
Resumen: Analiza la ética profesional del bibliotecario y el anteproyecto de código de ética del bibliotecario de Chile

Clasificación: REV

29. Autor: Robes Masses, Raquel

Título: Código de ética profesional

Revista: Boletín de la Asociación Cubana de

Bibliotecarios

Fascículo: Vol. 3, no. 4 (dic. 1952), p. 129-130

Resumen: Se incluye el texto del código, donde se incluye la relación del bibliotecario con sus superiores, con la comunidad y la sociedad, las relaciones dentro de su biblioteca y en su profesión en general.

Clasificación: REV

30. Autor: Rodríguez Gallardo, Adolfo

Título: Sobre los valores de la profesión

Revista: Hemera : revista de ciencias bibliotecológica y de la información

Pie de Imprenta: México: 2003

Fascículo: Vol. 1, Núm. 1 (ene./jun.), p. 3-4

Resumen: El autor comenta, de manera breve, acerca de la ética profesional, mencionando que toda profesión debe tener una serie de valores sobre los cuales construir su práctica y ejercicio. Enfatiza que los bibliotecarios deben pugnar porque se preserven ciertas condiciones en el proceso de información, que garanticen a los participantes en este ciclo sus 
derechos y obligaciones, menciona los siguientes: la libertad de expresión; la libre acceso a la información; la preservación de los materiales informativos para que se conserven y se transmitan; y que los bibliotecarios deben propugnar por un derecho a la información así como a la educación Clasificación REV 31. Autor: Rodríguez Ramírez, Carlos Alb.

Título: Importancia de la ética en la bibliotecología Revista: Revista de Bibliotecología y Ciencias de la Información

Pie de Imprenta: Costa Rica, 1995

Fascículo: Vol. 10, Núm. 1-3 (ene./dic. 1995), p. 14-17 Resumen: El ejercicio de cualquier profesión requiere no sólo de la adquisición y destreza de un cúmulo de conocimientos específicos, sino también del cumplimiento de normas deontológicas, para garantizar la buena práctica profesional. En este sentido se hacen algunas reflexiones éticas respecto del ejercicio profesional del bibliotecólogo , tomando como base el Código de Etica del Colegio de Bibliotecólogos de Costa Rica.

Clasificación: REV

32. Autor: Sanz, Maria Teresa

Título: Código de ética profesional: sobre la profesión en general y la profesión de bibliotecario en particular

Pie de Imprenta: Chile: [s.n.], 1977 
Paginación: $4 \mathrm{~h}$.

Resumen: Discurso que reflexiona sobre la profesión comparándola y diferenciándola de la ocupación con la intención última de averiguar si la profesión de bibliotecario cumple con los rasgos requeridos. La respuesta es afirmativa./ CUIB

Clasificación: LAT/001482

33. Autor: Servidio, Roberto

Titulo: Algunas reflexiones sobre ética profesional Fuente: Memorias del primer encuentro centroamericano de asociaciones de bibliotecarios: Fortalecimiento y creación de asociaciones de bibliotecarios en Centroamérica (San Salvador 27-31 de abril de 2004)

Pie de Imprenta: El Salvador: Asociación de Bibliotecarios de El Salvador ABES y Federación Internacional de Asoc. Bibliotecarios y Bibliotecas Sec. América Latina y el Caribe Paginación: 153p.

34. Autor: Souza, Francisco das Chagas de

Titulo: Possibilidades de entrever a ética na informaçao empresarial

Revista: Informaçao \& Informaçao

Tit.Par. Posibilidades de entrever la ética en la información empresarial

Editorial: Brasil, 2002

Fascículo: Vol. 7, Núm. 2 (jul/dez.), p. 95-104 
Resumen: Discute el sentido o contenido que puede tener el tema o noción "ética en la información empresarial", al considerar que para su comprensión tornase necesario hacer y haz en síntesis la discusión previa de las nociones de "ética del empresario", "ética de la empresa", "ética del mercado", "ética del cliente/consumidor de productos y servicios" y "ética del gestor de la información" /F.C.S. Clasificación: REV

35. Autor: Targino, Maria das Graças

Título: Ética professional e o bibliotecário Revista: Revista de Biblioteconomia do Maranhao Fascículo: Vol. 1, p. 43-56

Resumen: Nocoes básicas sobre ética. Analise do Código de Etica Profissional do Bibliotecário em vigor, constante da resolucao no. 327/86 do Conselho Federal de Biblioteconomia. Necessidade de revisao dos procedimentos considerados até entao éticos, diante do avanco das novas tecnologias de informacao e comunicacao. Apresentacao de casos para discussao./ MDGT

Clasificación: REV

36. Autor: Triana Ortíz, Manuel

Título: La profesión del bibliotecario: notas para la ética profesional de la bibliotecología

Revista: Revista de Bibliotecología y Ciencias de la Información 
Mesa redonda. Ética e infomación

Fascículo: Vol. 7, Núm. 2-3 (mayo/ago./sep. 1992), p. 7-9

Resumen: Reflexiones sobre el quehacer bibliotecológico y su ética, principalmente entendida como una praxis positiva y responsable en beneficio del hombre y su bienestar integral. También la urgente necesidad de formar un profesional de acuerdo a las exigencias de la era electrónica y los cambios tecnológicos acelerados./ MTO, HRC Clasificación: REV 37. Autor: Weckert, John

Titulo: Ética informática y las ciencias de la información

Editorial: Madrid: Fragua, 2000

Paginación: 287p.

Clasificación: QA76.9.M65 W4318

\section{ARTÍCULOS LOCALIZADOS EN LISA Y LI- BRARY LITERATURE}

\section{A. LISA: Library and Information Science Abstracts}

1. TI: Access to electronic information, services, and networks: an interpretation of the Library Bill of Rights

SO: Idaho Librarian; 48 (2) Apr 96, p.34-5 
DE: Access to information; Computerized information work; Codes of ethics; USA; American Library Association Code of Ethics; Library Bill of Rights, USA

$A B$ : The American Library Association (ALA) expresses the basic principles of librarianship in its Code of Ethics and in the Library Bill of Rights and its interpretations. Reviews the provision of computerized information services and access to electronic networks in the context of constitutional principles and ALA policies.

2. AU: Albaric, Michel

TI:Necessite d'une ethique dans la recherche. The necessity for a research ethic

SO: Bulletin des Bibliotheques de France; 27 (1) Jan 82, 23-24.s

$D E$ : Ethics; Profession; Librarianship

$A B$ : Considers the responsibilities of the librarian as custodian of information. Refers to the US and Canadian codes of practice, and reviews the situation in France, in relation to the necessity for establishing an international ethic. A professional charter should cover the following topics: free circulation of knowledge and censorship; the librarian's responsibilities, his right to make mistakes, and the notion of service; the ethical and human implications of information techniques; and training for librarians 
of the future. Each point is briefly discussed, and the dignity of librarianship as a profession emphasised. 3. AU: Auer, N J; Krupar, E M

TI: Mouse click plagiarism: the role of technology in plagiarism and the librarian's role in combating it SO: Library Trends; 49 (3) Winter 2001, p.415-32 $D E$ : Authorship; Ethics; Plagiarism; Role in; Full text databases; And; Internet

$A B$ : Article included in a special issue devoted to the theme: Ethical issues in information technology. The proliferation of full text databases and the World Wide Web has made plagiarism a rapidly growing problem in academia. Possible factors influencing student behaviour and attitudes toward plagiarism include ignorance, lack of personal investment in their education, situational ethics and lack of consistent styles among and within various disciplines. Librarians are in a unique position to help prevent and detect plagiarism by forming partnerships with faculty to re-examine assignments and instructional sessions and by informing them of Internet paper mills and useful Internet search strategies. (Original abstract)

4. $A U$ : Bazirjian, Rosann

TI: The ethics of library discard practices

SO: Acquisitions Librarian; (3) 1990, 135-146. bibliog $D E$ : Technical services; Acquisitions; Stock revision; Withdrawals; Revision; Discards; Ethics 
$A B$ : Contribution to an issue devoted to Legal and ethical issues in acquisitions. Defines ethics, highlights some of the major philosophical theories related to ethics and discusses these in a college library setting. Examines components of moral obligation, a key phrase when considering the concept of ethics, as they relate to the moral obligation most libraries have to keep their collections current. Provides an analysis of the professional status of librarians and addresses the concept of the American Library Association (ALA) Code of Ethics in order to place the issue in historical perspective. Discusses the issue of ethics versus law and where discarding practices fit into that scheme. 00 Original abstract—amended 5. AU: Bunge, $\mathrm{C}$ A

TI: Ethics and the reference librarian

SO: Reference Librarian; (66) 1999, p.25-43

$D E$ : Reference work; Ethics

$A B$ : Contribution to an issue devoted to a tribute to Charles A. Bunge and the challenges of contemporary reference service. Article reprinted from 'Ethics and the Reference Librarian' by Charles A. Bunge, in F. W. Lancaster (ed.), 'Ethics and the Librarian' (Papers presented at the Allerton Park Institute No. 31) Urbana Champaign IL: Graduate School of Library and Information Science, University of Illinois. Copyright 1990 by The Board 
of Trustees of The University of Illinois. Aims to help reference librarians answer the question, 'What is ethical reference practice?' Sets out a group of norms or obligations that should guide the reference librarian's service to clients. Puts forward guidelines for following these norms, along with strategies for applying them.

6. AU: Crowe, Lawson; Anthes, Susan H

TI: The academic librarian and information technology: ethical issues SO: College and Research Libraries; 49 (2) Mar 88, 123-130.s

DE: Technological innovations; Ethics; Academic libraries; Profession; Librarianship $A B$ : Academic librarians face a new working environment engendered by the rapid growth of information and advances in information technology. New conditions create ethical considerations that go beyond questions of individual behaviour. Value conflicts and ethical dilemmas arise from the more active, substantive role required of the academic librarian by technological developments. The librarian's commitment to freedom of access to information is challenged by issues such as fee-based information service and governmental restrictions on information access. Academic librarians must be sensitive to ethical requirements inherent in their role as information mediators. 


\section{AU: Danielson, E S}

TI: Ethics and reference services

SO: Reference Librarian; (56) 1997, p.107-24

$D E$ : Reference work; Archives; Ethics

$A B$ : Contribution to an issue devoted to reference services for archives and manuscripts. Reference archivists face challenging ethical dilemmas in the course of seemingly mundane daily tasks. While newly revised ethical codes provide helpful guidelines, there are many ethical questions without clear answers. Rapidly evolving technology, changing expectations, and inconsistent privacy laws place pressures on reference work. These issues also open a window on the society whose cultural property archivists manage. Original abstract-amended 8. AU: Dayan, $\mathrm{S}$

TI: Professional ethics in librarianship [in Hebrew] SO: Bulletin of the Israel Society of Special Libraries and Information Centres; 19 (1) Dec 92, p.24-28 $D E$ : Librarianship; Profession; Ethics $A B$ : Examines the nature of professional ethics in librarianship. Questions whether changes have taken place in the rules of professional conduct in librarianship, reflecting the rapid technological developments in the modern world of information. Also asks whether professional ethics can be measured and what the obligation of the librarian is in relation to them, as well as to the organization 
being served. Gives examples from the everyday routine of the librarian, who required to cope with decisions that reflect the conflict between the rules of professional ethical conduct and his obligation towards the organization to which he belongs and the customers being served. Original abstract-amended 9. AU: Devlin, M; Miller, $\mathrm{H}$ TI: Ethics in action: the vendor's perspective SO: Serials Librarian; 25 (3/4) 1995, p.295-300 DE: Acquisitions; Libraries; Ethics; Vendors AB: Report of a workshop at the Ninth annual conference of the North American Serials Interest Group, University of British Columbia, Vancouver, Canada, 2-5 June 1994: A kaleidoscope of choices: reshaping roles and opportunities for serialists. Through discussion of situations experienced by a number of vendors in which they perceived the behaviour of librarians to be possibly unethical, workshop participants explored a variety of issues related to vendor librarian encounters in an attempt to understand more about ethical boundaries in these situations. The Association for Library Collections and Technical Services (ALCTS) Statement of Principles and Standards of Acquisitions Practice (included in an appendix) was used as a framework, but most of the discussion 
emerged from the participants' personal experiences and beliefs.

10. AU: Diamond, R; Dragich, $\mathrm{M}$

TI: Professionalism in librarianship: shifting the focus from malpractice to good practice SO: Library Trends; 49 (3) Winter 2001, p.395-414 DE: Library and information science; Profession; Ethics

$A B$ : Article included in a special issue devoted to the theme: Ethical issues in information technology. Much of the previous discussion in library literature about professional standards concerns librarian malpractice risks. After explaining why these risks have not materialized, examines the role of professional standards in fostering good practice in librarianship. Components of good practice include professional knowledge, core competencies, and professional values. (Original abstract) 11. AU: Froehlich, T J

TI: Ethical considerations regarding library nonprofessionals: competing perspectives and values SO: Library Trends; 46 (3) Winter 1998, p.444-66 DE: Library staff; Professional staff; Non professional staff; Paraprofessionals; Ethics $A B$ : Article included in a special issue devoted to the theme: professionals, paraprofessionals, and nonprofessionals: the academic's viewpoint. Considers 3 major ethical issues relating to librarians 
and information professionals: the role, status, and compensation of such non professionals as library clerks or technicians in relation to professionals, the organization, and the public, particularly in their claims for professional status; the role, authority, status, and compensation of non librarian professionals appointed as directors or supervisors; and the relation of professional librarians to other professionals on the library or information centre staff. After characterizing the nature of a professional librarian, discusses the actual and theoretical criteria for such a designation. There are many stakeholders, a variety of ethical principles (justice, fairness, preserving professional or organizational trust) and a variety of ethical obligations (to the self, the organization, or society), diverse loyalties and varying circumstances and conditions each of which must be brought into ethical deliberation. Sets out the perspectives, values, obligations, and priorities that stakeholders bring to these issues. (Original abstract - amended)

12. AU: Garner, Kathy

TI: Lawyer-librarian in public law schools: the ethical conundrums of pro bono activities

SO: Law Library Journal; 84 (1) Winter 92, 31-66.s DE: Library staff; Ethics; Law libraries; Academic libraries; Lawyer librarians 
$A B$ : Lawyer-librarians in academic law libraries are subject to a variety of ethical and professional codes, none of which definitively addresses questions of pro bono service (that portion of lawyers' work which has a public quality and for which a lawyer is not paid or at least is paid at below the commercial rate). 00 Original abstract_-amended 13. AU: Garoogian, Rhoda TI: Librarian/patron confidentiality: an ethical challenge

SO: Library Trends; 40 (2) Fall 91, 216-233.s

DE: Libraries; Library materials; Information work; Use; Privacy; Confidentiality; Ethics $A B$ : Presents moral, legal, and professional arguments for the protection of a patron's privacy, reviews how some librarians have dealt with the issue, and concludes that librarians should lobby for legal recognition of librarian/patron privilege of confidentiality. 00 Original abstract 14. AU: Garreta, Jean Claude TI: Rapport moral. Moral report SO: Bulletin d'Informations de l'Association des Bibliothecaires Francais; (119) Second Quarter 1983, 29-30

DE: Profession; Librarianship; Library associations; Association des Bibliothecaires Francais $A B$ : Presented at the Association des Bibliothecaires Francais Congress, May 83 on access to information. 
Report on Association des Bibliothecaires Francais activities during 1982. The central bureau fulfilled its responsibilities in issuing the Bulletin and Note d'information and organised a study day on the costs of modern information. Further study days on automation, the librarian's professional ethics and the new law on higher education were organised by the various sections, and still others by the regional groups. The Association continued to promote training courses and exhibitions, to collaborate with other professional organisations, and to represent membership interests at government commisions. The vitality of the Association is assured despite the secession of some regional groups. $15 A U$ : Goasguen, Jean

TI: Deontologie et actualite. Professional ethics in the present situation

SO: Bulletin d'Informations de l'Association des Bibliothecaires Francais; (115) Second Quarter 82, 5-6.s

DE: France; Profession; Librarianship; Ethics $A B$ : An introductory paper presented at a 1982 Association des Bibliothecaires Francais conference, surveying current attitudes in relation to present circumstances. Recent press reports calling in question the librarian's competence in book selection have focused attention on the need for a code of ethics, to be incorporated into professional training 
courses clarifying the librarian's duties and responsibilities, his relations with his employers, and his obligations to the public. The growth of interest within the profession from 1975 is traced, with reference to conference debates and resolutions; and in conclusion the need for professionals to be informed about the implications for their own guidance in practice is emphasised.

16. AU: Golden, Fay Ann

TI: The ethics of reference service for the public librarian

SO: Reference Librarian; (30) 1990, 157-166. bibliog $D E$ : Services; User services; Reference work; Ethics AB: The ethics of library service are concepts that novice librarians must be educated to. Supervisors must make sure that trainees understand the basic documents published by the American Library Association, The Library Bill of Rights, and The Statement on Professional Ethics. 00 Original abstract—amended 17. AU: Goldstein, $\mathrm{C} \mathrm{H}$ TI: Ethics in technical services SO: LLA Bulletin; 58 (1) Summer 95, p.34-8 DE: Descriptores Union catalogues; OCLC; Input; Ethics; Acquisitions; Vendors; Libraries $A B$ : Discusses ethics in librarianship in the areas of acquisitions, serials and cataloguing. For acquisitions and serials librarians, ethical behaviour means placing 
the objectives and policies of the institution above any personal consideration or gain or treating all vendors fairly, with courtesy and respect. Considers ethical aspects of the librarian/vendor and librarian/publisher relationships. Examines the obligations on cataloguers participating in the OCLC online union catalogue to contribute to as well as to make use of member cataloguing, and to adhere to accepted bibliographic standards. Questions whether it is ethical to do minimal level cataloguing which provides fewer access points to the materials. The problem for technical services librarians is how best to accomplish the mission of the library within existing constraints. 18. AU: Greenwood, Terry TI: Professional ethics SO: New Library World; 82 (973) July 81, 123-125 DE: UK; Ethics; Profession; Librarianship; Library Association Working Party on Ethics Draft code AB: Critique of the Draft Code on Professional Ethics produced by the Library Association. The code is badly written, confused, silly, contradictory and threatens to bring the LA into disrepute. Notes provide little illumination; codes of ethics do not per se bring professionalism; a librarian's primary duty is often to a corporate body; there is confusion about possible conflicts in service; and the Library Association is impudent in suggesting that it will 
impose sanctions on those who fail to keep abreast of developments in librarianship. Suggests that the Working Party would do well to refer to the American Library Association code. 19. AU: Gupta, Shamsher; Gupta, Rashmi TI: Towards a code of professional ethics SO: International Library Movement; 7 (2) 1985 , 83-95.s

DE: Codes of ethics; Profession; Librarianship; Ethics $A B$ : A profession consists of a limited group of persons who have acquired some special skill which they can exercise better than the average person, and through this skill, training, and experience they may advise others in that field. Outlines 3 characteristics of the professional. Lists 3 problems in connection with professional standards which need urgent attention. Examines 5 objectives in the development of professional codes of ethics. Lists 7 principles to be kept in mind if the librarian is to be a successful professional.

20. $A U$ : Hauptman, Robert

TI: Overdue: professionalism or culpability? An experiment in ethics

SO: Wilson Library Bulletin; 50 (8) Apr 76, 626-627.s

DE: Hauptman R; Explosive device experiment; Bombing experiment; USA; Users; Requests; Ethics; 
Codes of conduct; Conduct; Services; User services; Reference work

$A B$ : Briefly describes an experiment undertaken in 6 public and 7 academic libraries during which the author approached the reference librarian with a request for information on the construction of a small explosive device and how much cordite would be needed to blow up a normal-sized house. In no case was the information refused on the grounds of ethics, even though urban bombings are now becoming almost commonplace. There is much discussion about submerging personal beliefs in favour of users' wishes, but librarians have no right to abjure ethical responsibility for fear of the censorship tag.

21. AU: Hedges, Graham

TI: Professional ethics for librarians

SO: Librarians' Christian Fellowship Newsletter; (25) Winter 83, 15-17.s

DE: Profession; Librarianship; Librarians' Christian Fellowship; Library Association Code of Professional Conduct $A B$ : Discusses, from the viewpoint of members of the Librarians' Christian Fellowship, the Library Association's proposed Code of Professional Conduct which was passed at its 1983 Annual General Meeting. Criticisms made include: an over-emphasis in the code on the role of the 
librarian in providing information services, with little to suggest that works of the creative imagination are a legitimate part of library collections; and an assumption that racial and sexual prejudices are the sole evils from which society must be protected, with no guidelines for dealing with books that are considered to be pornographic or over-violent. Notes that some members of the Librarians' Christian Fellowship are dubious about the value of trying to reduce professional ethics and standards to a formal written statement. 22. AU: Katz, Bill; Fraley, Ruth; Rothstein, S; Farley, J; Broderick, D; Clarke, J; Davis, E; Durrance, J C; Blazek, R; Wood, M S; Renford, B L; Lubans, J; Swan, J C; Watson, M; O’Brien, P M; Strickland Hodge, B; Hodge, B Strickland; Teller, R; Meador, J; Buthod, C; Schluckebier, D; Flinner, B; McCoy, M TI: Ethics and reference services SO: Reference Librarian; (4) Summer 82, 1-164. bibliog

DE: Ethics; Services; User services; Reference work AB: Special issue devoted to ethical aspects of reference work. Papers include: Where does it hurt: identifying the real concerns in the ethics of reference service, by Samual Rothstein; Reference ethics: a true confession, by Judith Farley; Value laden barriers to information dissemination, by Dorothy Broderick; Reference ethics-do we need 
them?, by Jack Clarke; The ethics of information serving Homo Sapiens Vs Homo Biblios, by Emmett Davis; Toward the development of an informed citizenry, by Joan C. Durrance; User fees: a survey of public and academic reference librarians, by Ron Blazek; Ethical aspects of medical reference, by M. Sandra Wood and Beverly L. Renford; Teaching the user: ethical considerations, by John Lubans; Ethics at the reference desk: comfortable theories and tricky practices, by John C. Swan; The unresolved conflict, by Melissa Watson; Some ethical problems of reference service, by Patrick M. O'Brien; Ethics and the reference librarian, by B. Strickland-Hodge; Ethical considerations in the question negotiation cycle, by Richard Teller; Triage, by Joan Meador and Craig Buthod; Regional public libraries and reference ethics, by Debbie Schluckebier; Academic libraries and reference ethics, by Bea Flinner; Bibliographic overview: the ethics of reference services, by Michael McCoy.

23. AU: Lancaster, $\mathrm{F}$ W

TI: Ethics and the librarian

SO: Library Review; 42 (7) 1993, p.46-7

$D E$ : Librarianship; Profession; Ethics; Book review abstracts; Ethics and the librarian $A B$ : Book review abstract. Edited by F. W. Lancaster. Urbana-Champaign, Illinois University, 1991, 126p., 20 dollars. ISBN 0-87845-085-8 
(Allerton Park Institute No. 31). Reviewed by R. V. Pringle.

24. AU: Lanier, Don; Boice, Dan

TI: The Statement on Professional Ethics:

implications and applications

SO: Serials Librarian; 8 (2) Winter 83, 85-93.s

$D E$ : Profession; Librarianship; Ethics

AB: The 1981 ALA Statement on Professional

Ethics differs significantly from previous statements, which were, by and large, neglected. In recent years, particularly since 1975 , more interest has been shown by librarians in the development of a meaningful statement which speaks in a practical way to services they provide. The purpose of this article is to encourage reference to the 1981 Statement as a point of departure in developing more specific approaches to ethical or professional library service. The specific approaches work themselves out in the areas of competency, business affairs, loyalty, and interpersonal relations. 25. $A U$ : Lorenzen, E A TI: The librarian's role in the job search of the future: issues and ethics in the electronic environment SO: Reference Librarian; (55) 1996, p.1-6 $D E$ : Online reference work; Job hunting; Document delivery; Electronic media $A B$ : Contribution to an issue devoted to career planning and job searching in the information age. 
The impact of the Internet and other forms of electronic information delivery upon the way individuals conduct their job searches is deepening daily. Also, as the Internet becomes increasingly commercialized, it is having a profound effect upon the way that employers communicate; between each other, the customers they serve, and even prospective employees. Looks at recent changes in workforce paradigms and outlines career information resource development strategies for the reference librarian.

26. AU: Luey, $\mathrm{B}$

TI: The librarian's role in teaching academic authors about publishing procedures and ethics SO: Serials Review; 22 (1) Spring 96, p.39-46 $D E$ : Scholarly publishing; Ethics; Faculty; Postgraduate students; Teaching; Library staff; Periodicals

$A B$ : Asserts that serials librarians can play an important role in teaching graduate students and new faculty about the procedures for submitting journal articles and book manuscripts and about the ethics of scholarly publishing. Reviews the issues to be covered, and describes a variety of resources for workshops and discussions. Original abstract. 27. AU: Miller, John

TI: Ethics and the mission of our profession 
SO: Impact, the Journal of the Career Development Group; 6 (1/2) Spring 2003, pp.5-7

$D E$ : Library and information science; Profession; Codes of ethics; Library associations; UK; CILIP $A B$ : The Chartered Institute of Library and Information Professionals in the UK is drafting a new code of ethics and has included a section on ethics in the new Chartership regulations. Defines ethics and explains why it is important, what it means to be an ethical librarian, the difference between being ethical and being professional, and what is an ethical library. Reflects on some of the ethical issues facing the Ministry of Defence Information and Library Service in London. 28. AU: Mintz, Anne P

TI: Ethics and the news librarian SO: Special Libraries; 82 (1) Winter 91, 7-11.s $D E$ : Services; User services; Information work; Ethics; Newspaper publishers' libraries $A B$ : Paper presented to the News Division at the 1990 SLA Annual Conference as part of a panel entitled 'Ethics and the News'. Addresses the topic of ethics as they relate to the librarians in news organisations. 00

Original abstract—amended 29. $A U$ : Moran, Gordon 
TI: Scholarly communication, peer review, and reference librarian ethics: a case study of the Lexicon of the Middle Ages

SO: Reference Librarian; (33) 1991, 159-172.s

$D E$ : Library staff; Reference work; Ethics

$A B$ : Discusses the apparent conflict involving reference librarian ethics and their relationship to some recently published views relating to peer review and the scholarly communication system. A case study, based on the gap between the promotional rhetoric and the actual peer review, editorial practices of a famous reference work, the Lexicon of the Middle Ages (Artemis Verlag, Munich), brings this conflict into sharp relief. 00 Original abstract-amended 30. AU: Nwafor, B U

TI: Librarians and the quest for truth SO: Bendel Library Journal; 7 (2) Dec 84, 58-64 DE: Censorship; Profession; Librarianship; Social aspects

$A B$ : Talk given to the Rotary Club of JOS, Nigeria, 11 Apr 85. Asserts that a society which promotes only one viewpoint and denies citizens access to alternative viewpoints is practising censorship. Discusses the history of censorship, the role of the librarian in relation to the collections he or she supervises, and the US Library Bill of Rights which is the embodiment of the professional ethics of US 
librarians. Suggests that the librarian has a dual role to play in the quest for truth; neutrality and advocacy. Emphasises the need for library collections to be balanced and accessible to all people at all times.

31. AU: Pearce, Brian L

TI: The ethics of further education librarianship SO: Education Libraries Bulletin; 24 (2) Summer 81, 32-43.s

$D E$ : Ethics; Library staff; School libraries $A B: \operatorname{Res} \tilde{A}^{\circ}$ men The librarian's 'clients' in the further education sector are identified. His duties towards them and the problems raised by them are discussed, with special reference to the education of the 16-19 age group. The need for the librarian to hold their diverse and sometimes conflicting demands in balance is seen as an aspect of his duties that requires professional autonomy for its satisfactory performance. The need for a balanced use of the facilities, coverage of subject areas, provision for divergent views, and encouragement of free enquiry leads to the suggestion that treatment rather than ideas is what the librarian is best qualified to assess. Pornography is discussed in relation to this and other criteria. The growth of open learning is seen as demanding a positive tutorial approach. The need for moral courage is affirmed.

32. AU: Ponce, Roberto Hernández 
TI: Algunas reflexiones en torno a la ética profesional del bibliotecario. Some reflections on professional ethics for librarians SO: Revista Chilena de Bibliotecologia y Documentacion; 1 (1 and 2) June and Dec 75, 27-33 DE: Ethics; Codes of conduct; Conduct; Library staff

$A B$ : Professional ethics are not a negative code, but govern the librarian's relations with other people, with society, and with authority. Professional workers have rights and obligations, attitudes and a manner of life which affect their actions, and librarians are specially concerned with culture and general knowledge. A critical spirit must be combined with a devotion to the maintenance of cultural patrimony.

33. AU: Prokop, Mary; McClure, Charles $\mathrm{R}$ TI: The public librarian and service ethics: a dilemma SO: Public Library Quarterly; 3 (4) Winter 82, 69-81.s DE: Ethics; Public libraries $A B$ : The relationship between personal and professional ethics is examined from the standpoint of the public librarian. Librarians' personal attitudes and the service philosophy implicit in public librarianship often suggest contradictory responses to information or service requests which are personally offensive to the librarian, resulting in ethical dilemmas. Examples of such dilemmas are 
given: reasons for their occurrence and different opinions regarding ethical behaviour are discussed. This type of conflict is itself neither good nor bad, but must be acknowledged by librarians and dealt with by the profession. Existing ethics of service guidelines are reviewed, and recommendations for resolving ethical conflict are offered. 34. AU: Protti, Maria E

TI: Dispensing law at the front lines: ethical dilemmas in law librarianship SO: Library Trends; 40 (2) Fall 91, 234-243.s $D E$ : Profession; Librarianship; Ethics; Law $A B$ : The law librarian has special ethical dilemmas because transferring information is so important in the US legal system. Argues that a duty exists, to keep legal queries confidential, but there is no clearly defined duty for the librarian not to comment on the possible establishment of an American Association of Law Libraries (AALL) commission to review the ethics of law librarian activities. 00 Original abstract-amended 35. AU: Pullinger, David TI: Librarians: experts in Internet ethics

SO: Christian Librarian; (28) 2004, pp.26-39

$D E$ : Librarianship; Ethics; Internet

$A B$ : Librarians may be considered to be experts in the ethics of the Internet, since some of the main concerns on the Internet have already been 
addressed in the history of libraries and ethics. Key concerns on the Internet include what is available, to whom it is available and the resulting change in people. Those are exactly the debates that have been important to the development of libraries: in the discussion over what to keep and what not to store; in the arguments over who should have access and under what terms; and in the purpose of information to change individuals and society. Many of the current debates about the Internet are old ones and well familiar to librarians. Concludes that librarians have valuable insights to offer by focusing on the historical controversies of the past to draw some parallels with the present, and so encourage librarians into playing their part in shaping the future. (Original abstract - amended) 36. AU: Roelants, J TI: Ethique and qualite en bibliotheconomie. Ethics and quality in librarianship SO: Libri; 43 (3) Jul-Sep 93, p.198-209 $D E$ : Librarianship; Profession; Ethics $A B$ : Ethics applies, in principle, to all human and professional activities. The conservation, preservation, acquisition and dissemination of knowledge have been the province of the librarian since the creation of libraries. Professionalism is a mixture of ethics and quality and cannot be dissociated from each other. The task of the library 
is enormous by reason of its monopoly which is to be the intermediary between information resources and their utilization. Original abstract-amended. 37. $A U$ : Rosenquist, $\mathrm{K}$

TI: The librarian's conscience: on professional ethics of librarians in the Nordic countries

SO: Scandinavian Public Library Quarterly; 29 (1) 1996, p.18-23

DE: Library staff; Ethics; Public libraries;

Scandinavia; Surveys

$A B$ : Describes the results of a questionnaire survey of public librarians' professional ethics in Denmark, Finland, Norway, Sweden and Iceland. The survey asked questions on a variety of topics including: the librarian as guardian, the obligation to provide information, equality of treatment of users, attitudes towards rules, political pressure, priority of borrowers vis a vis network cooperation, priorities in times of scarce resources, and attitudes towards charging for services. Concludes with a discussion of the influence of ideological changes from the social commitment of the 1960s and 1970s to the market orientation of subsequent years, on the ethical attitudes of librarians. 38. AU: Rothstein, J

TI: Ethics and the role of the medical librarian: health care information and the new consumer 
SO: Bulletin of the Medical Library Association; 81 (3) Jul 93, p.253-8

DE: Librarianship; Profession; Medical libraries; Ethics

$A B$ : Because medical libraries increasingly serve non professionals, medical librarians may need to reconsider their role. As clients alter their expectations about librarians and begin to think of them as participants in health care delivery, librarians face new ethical challenges. Compares the values and goals of the library and medical professions in the provision of health care information and examines the factors that health care professionals consider when deciding what information to share with patients. Challenges medical librarians to reconsider their duties toward their non professional clients and to clarify the goals of the health science library profession regarding the provision of information. Original abstract-amended. 39. AU: Sawyer, D S

TI: Reference librarians in private practice: ethical issues in the transition from employee to self-employment SO: Journal of Information Ethics; 4 (2) Fall 95, p.52-9

$D E$ : Library and information professionals; Freelance staff; Ethics 
$A B$ : Discusses the ethical issues involved when a librarian moves from being an employee to being self-employed. With librarianship still largely an institutionalized profession, there is little guidance available on such issues as: working out what to charge; proving the worth of the service to potential clients; dealing with a higher threshold of expectations; and the lack of any support network. In addition there are the ethical problems of how to get information without bending the rules, and what to do about charging clients when no information can be found. Also considers how to assess charges in general, and what to do when asked to obtain information for clients with objectives diametrically opposed to those of the librarian. Stresses the need for a proper consideration of such issues before one embarks upon self-employment.

40. AU: Schmidmaier, Dieter

TI: Library ethics and the special library network in science and technology

SO: Inspel; 19 (2) 1985, 106-119.s

$D E$ : Hungary; Science and technology; Organization;

Management; Cooperation; Special libraries

$A B$ : Considers the given professional duties and the librarian's concept of self. Stresses the need for the librarian to identify with the user and emphasises that only throught cooperation can service be assured, above all between specialised technical and 
scientific libraries. Various forms of cooperation are illustrated using examples from Hungary. Considers the question of cooperation and the problems which arise when collections are combined and a common catalogue is used. Investigates problems surrounding grey literature, the cataloguing of older collections, use and prompt returns, and mutual calculation of costs. Discusses problems and disciplinary issues arising from dependence of different professional groups on a single library. 41. AU: Seibel, Bernadette TI: Transformations de la profession de bibliothecaire et deontologie. Changes in the librarianship profession and professional ethics SO: Bulletin d'Informations de l'Association des Bibliothecaires Francais; (115) Second Quarter 82, 11,13-15.s

DE: Organization; Management; Social aspects; Libraries; Public libraries; France $A B$ : A paper presented at a 1982 Association des Bibliothecaires Francais conference interpreting data from a 1978 study of public librarians in France involved in cultural activities, in the light of current sociological theory on professional groups. Evidence is presented that the profession is becoming increasingly institutionalised, and at the same time undergoing radical change particularly in the public library sector, corresponding to social changes 
evident in the wider population. Statistics are presented showing a predominance of young, trained personnel in public libraries, and a resultant tendency to specialisation of roles and development of new categories of personnel. The new public requires a new kind of librarian, to meet the needs of a changing social situation. This raises the ethical question of whether the librarian should remain socially neutral or participate actively in promoting change, with the inherent danger of becoming the instrument of 1 particular social group.

42. AU: Strife, M L

TI: Special libraries and diversity: ethical considerations

SO: Reference Librarian; (45/46) 1994, p.213-19 $D E$ : Special libraries; Ethics $A B$ : Contribution to a thematic issue devoted to Racial and ethnic diversity in academic libraries: multicultural issues. By their very nature, special libraries are often restricted to a certain user population, be it an in-house corporate information centre, hospital library, or newspaper library. Or the collection may be of a particular era, or on a particular person or ethnic group. Some specialized collections are open to the public; some are restricted to scholars while others are available only to the people working for the organization. Special librarians walk a thin line between information 
access, serving specific clients and preserving the information in their trust. Original abstract-amended. 43. AU: Tabor, R B TI: Ethics of information giving: the librarian's view SO: Health Libraries Review; 2 (3) Sept 87, 105-107.s $D E$ : Ethics; Profession; Librarianship AB: Paper presented at the Nursing Interest Sub Group Study Day on Health care information: ethical and legal issues, 19 Feb 85. Discusses the American Library Association's Statement on Professional Ethics and the Library Association's Code of Professional Conduct with particular reference to the responsibilities of librarians working within the context of the National Health Service. 44. AU: Thies, T M

TI: Beyond ethics laws: avoiding appearances of impropriety SO: Ohio Libraries; 7 (3) Summer 94, p.32-3 DE: Library staff; Ethics; Impropriety; USA $A B$ : In the USA it is no longer enough for a public employee, such as a librarian, to simply adhere to ethics rules or regulations created by legislatures. Instead, they must recognize their moral obligation to the public and act to avoid even the appearance of impropriety. Urges librarians to consider their decisions carefully to avoid any appearance of impropriety. 
45. AU: Vaagan, Robert W

TI: The ethics of librarianship: an international survey

SO: Serials Librarian; 47 (1/2) 2004, pp.251-252

$D E$ : Book review abstracts; Ethics of librarianship AB: Book review abstract. IFLA Publications 101. Munich: K. G. Saur, 2002, 344pp., 64.00 Euro/48.00 Euro IFLA members. ISBN 3598218311. Reviewed by Jeanne M. K. Boydston. 46. AU: Vecchio, R A D

TI: Privacy and accountability at the reference desk SO: Reference Librarian; (38) 1992, p.133-40

$D E$ : Library staff; Reference work; Privacy; Accountability; USA

$A B$ : Contribution to an issue devoted to assessment and accountability in reference work. Explores the questions of expectation of privacy by the user and the accountability of the reference librarian to ensure privacy. Discussion reveals that different user types have different expectations of confidentiality.

Librarians have an ethical accountability based on ALA Codes of Ethics, but social and personal conflicts may arise. The reference librarian has no legal accountability to protect the user's confidentiality during a reference interview. Although the Codes need to protect the librarian more and reflect the dualities, there may be no 
resolution to conflicts between professional and personal integrity. Original abstract-amended.

\section{B. Library literature}

1. TI: When a new fee based reference service poses an ethical dilemma SO: One-Person Library; 14 (7) NOV 97, p.4-6

DE: Library management; Ethics; Commercial services; Competition; One person libraries.

2. AU: Boston,-George

TI: Ethics and new technology

SO: IFLA Journal v 21 no3 1995. p. 211-12

DE: Archives-Standards;

Audiovisual-archives-Automation

DOCUMENT TYPE: Feature-Article

3. AU: Goehner,-Donna-M

TI: Ethical aspects of the librarian/vendor relationship

SO: In: Ethics and the librarian University of Ill at

Urbana-Champaign Graduate School of Lib and Information Science, 1991. p. 73-82

IB: 0878450858

DE: Jobbers-suppliers-and-wholesalers; Ethics-

4. AU: Hauptman,-Robert

TI: Five assaults on our integrity

SO: In: Ethics and the librarian University of Ill at Urbana-Champaign Graduate School of Lib and Information Science, 1991. p. 83-91 
IB: 0878450858

DE: Ethics-Case-studies

5. AU: Irish,-D.-Elizabeth

TI: And ne'er the twain shall meet? Personal vs professional ethics

SO: Christian Librarian v 36 Nov 1992. p. 14-19

DE: Ethics-; Librarianship-as-a-profession

6. AU: McCook,-Kathleen-de-la-Pena

TI: Human resources management: ethics in personnel

SO: In: Ethics and the librarian University of Ill at Urbana-Champaign Graduate School of Lib and Information Science, 1991. p. 101-13

IB: 0878450858

DE: Personnel-Administration; Ethics-

7. AU: Morrison,-Samuel, 1936-

TI: The ethics of access: towards an equal slice of the pie (minority outreach at Chicago Public Library)

SO: In: Ethics and the librarian University of Ill at Urbana-Champaign Graduate School of Lib and Information Science, 1991. p. 93-100

IB: 0878450858

DE: Chicago-Public-Library; Access-to-libraries; Ethics-; Public-libraries-Services-to-minorities 8. AU: Roberto,-Katia, 1975-, ed; West,-Jessamyn, 1968-, ed

TI: Revolting librarians redux: radical librarians speak out 
PB: McFarland \& Co., 2003. 219 p. IB: $0786416084(\mathrm{pa})$

DE: Librarianship-Philosophical-aspects;

Education-for-librarianship; Ethics-

9. $A U$ : Rothstein,-Samuel, 1921-

TI: Where does it hurt? Identifying the real concerns in the ethics of reference service

OT: Augmented title: reprinted from Ref Libr Summ '82

SO: The Reference Librarian no25/26 1989. p. 307-20

DE: Ethics-; Reference-services-Evaluation

10. AU: Shields,-Gerald-R

TI: Ethics and the librarian: taking stock at Allerton SO: In: The ALA yearbook of library and information services, v15, 1990 American Lib Assn, 1990. p. 1-10 IB: 0838905412

DE: Allerton-Park-Institute;

University-of-Illinois-at-Urbana-Champaign-Graduat e-School-of-Library-and-Information-Science; Ethics-

11. $A U$ : Shields,-Gerald-R

TI: The FBI creates an awareness of librarian ethics: an opinionated historical review SO: In: Ethics and the librarian University of Ill at Urbana-Champaign Graduate School of Lib and Information Science, 1991. p. 19-30 IB: 0878450858 
Bibliografía: Etica y bibliotecología

$D E$ : United-States-Federal-Bureau-of-InvestigationLibrary-Awareness-Program; Libraries-Legal-aspects; Ethics-

12. AU: White,-Herbert-S

TI: Teaching professional ethics to students of library and information science

SO: In: Ethics and the librarian University of Ill at Urbana-Champaign Graduate School of Lib and Information Science, 1991. p. 31-43

IB: 0878450858

DE: Library-schools-Curriculum; Ethics-Teaching 13. AU: Wessells,-Michael-B

TT: Feeding the hand that bites you (two case studies in ethics)

SO: In: Ethics and the librarian University of Ill at Urbana-Champaign Graduate School of Lib and Information Science, 1991. p. 63-71

IB: 0878450858

$D E$ : Ethics-Case-studies 

Mesa redonda. Ética información. La edición consta de 150 ejemplares. Coordinación editorial, Ignacio Rodríguez Sánchez. Diseño y formación editorial, Carlos Ceballos Sosa. Centro Universitario de Investigaciones Bibliotecológicas/ UNAM. Fue impreso en papel cultural ahuesado de 90 gr. en Marlou Impresiones, ubicados en Zapotecas Mz. 1 Lt. 9, Col. Tlalcoligia. México, D. F. Se terminó de imprimir en el mes de diciembre de 2005. 